LUCAS SEGISMUNDO MORENO LAGO

FATORES HUMANOS NA DEPENDABILIDADE DE SISTEMAS DE SOFTWARE DESENVOLVIDOS COM PRÁTICAS ÁGEIS

SÃO PAULO

2014 


\section{FATORES HUMANOS NA DEPENDABILIDADE DE SISTEMAS DE SOFTWARE DESENVOLVIDOS COM PRÁTICAS ÁGEIS}

Dissertação apresentada à Escola

Politécnica da Universidade de São Paulo para obtenção do Título de Mestre em Engenharia.

SÃO PAULO 


\section{FATORES HUMANOS NA DEPENDABILIDADE DE SISTEMAS DE SOFTWARE DESENVOLVIDOS COM PRÁTICAS ÁGEIS}

Dissertação apresentada à Escola

Politécnica da Universidade de São Paulo para obtenção do Título de Mestre em Engenharia.

Área de concentração:

Engenharia de Computação

Orientador:

Prof. Dr. Edison Spina

SÃO PAULO 


\section{DEDICATÓRIA}

À minha mulher que esteve ao meu lado durante essa jornada e permitiu que tudo isso fosse possível. 


\section{AGRADECIMENTOS}

À minha mãe, Márcia, pela oportunidade de estudar, apoio e carinho.

À minha mulher Jalousie, por suportar a minha ausência durante essa empreitada e apoiar nos momentos difíceis. Além de ter ajudado com a revisão do texto.

Ao meu orientador Edison Spina, pela oportunidade, confiança e orientação.

Aos colegas de laboratório Marcel, Marvin e Rodrigo pela companhia nas reuniões e opiniões sobre o trabalho.

Ao professor Luiz Barco, que com suas aulas mudaram a percepção da minha contribuição para o mundo.

À Ely Bernardi e Maria Cristina por facilitarem a realização desse trabalho.

Aos programadores André Noel e Ana Paula pela divulgação do questionário.

À todos que de alguma forma me ouviram, opinaram e direta ou indiretamente ajudaram na realização desse trabalho. 
Science, my lad, is made up of mistakes, but they are mistakes which it is useful to make, because they lead little by little to the truth.

(Júlio Verne) 


\section{RESUMO}

As práticas ágeis de desenvolvimento de sistemas de software são, neste trabalho, classificadas sob três aspectos: dependabilidade, domínios do ESSENCE e guidelines para redução de erro humano. A partir dessa classificação, um questionário baseado nas práticas relacionadas aos fatores humanos foi aplicado para desenvolvedores de sistemas de software com diferentes níveis de experiência com o objetivo de avaliar a interferência do ambiente na dependabilidade do sistema de software desenvolvido. O questionário foi respondido por 125 desenvolvedores. Os desenvolvedores foram separados em dois grupos e os grupos foram comparados em relação à percepção de certos guidelines para desenvolvimento de software para cada prática considerada. Os resultados do questionário mostraram que a utilização das práticas ágeis analisadas aumentou fatores que reconhecidamente facilitam a redução do erro humano.

PALAVRAS CHAVE:

Fatores humanos, dependabilidade de software, qualidade de software, sistemas sociotécnicos 


\begin{abstract}
In this work, agile software development practices are categorized using three aspects: reliability, ESSENCE's areas of concern and guidelines for human error reduction. From this categorization, it was applied to software developers with different levels of expertise a questionnaire with practices related to human factors with the goal of evaluating the interference of the environment on the reliability of the developed software. The questionnaire was answered by 125 developers. For every practice considered the developers were separated in two groups and compared in relation to the perception of certain guidelines. The results show that the use of those agile practices increase factors that help reduce human error.
\end{abstract}

KEY WORDS:

Human-factors, software reliability, software quality, sociotechnical systems 


\section{LISTA DE FIGURAS}

Figura 1 - Árvore de características da qualidade de um software ................................6 6

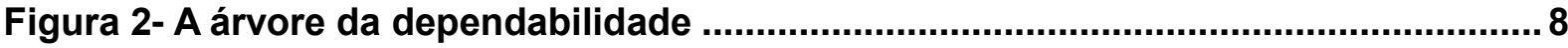

Figura 3 - Taxonomia das falhas em software ................................................................ 12

Figura 4 - Combinações possíveis entre classes elementares de falhas ....................... 13

Figura 5 - Modelo conceitual de um sistema de software e frequência de falhas......... 14

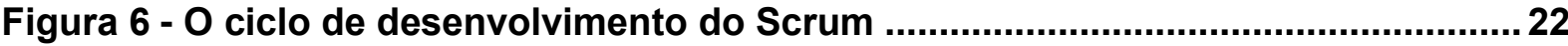

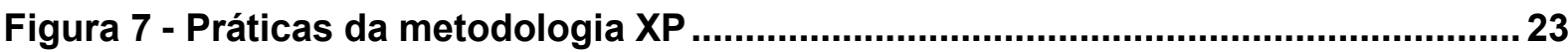

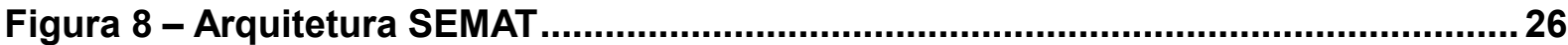

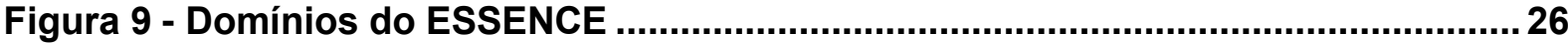

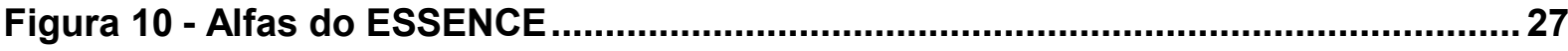

Figura 11 - Espaços de atividades ................................................................................ 28

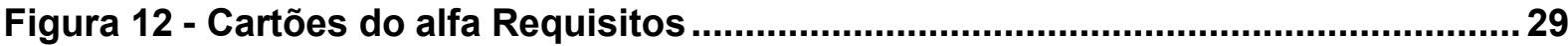

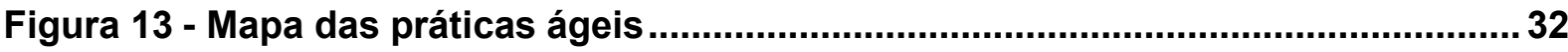




\section{LISTA DE GRÁFICOS}

Gráfico 1 - Distribuição da adoção de práticas ágeis................................................. 20

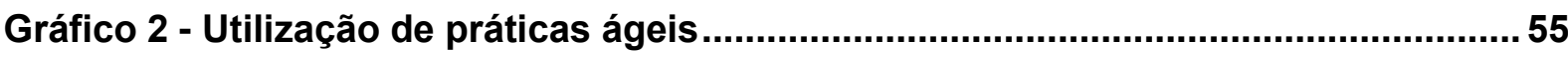

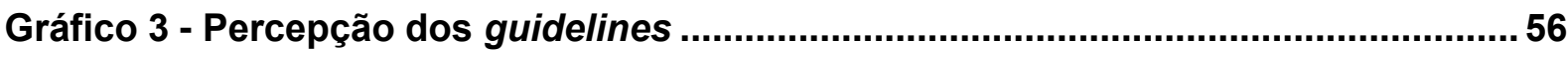

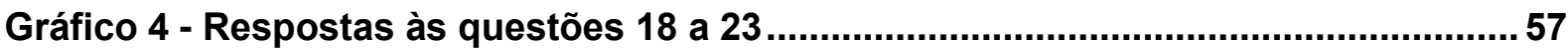




\section{LISTA DE QUADROS}

Quadro 1 - Descrição das técnicas de obtenção de dependabilidade .......................... 10

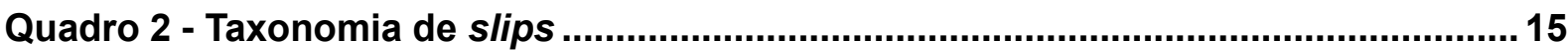

Quadro 3 - Guidelines para projeto de sistemas com redução de erro humano...........17

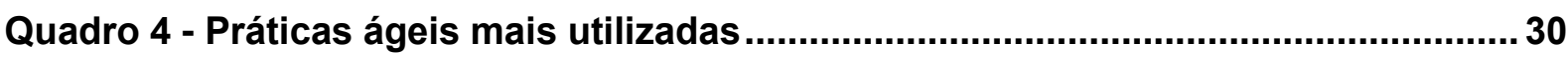

Quadro 5 - Classificação das práticas de acordo com a dependabilidade..................... 42

Quadro 6 - Relação entre práticas e domínios do SEMAT ................................................ 45

Quadro 7 - Relação entre práticas e guidelines de projeto de sistemas ....................... 47

Quadro 8 - Perguntas relacionadas aos guidelines ................................................... 51

Quadro 9 - Relações entre práticas e guidelines..................................................... 52

Quadro 10 - Checklist do alfa oportunidade ..................................................................... 72

Quadro 11 - Checklist do Alfa stakeholders................................................................ 74

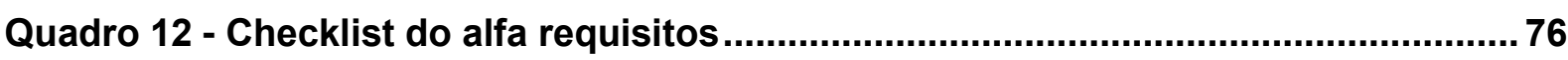

Quadro 13 - Checklist do alfa sistema de software .................................................... 79

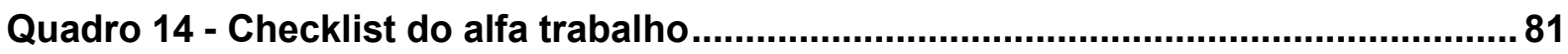

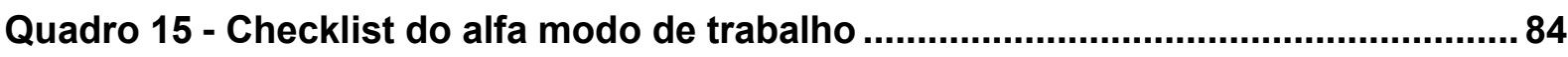

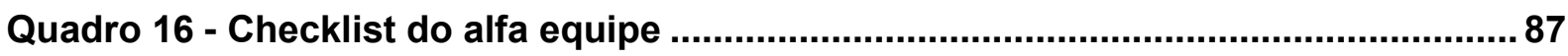




\section{LISTA DE TABELAS}

Tabela 1 - Experiência em desenvolvimento de software

Tabela 2 - Número de funcionários no local de trabalho 53

Tabela 3 - Metodologias habitualmente utilizadas 54

Tabela 4 - Quartis da escala Likert para utilização de práticas ágeis. 54

Tabela 5 - Quartis da escala Likert para utilização de práticas ágeis (continuação).... 54

Tabela 6 - Quartis da escala Likert para afirmações relativas aos guidelines. 56

Tabela 7 - Quartis da escala Likert para afirmações relativas aos guidelines (continuação)

Tabela 8 - Mediana do score dos guidelines para os grupos com uso intenso e uso baixo do pacote de práticas analisado. 


\section{SUMÁRIO}

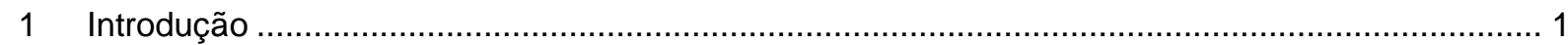

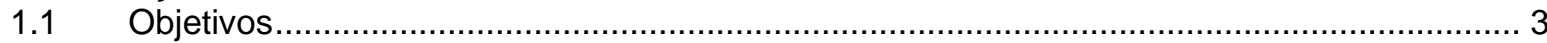

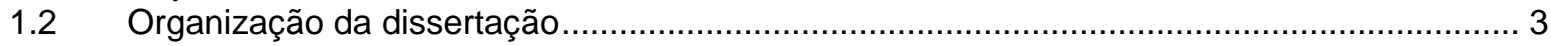

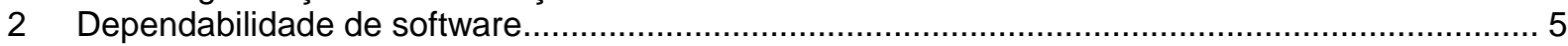

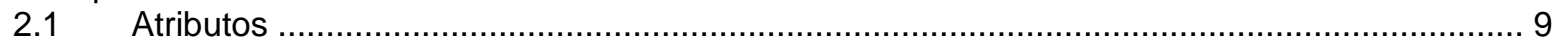

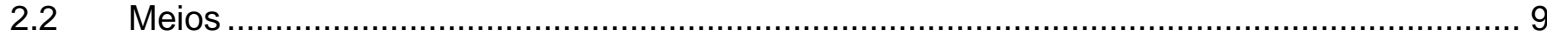

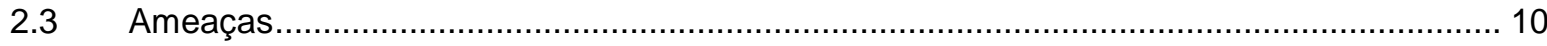

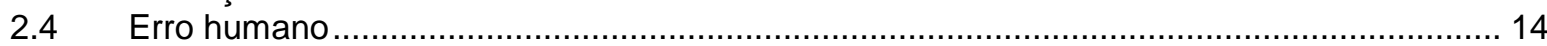

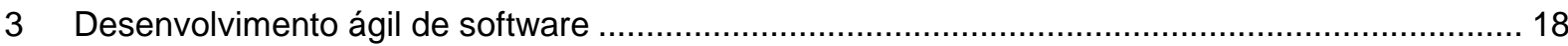

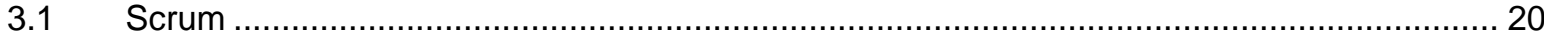

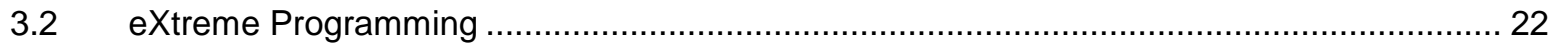

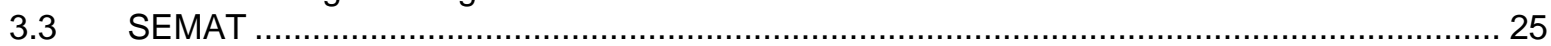

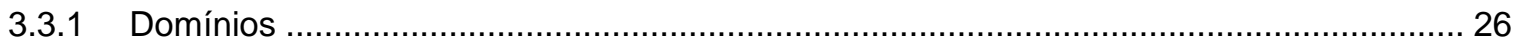

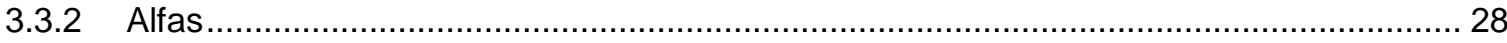

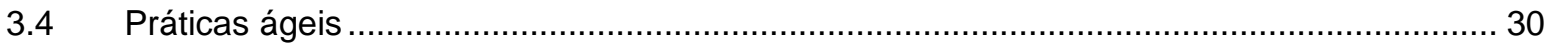

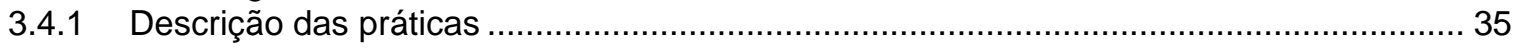

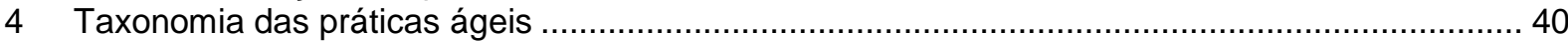

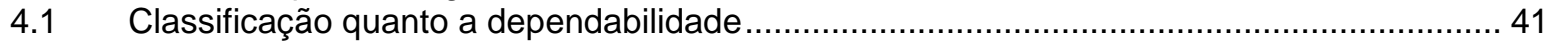

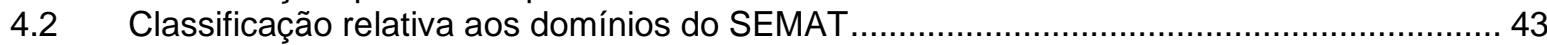

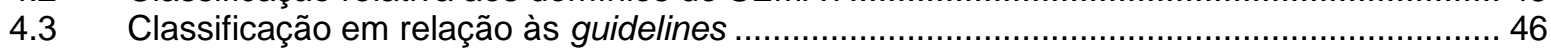

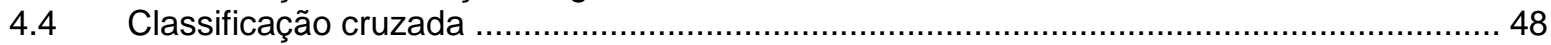

5 Efeito das práticas na dependabilidade de software ……........................................................ 50

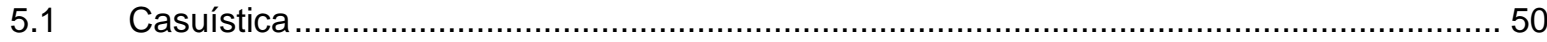

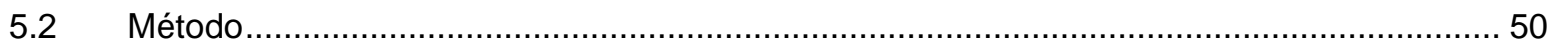

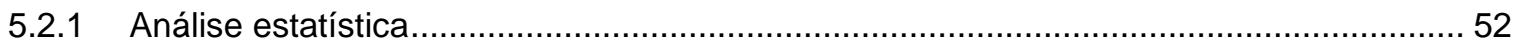

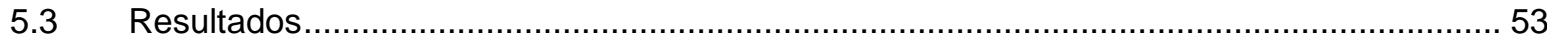

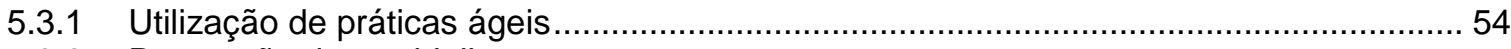

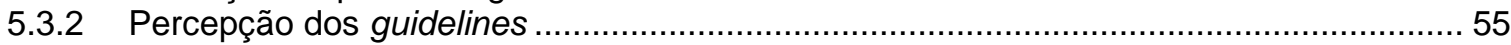

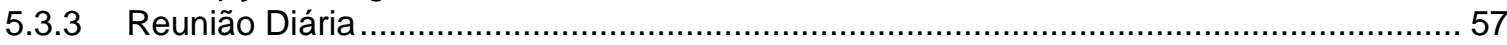

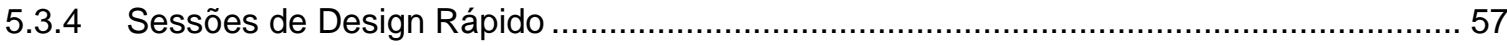

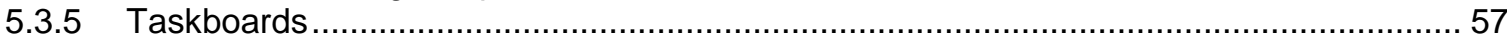

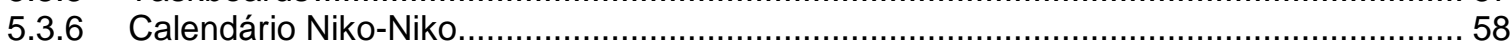

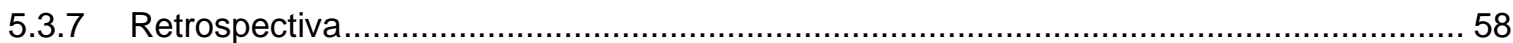

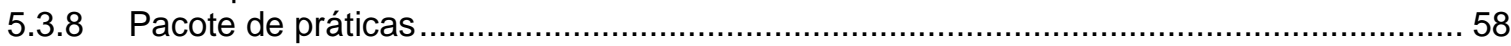

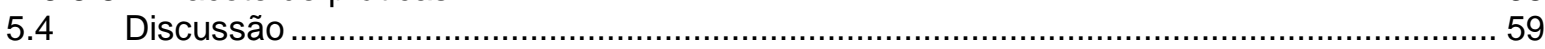

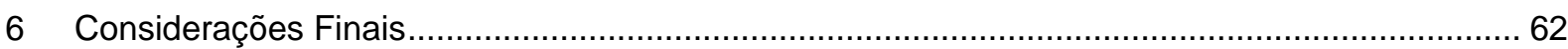

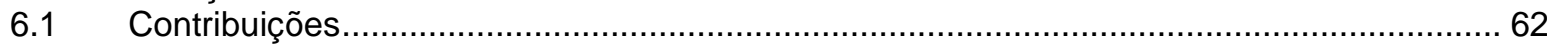

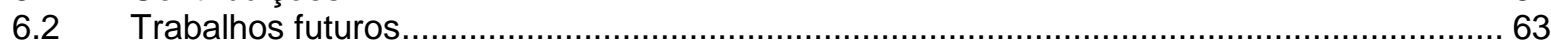

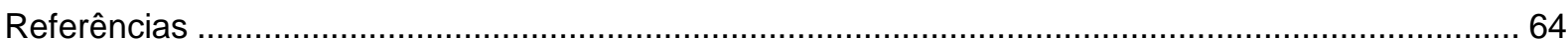

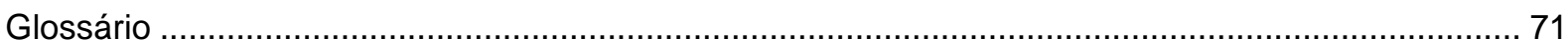

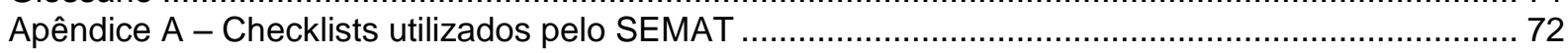

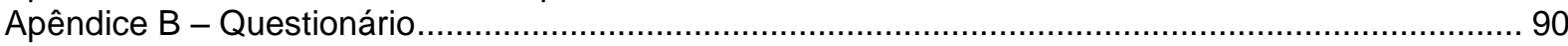

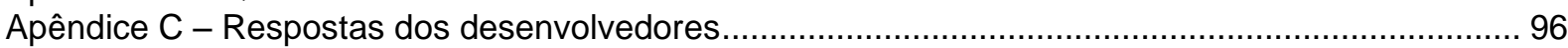




\section{INTRODUÇÃO}

A dependabilidade do software é a propriedade que define a capacidade de sistemas computacionais de prestarem um serviço que se pode justificadamente confiar ("IEEE Standard Dictionary of Measures to Produce Reliable Software," 1989). Essa característica da qualidade é extremamente relevante nos dias atuais dado que falhas de software podem gerar problemas graves, como por exemplo os problemas no software da Nasdaq que causaram a perda de milhões de dólares (MAMUDI, 2013), os erros nas bombas de insulina que teriam levado pacientes a óbito (CAYOT-CONSTANTIN et al., 2010) e erros em procedimentos automatizados na navegação de aeronaves que causaram sérios acidentes (LIESOWSKA, 2013).

É sabido que sistema é um conjunto de objetos (pessoas, células, moléculas ou qualquer coisa) interconectados de tal forma que produzam respostas próprias com o tempo (MEADOWS; WRIGHT, 2008). Um conjunto de pessoas com o objetivo de desenvolver um sistema de software, forma um sistema sociotécnico (SIMONETTE; SPINA, 2010)

Esse sistema, que é composto também pelo ambiente e tecnologias utilizadas é afetado diretamente pelas práticas escolhidas para o desenvolvimento do sistema de software.

Em 2001, um conjunto de práticas visando romper com os métodos tradicionais de desenvolvimento de software foram estabelecidas através do manifesto ágil. Este evento agrupou diversas práticas já existentes que ganhavam popularidade nos últimos anos (AMBLER, 2007) e tinham como objetivo tornar as organizações capazes de reagir a mudanças em seu ambiente mais rápido que a taxa de mudanças (KRUCHTEN, 2013).

As práticas ágeis são largamente adotadas pelas empresas (AMBLER, 2007). Porém há escassez de estudos experimentais e de validação de tais práticas (JACOBSON; MEYER; SOLEY, 2009). Além disso especialistas as contestam, 
especulando que seriam incapazes de desenvolver softwares de alta dependabilidade (MISRA, 2012).

Neste contexto e devido à escassez de evidências sobre as práticas de desenvolvimento de software, surgiu o SEMAT (Software Engineering Method And Theory) com o objetivo de reestabelecer a engenharia de software baseado em uma teoria sólida, princípios comprovados e melhores práticas. (JACOBSON; MEYER, 2009)

Para que esses estudos sejam possíveis, o SEMAT criou uma arquitetura baseada em um conjunto de elementos essenciais que são prevalentes em todo projeto de desenvolvimento de software. Esse conjunto recebe o nome de kernel. (OMG, 2013)

O kernel possui 9 elementos essenciais que são chamados de alfas e os mesmos são agrupados em 3 domínios - Cliente, solução e empreitada - cada um possui seus alfas particulares.

A redução de erro humano no desenvolvimento de software implica diretamente na redução de falhas de software e tem como consequência direta o aumento da dependabilidade (AVIZIENIS; LAPRIE, 2004).

Norman enumerou algumas características de sistemas com baixa ocorrência de erro humano (NORMAN, 1983), e a partir desse trabalho, Rasmussen e Vicente elaboraram dez guidelines para o desenvolvimento de sistemas com redução de erros. (RASMUSSEN; VICENTE, 1989)

Segundo alguns autores, equipes ágeis reduzem o custo de movimentar informação entre as pessoas e o tempo entre a tomada de uma decisão e a percepção da consequência daquela decisão (COCKBURN; HIGHSMITH, 2001). Essas características são semelhantes a duas das guidelines para o projeto de sistemas visando a redução do erro humano (RASMUSSEN; VICENTE, 1989).

A partir da observação de que práticas ágeis e projetos de sistemas com baixo erro humano possuem características em comum, foi formulada a hipótese que as 
práticas ágeis podem de forma indireta contribuir para a dependabilidade do software desenvolvido. Atuando na redução do erro humano através de alterações sistemáticas na forma como o desenvolvimento de software é conduzido.

\subsection{OBJETIVOS}

O objetivo geral da dissertação é avaliar se as práticas ágeis inseridas no domínio de Empreitada do SEMAT auxiliam na criação de um ambiente para desenvolvimento de software com maior dependabilidade.

Os objetivos específicos são:

- Identificar quais dentre as práticas ágeis mais utilizadas estão inseridas no domínio empreitada do SEMAT;

- Classificar as práticas ágeis entre práticas com influência direta e indireta na dependabilidade de software;

- Relacionar as práticas ágeis com guidelines para a construção de sistemas com redução de erro humano;

- Avaliar se a adoção dessas práticas por equipes que utilizam desenvolvimento ágil faz com que essas equipes possuam características relacionadas à redução do erro humano.

\subsection{ORGANIZAÇÃO DA DISSERTAÇÃO}

A estrutura do trabalho apresenta a seguinte divisão:

- Capítulo 1: compreende as seções introdução, objetivos e a organização da dissertação.

- Capítulo 2: compreende a revisão bibliográfica a respeito de desenvolvimento ágil, dependabilidade de software, erro humano, iniciativa SEMAT e práticas de desenvolvimento ágil.

- Capítulo 3: compreende a taxonomia das práticas de desenvolvimento ágil. 
- Capítulo 4: compreende resultado, análise e discussão do levantamento realizado com desenvolvedores de software.

- Capítulo 5: considerações finais e trabalhos futuros.

- Referências citadas para a elaboração do texto da dissertação.

- Apêndices: apresenta o checklist utilizado nos alfas do SEMAT, o questionário aplicado durante o trabalho e os dados coletados. 


\section{DEPENDABILIDADE DE SOFTWARE}

A dependabilidade é uma das características da qualidade do software, e é definida pelo Standard Dictionary of Measures to Produce Reliable Software como: a propriedade que define a capacidade de sistemas computacionais de prestar um serviço que se pode justificadamente confiar. (IEEE, 1989)

Dependabilidade e qualidade foram relacionadas em 1976 em um artigo que apresentou uma árvore de características da qualidade do software. Apesar da relação não ser feita de forma explícita, observava-se ali características da dependabilidade de software (destacadas na Figura 1). (BOEHM; BROWN; LIPOW, 1976)

A saber:

(1) Confiabilidade: probabilidade que um item irá funcionar sem falhas durante um tempo de uso especificado;

(2) Autocontido: extensão que o código executa suas funções implícitas e explícitas dentro dele mesmo;

(3) Precisão: extensão que a saída produzida pelo código é suficientemente precisa para satisfazer sua intenção de uso;

(4) Completude: extensão que todas as partes do código estão presentes e desenvolvidas;

(5) Robustez e integridade: extensão que o código pode continuar a executar apesar de uma violação de um requisito;

(6) Acessibilidade: extensão que o código facilita o uso de suas partes; 


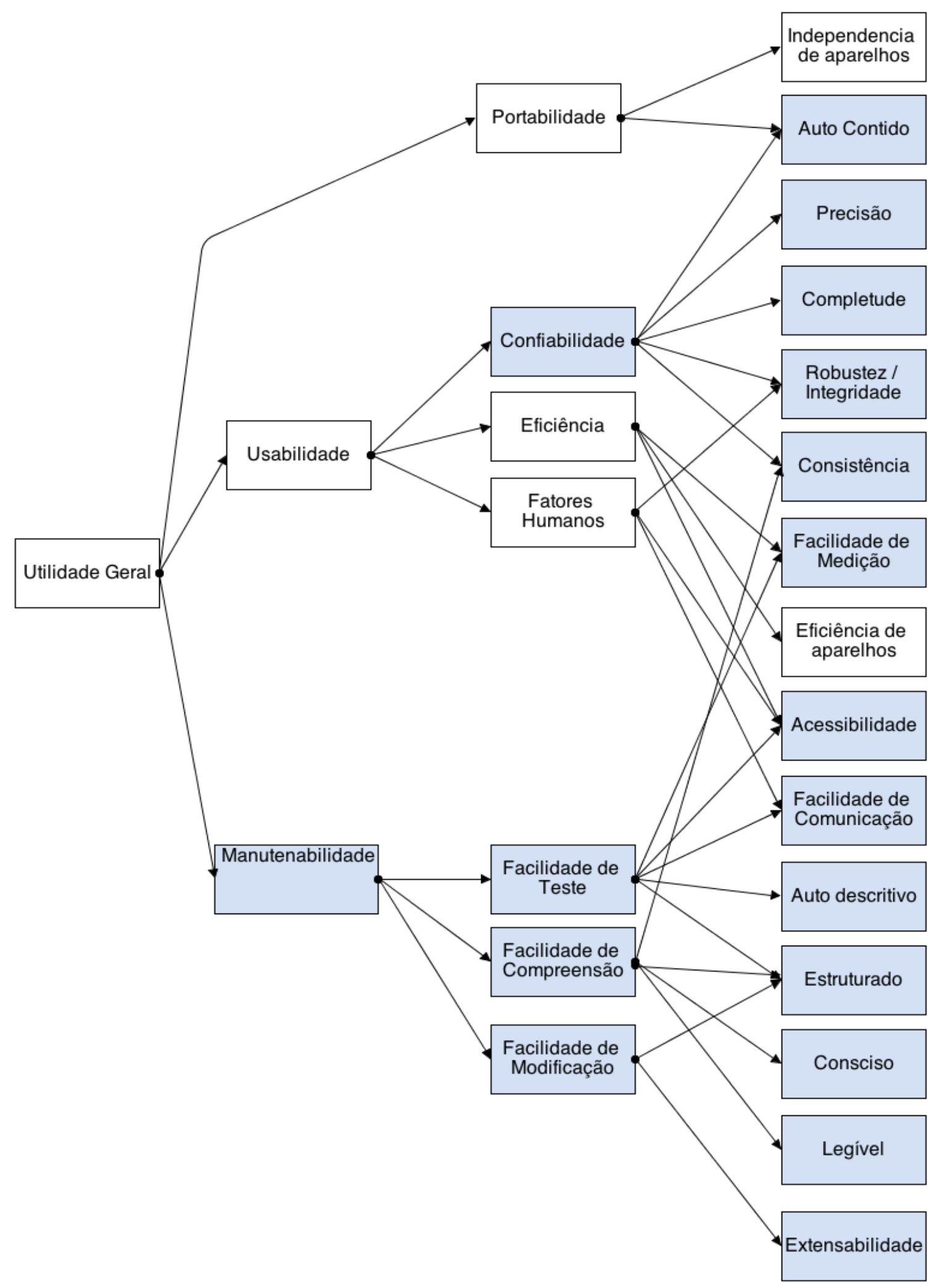

Figura 1 - Árvore de características da qualidade de um software

Fonte: Boehm, 1976 
(7) Consistência: extensão que o código contém notações, terminologia e simbologia uniformes internamente, e consistência externa - o conteúdo por ser rastreado aos requisitos;

(8) Facilidade de comunicação: extensão que o código facilita a especificação das entradas e provém respostas com forma e conteúdo fácil de se assimilar;

(9) Auto descritivo: extensão que o leitor do código é capaz de determinar seus objetivos, suposições, restrições, entradas, saídas, componentes e estado da revisão;

(10) Estruturado: não definido pelo autor;

(11) Conciso: extensão na qual o excesso de informação não está presente;

(12) Legível: extensão na qual as funções são facilmente discernidas na leitura do código;

(13) Extensibilidade: extensão que o código pode ser expandido em funções computáveis, ou armazenamento de dados.

O conceito de dependabilidade considerado pelo IEEE utiliza a seguinte divisão: ameaças ou causas da perda de dependabilidade, formas e métodos de se obter uma maior dependabilidade, e os atributos presentes em softwares com alta dependabilidade (Figura 2). (AVIZIENIS; LAPRIE; RANDELL, 2001) 


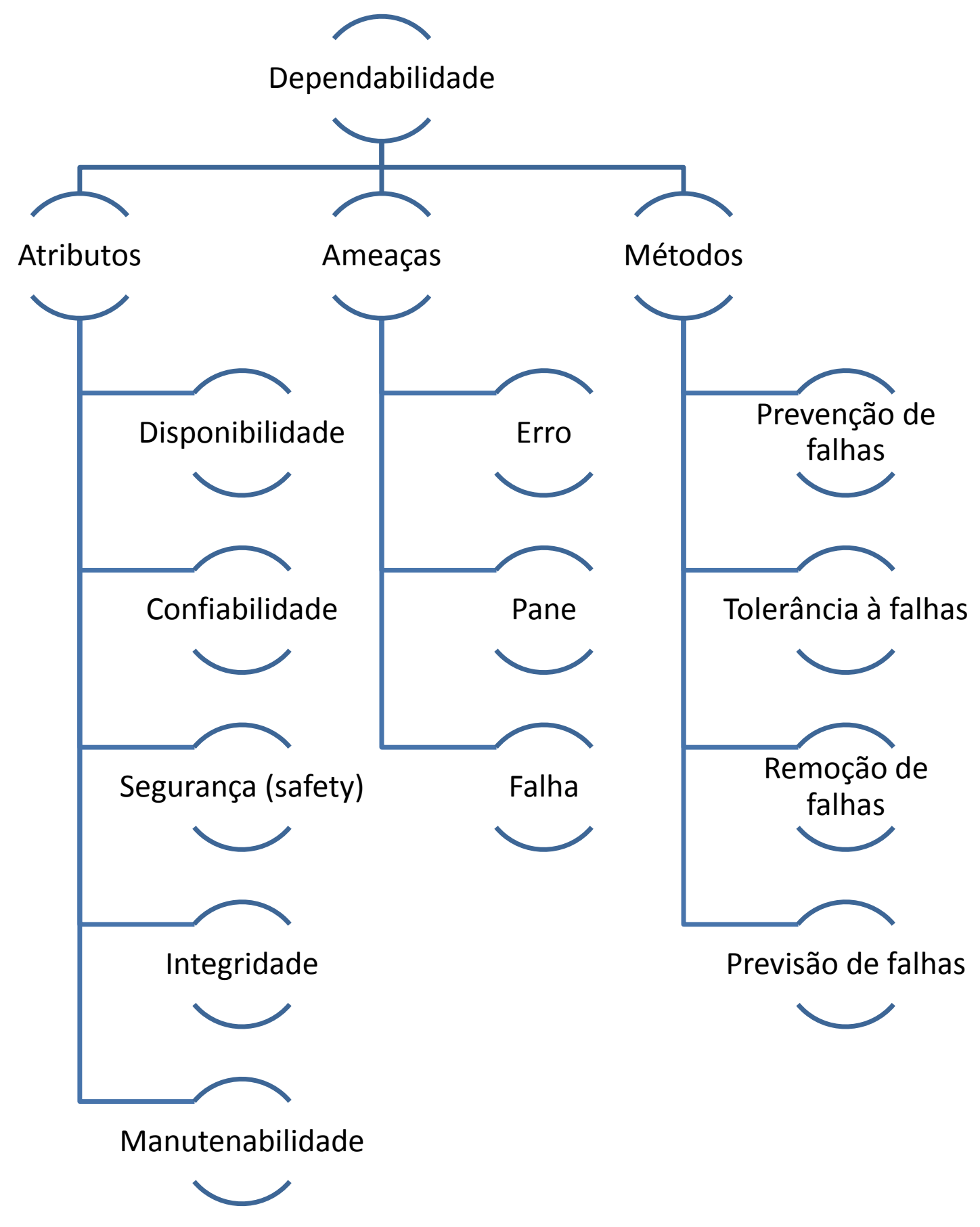

Figura 2- A árvore da dependabilidade

Fonte: Avizienis, 2001 


\section{$2.1 \quad$ ATRIBUTOS}

Segundo Avizienis, a dependabilidade de software é determinada por cinco atributos: confiabilidade, segurança, disponibilidade, integridade e manutenabilidade. Tais atributos podem ser enfatizados dependendo da aplicação e nunca devem ser interpretados de forma determinística dada a inevitável presença de falhas. (AVIZIENIS; LAPRIE; RANDELL, 2001)

O atributo disponibilidade mede o grau que um sistema ou componente está operacional e acessível quando seu uso é necessário. Usualmente é medido em porcentagem do tempo realmente disponível dividido pela quantidade de tempo de uso definida para o serviço.

A confiabilidade é a habilidade do sistema ou componente de realizar suas funções sob condições especificadas por um período também especificado de tempo. As limitações de confiabilidade de um software não são causadas por desgaste, e sim por erros no levantamento de requisitos, desenho ou implementação do mesmo.

A segurança é definida como a expectativa que o sistema não irá, dentro de condições normais, chegar a um estado onde vidas humanas, sua saúde ou propriedade sejam ameaçados.

A capacidade do sistema ou componente de impedir acesso ao, ou modificação do, software ou dados por entidades não autorizadas é chamada de integridade.

Manutenabilidade é a velocidade (ou facilidade) que um programa pode ser corrigido ou alterado. ("IEEE Standard Glossary of Software Engineering Terminology," 1990)

\subsection{MEIOS}

O desenvolvimento de software de alta dependabilidade está apoiado na utilização combinada de quatro técnicas: prevenção de falhas, tolerância a falha, remoção de falhas e previsão de falhas. (AVIZIENIS; LAPRIE, 2004)

As definições dessas técnicas podem ser encontradas no Quadro 1: 
Quadro 1 - Descrição das técnicas de obtenção de dependabilidade

\begin{tabular}{|l|l|}
\hline Técnica & Descrição \\
\hline Prevenção de falhas & $\begin{array}{l}\text { É conseguido através de técnicas de } \\
\text { controle de qualidade durante o projeto } \\
\text { e criação do software. }\end{array}$ \\
\hline Tolerância a falha & $\begin{array}{l}\text { É a preservação da entrega de serviço } \\
\text { sem erros mesmo na presença de } \\
\text { falhas ativas. }\end{array}$ \\
\hline Remoção de falhas & $\begin{array}{l}\text { Durante a fase de desenvolvimento do } \\
\text { software consiste em: verificação, } \\
\text { diagnóstico e correção. Durante a } \\
\text { operação é a manutenção corretiva ou } \\
\text { preventiva do sistema de software. }\end{array}$ \\
\hline Previsão de falhas & $\begin{array}{l}\text { Consiste em avaliar o funcionamento do } \\
\text { sistema em relação a ocorrência ou } \\
\text { ativação de falhas. }\end{array}$ \\
\hline
\end{tabular}

Essas técnicas são a base de diversos modelos utilizados pela indústria de software como: CMMI, ISO9000, ISO12207, P-CMM e o PSP. Porém nenhum dos modelos citados considera que o desempenho humano é fortemente influenciado pelo ambiente. (SANDHOF; FILGUEIRAS, 2006)

\subsection{AMEAÇAS}

As ameaças à dependabilidade de software estão encadeadas segundo a sequência: falha, erro e disfunção. Falha constitui uma incorreção de uma definição 
de dados, de um passo ou de um processo em um sistema de software. (AVIZIENIS; LAPRIE, 2004)

O erro é definido como a diferença entre um valor ou condição observada, medida ou computada, e um valor ou condição verdadeira especificada ou teoricamente correta, ou em uma ação humana que produza um resultado incorreto. (AVIZIENIS; LAPRIE, 2004)

E finalmente disfunção é a incapacidade de um sistema, ou componente, em realizar uma função requisitada de acordo com os requisitos de desempenho especificados. (AVIZIENIS; LAPRIE, 2004)

As falhas de software podem ser classificadas em classes elementares de acordo com 8 características (Figura 3). E há 31 combinações possíveis derivadas dessas classes elementares (Figura 4) das quais destacam-se 4 falhas provenientes de erro humano no desenvolvimento do software.

As falhas 1, 2, 3 e 4 (Figura 4) são as únicas que ocorrem em tempo de desenvolvimento, são internas ao sistema, causadas por humanos, estão limitadas ao software e não possuem intenção maliciosa, e portanto podem ser consideradas erro humano. (AVIZIENIS; LAPRIE, 2004)

A Figura 5 ilustra um modelo conceitual do software, as origens das falhas e a sua frequência. As falhas que ocorrem em tempo de desenvolvimento correspondem a $60 \%$ das disfunções percebidos pelo usuário do software. 


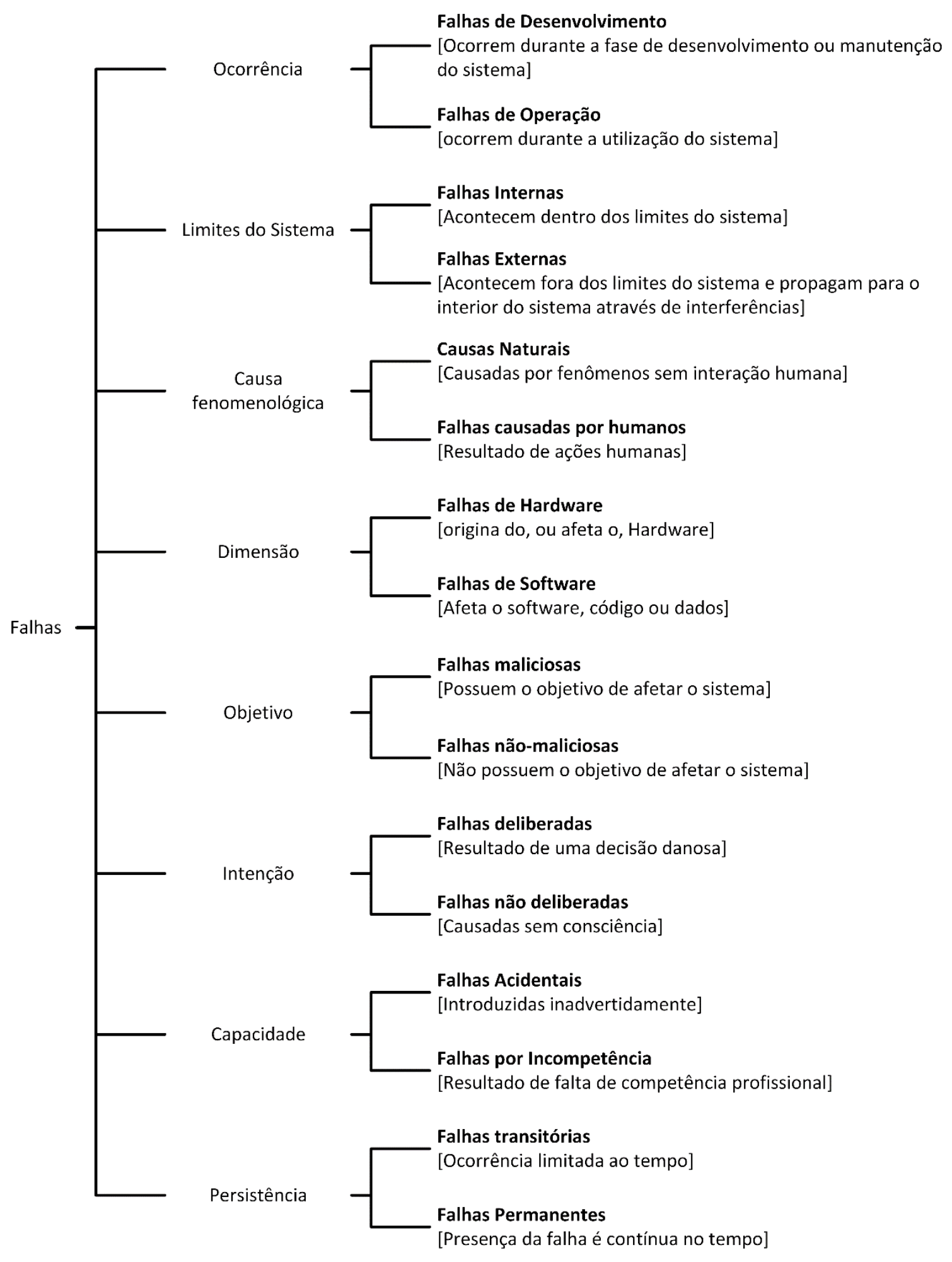

Figura 3 - Taxonomia das falhas em software

Fonte: Avizienis, 2004 


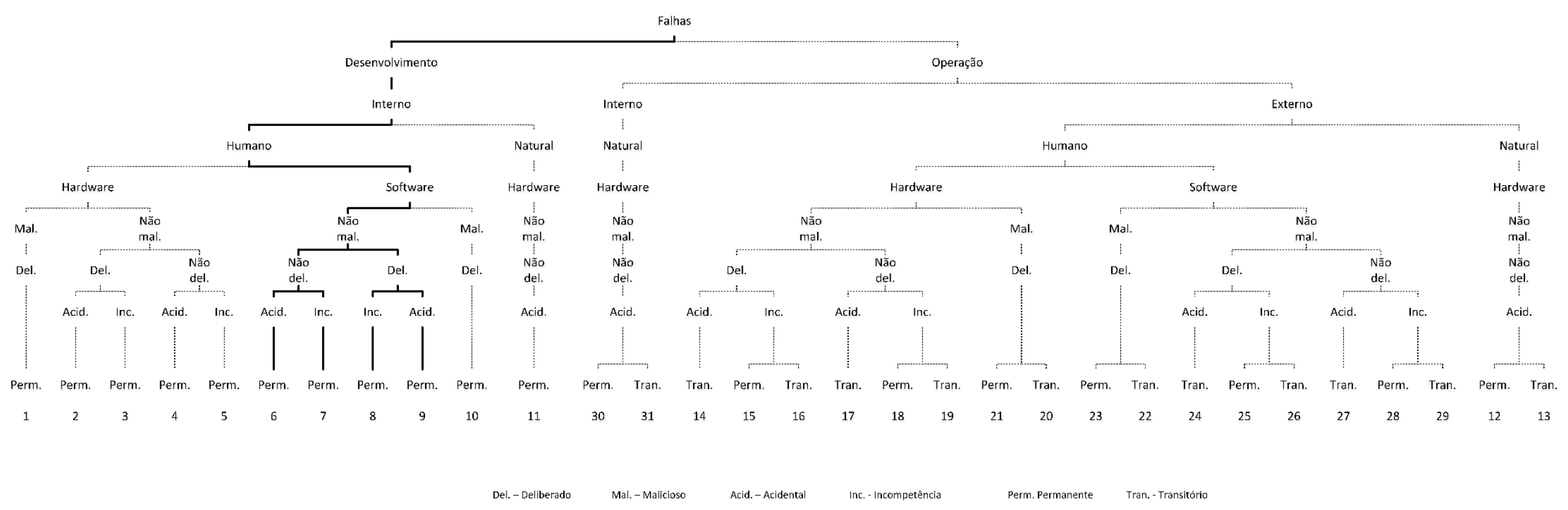

Figura 4 - Combinações possíveis entre classes elementares de falhas

Fonte: adaptada de Avizienis, 2004 


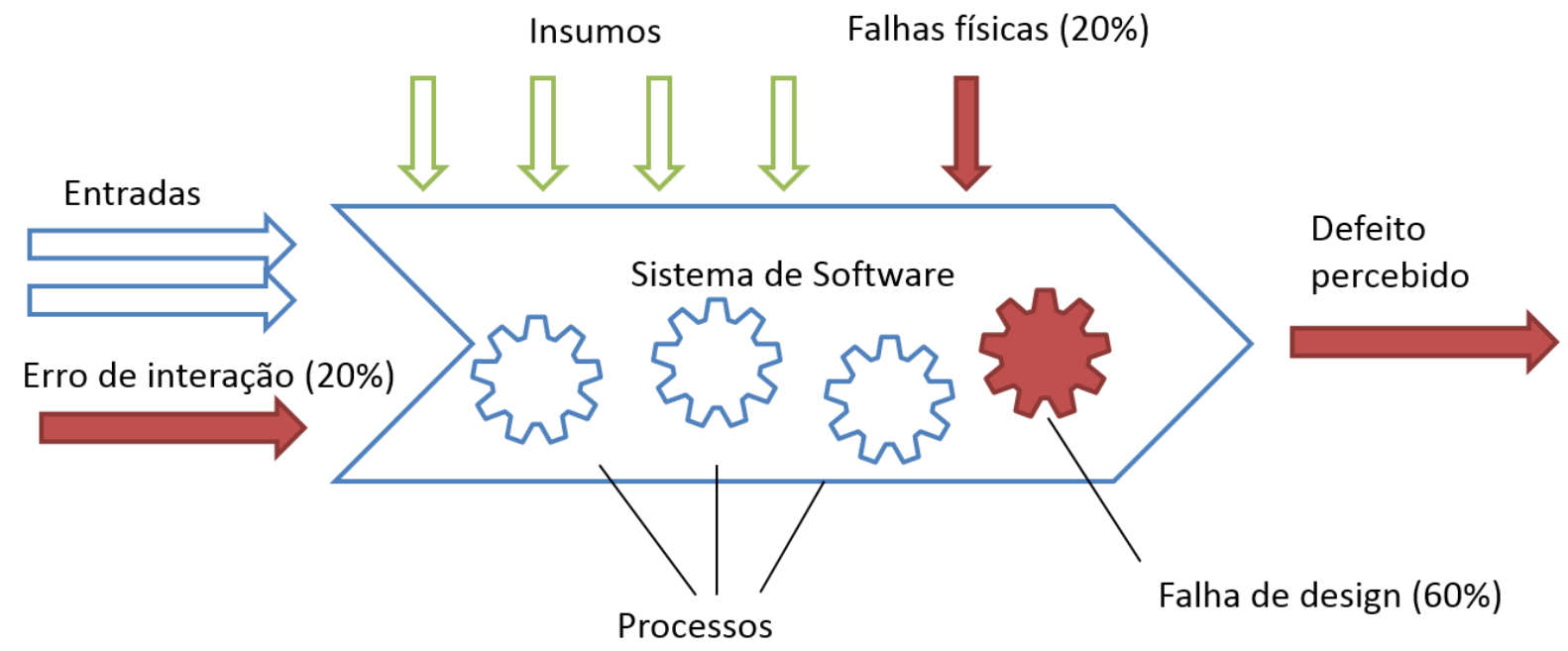

Figura 5 - Modelo conceitual de um sistema de software e frequência de falhas

Fonte: Avizienis, 2001

\subsection{ERRO HUMANO}

O erro humano pode ser analisado a partir da abordagem pessoal ou sistêmica. A primeira considera que os erros surgem de processos mentais errôneos e responsabiliza o indivíduo diretamente. A segunda tem como premissa a falibilidade das pessoas e considera que os erros são consequências de fatores sistêmicos. (REASON, 2000)

A abordagem pessoal encerra a busca pelos motivos que levaram ao erro ao encontrar a pessoa associada ao evento (BOGNER, 2007). Porém, o comportamento de uma pessoa é função do ambiente e o seu impacto não pode ser menosprezado (LEWIN; HEIDER; HEIDER, 1936).

Para o estudo de erros humanos em sistemas, os erros foram divididos em mistakes e slips diferenciados de acordo com a intenção. Erros deliberados são chamados de mistakes enquanto os não deliberados slips. (NORMAN, 1983)

Norman classifica e define os tipos de erros não deliberados no Quadro 2: 
Quadro 2 - Taxonomia de slips

\section{Slips na formação da intenção}

Erros de modo

Erros de descrição
Classificação errônea da situação

Especificação ambígua ou incompleta da intenção

\section{Slips resultantes da ativação errada de esquemas}

Ativação não intencional

Quando esquemas que não são parte da ação corrente são ativados por razões estranhas, e após disparados, levam à slips.

Erros de captura

Quando uma sequência que está sendo executada é semelhante a uma outra executada com mais frequência, a segunda pode tomar 0 controle.

Ativação data-driven

Eventos externos causam a ativação de esquemas.

Ativação associada

Esquemas atualmente ativos levam a ativação de outros.

Perda de ativação

Quando esquemas ativos perdem sua ativação, portanto perdendo efeito e controle.

Esquecimento da intenção Com manutenção da sequência de ações.

Desordenação dos Incluindo perda de passos ou a repetição de componentes de uma passos.

sequência de ação

Slips resultantes da ativação falha de esquemas

Disparo falso

Um esquema propriamente ativo é disparado em um momento inapropriado. 
Spoonerisms

Blends competidores.

Pensamentos levando a Disparo de um esquema feito somente para ser ações pensado, não executado.

\section{Disparo prematuro}

Falha no disparo

Quando um esquema ativo nunca é disparado.

Fonte: Norman, 1983

A partir desta análise de erros humanos foram levantados quatro pontos que se deve considerar para lidar com o erro humano (NORMAN, 1983):

- Feedback: O estado do sistema deve estar claramente disponível para o usuário, idealmente de uma forma não ambígua e que deixe as opções prontamente disponíveis para evitar erros de modo.

- Sequencias de resposta similares: Classes diferentes de ações deveriam ter sequencias de ação diferentes para evitar erros de captura e descrição.

- Ações devem ser reversíveis: (o máximo possível) e onde estas forem obrigatoriamente irreversíveis e com grande consequência, elas devem ser difíceis de se realizar, prevenindo ativação não intencional.

- Consistência do sistema: O sistema deve ser consistente em sua estrutura e projeto de comando para minimizar problemas de memória em relembrar operações.

Com base nessas características, foram elaborados dez guidelines para projeto de sistemas com redução de erro humano (RASMUSSEN; VICENTE, 1989), são elas: 
O projeto da interface deve ter como objetivo tornar visível os limites de

Guideline 1 desempenho aceitável para os operadores, enquanto os efeitos ainda são observáveis e reversíveis.

Guideline 2

Prover feedback aos atores para que eles possam lidar com o espaço de tempo entre a execução de uma intenção e a observação do seu efeito.

O monitor deve ser projetado para que exista um mapeamento consistente

Guideline 3 e único dos sinais que definem orientações para ação e os símbolos que indicam como o processo funciona.

Quando projetistas delegam aos operadores a tarefa de completar o projeto

Guideline 4 de estratégias durante situações inesperadas, eles devem fornecer ferramentas para fazer experimentos e testar hipóteses de forma reversível e segura.

Guideline 5

Disponibilizar monitores que permitam que rotinas independentes possam ser monitoradas com consciência marginal.

Faça as orientações para ações serem padrões integrados baseados tanto

Guideline 6 em atributos que a definam quanto em uma representação que permita o monitoramento funcional da performance.

Guideline 7 Apoie a memória com exteriorização de modelos mentais efetivos.

Guideline 8

Utilize os dados disponíveis para desenvolver conceitos de transformação de informação consistentes para integração de dados.

Apresente a informação embutida em uma estrutura que funcione como um

Guideline 9 modelo mental exteriorizado, efetivo para o tipo de raciocínio necessário para a tarefa.

Guideline 10

Suporte a itens de memorização, ações ou dados que não são parte de um modelo unificado podem ser úteis.

Fonte: Rasmussen (1989) 
Esses guidelines foram utilizados no Design de Interface Ecológica, um arcabouço para desenho de interfaces para sistemas sociotécnicos complexos. Observou-se que em usinas nucleares e unidades de tratamento intensivo neonatais, a implementação dessas interfaces resultou na redução de erro humano. (BURNS; JAMIESON, 2008; VICENTE, 2002)

\section{DESENVOLVIMENTO ÁGIL DE SOFTWARE}

O desenvolvimento ágil surgiu como uma resposta da indústria de software às práticas tradicionais no final do século passado e foi oficializado em $2001 \mathrm{com}$ a publicação do Manifesto Ágil e formação da Agile Alliance. (BECK; BEEDLE; BENNEKUM, 2001)

Este manifesto apresenta quatro grandes conceitos:

- Indivíduos e interação entre eles mais que processos e ferramentas;

- Software em funcionamento mais que documentação abrangente;

- Colaboração com o cliente mais que negociação de contratos;

- Responder a mudanças mais que seguir um plano.

Estes conceitos embasam os 12 princípios criados no manifesto:

(1) Nossa maior prioridade é satisfazer o cliente através da entrega contínua e adiantada de software com valor agregado;

(2) Mudanças nos requisitos são bem-vindas, mesmo tardiamente no desenvolvimento. Processos ágeis tiram vantagem das mudanças visando vantagem competitiva para o cliente;

(3) Entregar software funcionando com frequência, na escala de semanas até meses, com preferência aos períodos mais curtos;

(4) Pessoas de negócio e desenvolvedores devem trabalhar diariamente em conjunto por todo o projeto; 
(5) Construa projetos em torno de indivíduos motivados. Dê a eles o ambiente e o suporte necessário e confie neles para fazer o trabalho;

(6) O método mais eficiente e eficaz de transmitir informações para e entre uma equipe de desenvolvimento é através de conversa face a face;

(7) Software funcionando é a medida primária de progresso;

(8) Os processos ágeis promovem desenvolvimento sustentável. Os patrocinadores, desenvolvedores e usuários devem ser capazes de manter um ritmo constante indefinidamente;

(9) Contínua atenção à excelência técnica e bom design aumenta a agilidade;

(10) Simplicidade - a arte de maximizar a quantidade de trabalho não realizado - é essencial;

(11) As melhores arquiteturas, requisitos e designs emergem de equipes auto organizáveis;

(12) Em intervalos regulares, a equipe reflete sobre como se tornar mais eficaz e então refina e ajusta seu comportamento de acordo.

Todos esses princípios detalham os conceitos principais e definem práticas que podem ser utilizadas pelos praticantes. (BECK; BEEDLE; BENNEKUM, 2001)

O conceito de agilidade é a habilidade de uma organização de reagir a mudança em seu ambiente mais rapidamente que a taxa de mudanças. (KRUCHTEN, 2013). Esse conceito é amplamente aceito pela indústria de software, já que $69 \%$ dos indivíduos que utilizam métodos ágeis (AMBLER, 2007), e 83\% dos indivíduos planejam iniciar um projeto ágil (VERSIONONE, 2012).

Os métodos ágeis se diferem dos métodos tradicionais principalmente por integrarem explicitamente as preocupações comportamentais e sociais nas metodologias de desenvolvimento de software. (WHITWORTH; BIDDLE, 2007) 
Diversos métodos foram desenvolvidos desde o surgimento do desenvolvimento ágil, como o Scrum com 54\% de adoção, seguido do XP (eXtreme Programing) com 13\% (Gráfico 1).

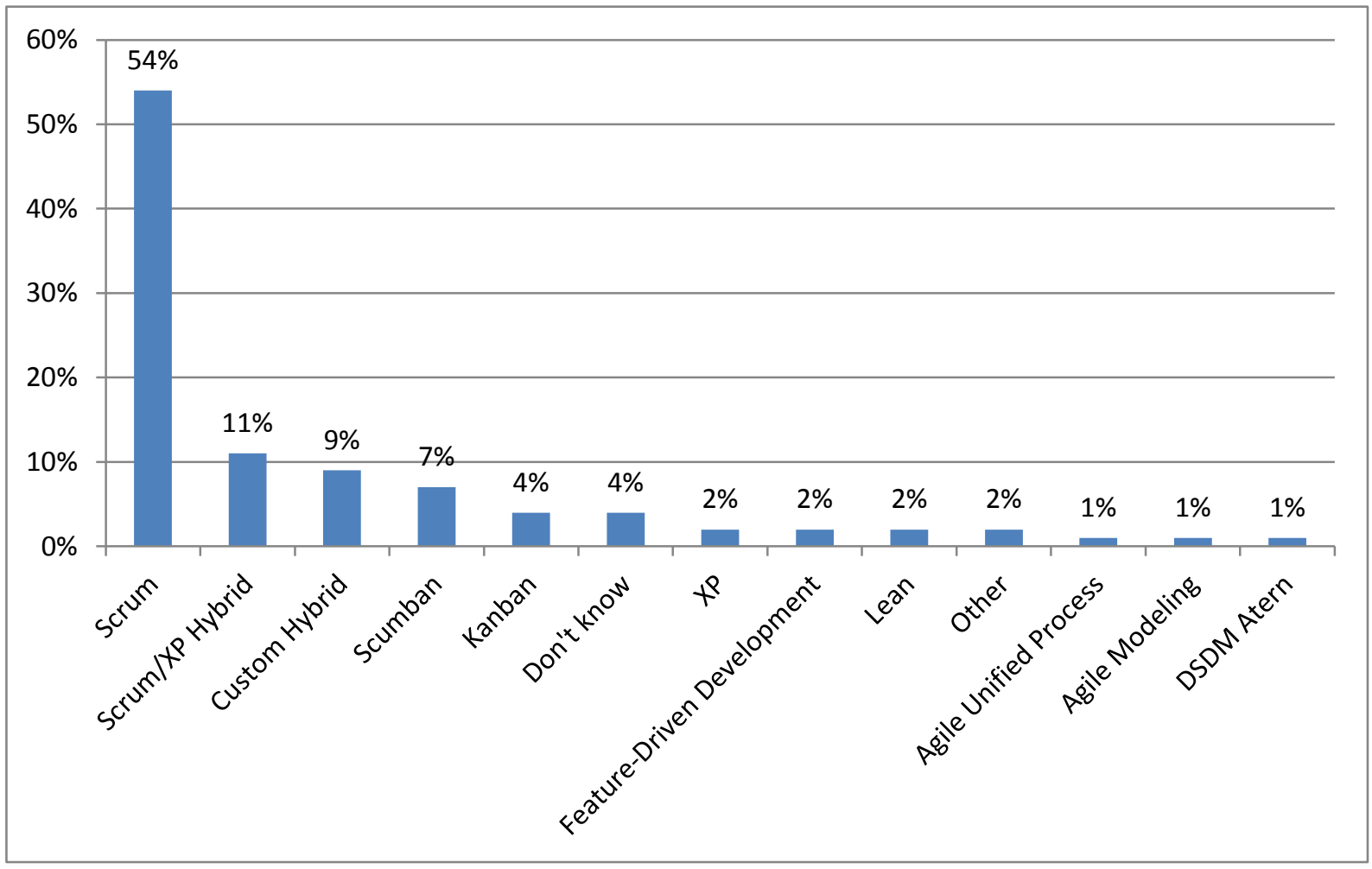

Gráfico 1 - Distribuição da adoção de práticas ágeis

\subsection{SCRUM}

O Scrum é um framework para desenvolver produtos complexos, apesar do método ser leve e de fácil compreensão é considerado de difícil domínio (SCHWABER; SUTHERLAND, 2009).

Práticas específicas de desenvolvimento não pertencem ao SCRUM, que pode trabalhar com diversas práticas diferentes, como a programação extrema. (BASSI, 2008)

O framework consiste nas equipes do SCRUM (formada pelo Product Owner, o Scrum Master e a Equipe de Desenvolvimento), nos eventos, nos artefatos e nas regras (SCHWABER; SUTHERLAND, 2009). 
O Product Owner é o responsável pelas atividades relacionadas ao backlog do produto como garantir a qualidade do que é entregue pela equipe de desenvolvimento e garantir a compreensão dos itens do backlog pela equipe de desenvolvimento.

A Equipe de Desenvolvimento é composta pelos profissionais que realizam o trabalho de entregar uma versão usável que incrementa o valor do produto no final do Sprint. Essas equipes são auto organizadas, multifuncionais e são responsabilizadas como um todo pelo produto entregue.

O Scrum Master está no papel responsável por garantir que o Scrum seja aplicado pela equipe, ele funciona como um facilitador nos eventos Scrum e busca sempre mudanças para melhorar a qualidade da equipe do Scrum.

No Scrum há diversos eventos, sendo o principal o Sprint, que consiste em um intervalo de tempo de menos de um mês durante o qual a equipe de desenvolvimento trabalha em uma versão incremental do produto.

Durante o tempo de um Sprint permanecem constantes os objetivos do Sprint, as metas de qualidade, a equipe de desenvolvimento.

Dentro de cada Sprint acontecem os outros eventos do Scrum: a Reunião de Planejamento, as Reuniões diárias, a Revisão do Sprint e a Retrospectiva do Sprint. A organização desses eventos pode ser observada na Figura 6. 


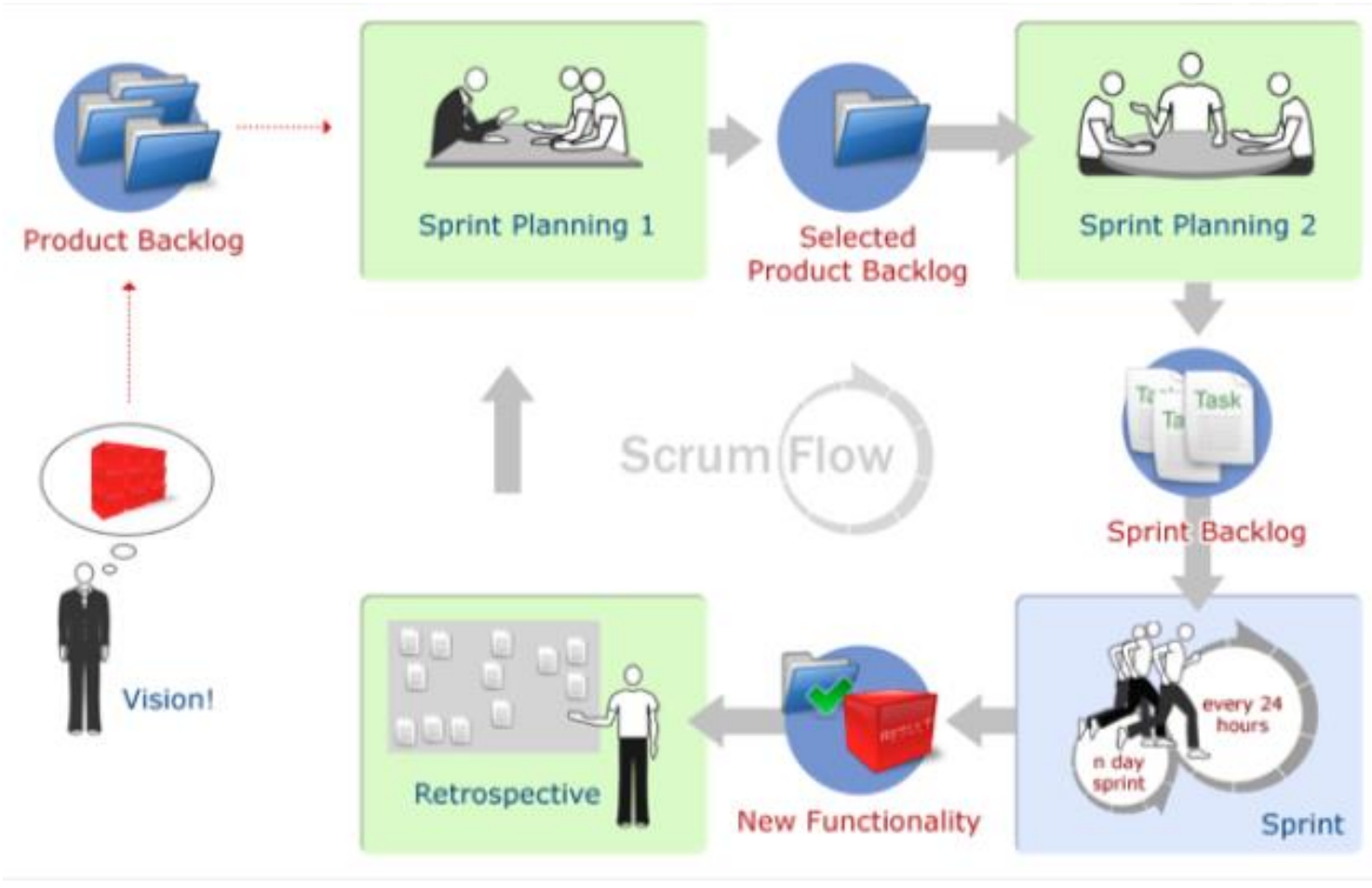

Figura 6 - 0 ciclo de desenvolvimento do Scrum

Fonte: Bassi, 2008

Os artefatos da metodologia Scrum são o Backlog do Produto que contém todas as funcionalidades esperadas definidas pelo Product Owner e o Backlog do Sprint que é um subconjunto das funcionalidades que serão entregues no Sprint atual.

\subsection{EXTREME PROGRAMMING}

O método da Programação eXtrema é atribuído a Kent Beck, Ron Jeffries, e Ward Cunninghan e consiste em 13 elementos básicos que estão ilustrados na Figura 7. 


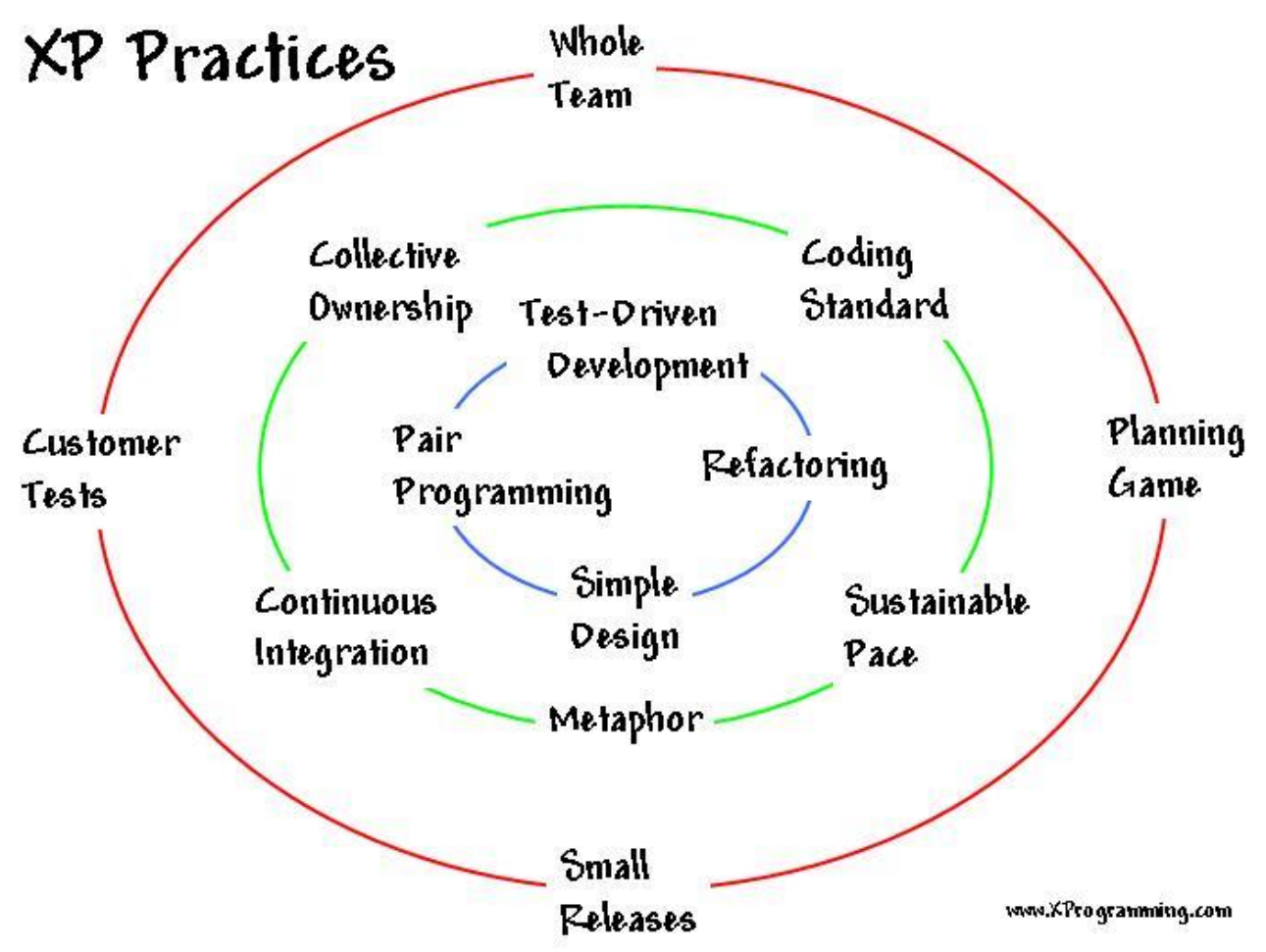

Figura 7 - Práticas da metodologia XP

Fonte: http://xprogramming.com/book/whatisxp/

Essas práticas podem ser definidas como (PAULK, 2001):

- Jogo de planejamento: determinar rapidamente o escopo da próxima entrega, utilizando prioridades do negócio e estimativas técnicas. O cliente decide escopo, prioridade, e datas de uma perspectiva de negócio enquanto a equipe técnica estima o progresso.

- Time Coeso: prática não definida pelo autor;

- Fases Pequenas: colocar um sistema simples em funcionamento. Lance novas versões em ciclos curtos (duas semanas).

- Testes: Desenvolvedores devem continuamente escrever testes que funcionam sem problemas; o cliente deve escrever testes para demonstrar que funções estão terminadas. "Teste, depois programe" significa que um caso de teste falho é um critério de entrada para escrita de código. 
- Metáfora: guia todo o desenvolvimento com uma história simples, compartilhada sobre como o sistema funciona no geral.

- Semana de 40 horas: Não trabalhe mais que 40 horas por semana sempre que possível. Nunca faça horas extras duas semanas seguidas.

- Programação Pareada: Todo código é produzido por dois desenvolvedores na mesma máquina.

- Propriedade Coletiva: Qualquer pessoa pode realizar melhorias em qualquer parte em qualquer momento.

- Padronização de Código: Possuir regras que enfatizem comunicação através do código.

- Integração Contínua: Integre o sistema diversas vezes por dia (sempre que uma tarefa é terminada).

- Refatoração: Reestruture o sistema sem alterar seu comportamento para remover duplicações, melhorar comunicação, simplificar ou adicionar flexibilidade.

- Design Simples: projete da forma mais simples possível a todo momento

Padronização de código, propriedade coletiva e integração contínua fazem do XP um processo que enfatiza o trabalho em equipe. (WOOD; MICHAELIDES; THOMSON, 2013)

A padronização de código requer que todos os desenvolvedores escrevam e mantenham o código de forma consistente provendo assim uma base comum para a compreensão de unidades de código. A propriedade coletiva encoraja os desenvolvedores a se responsabilizarem pelo código como um todo e não só por partes. A integração contínua implica em controle de qualidade contínuo pois pequenas partes do sistema são testadas frequentemente para prover feedback contínuo e aumentar a qualidade do software. (BECK, 2000) 


\subsection{SEMAT}

Atualmente há diversos métodos utilizados para o desenvolvimento de software, essa grande quantidade de métodos acarreta problemas específicos (JACOBSON; MEYER; SOLEY, 2009):

- A prevalência de modismos mais típicos da indústria da moda que de uma disciplina de engenharia;

- A falta de uma base teórica sólida e largamente aceita;

- Uma grande quantidade de métodos e variantes de métodos, com pequenas diferenças compreendidas e artificialmente aumentadas;

- A falta de avaliação e validação experimental de credibilidade; e

- A separação entre a pesquisa acadêmica e a prática da indústria.

Em oposição a esse cenário, foi lançada em 2009 a iniciativa SEMAT (Software Engineering Method and Theory) que objetiva redefinir a engenharia de software baseada em uma teoria sólida, princípios comprovados e melhores práticas que (JACOBSON; MEYER; SOLEY, 2009):

- Inclua um kernel de elementos amplamente aceitos, definidos, extensível para usos específicos;

- Aborde tanto questões de tecnologia quanto de pessoas;

- Seja suportada pela indústria, academia, pesquisadores e usuários; e

- Tenha suporte a extensões em face da mudança dos requisitos e da tecnologia.

A iniciativa teve como primeiro objetivo a criação de um kernel com elementos essenciais e comuns a todos os esforços de engenharia de software e uma linguagem para definir as práticas e métodos a partir desse kernel. O kernel possui os elementos alfas, espaços de atividades e competências, sendo esses elementos classificados em domínios. (JACOBSON et al., 2012) 


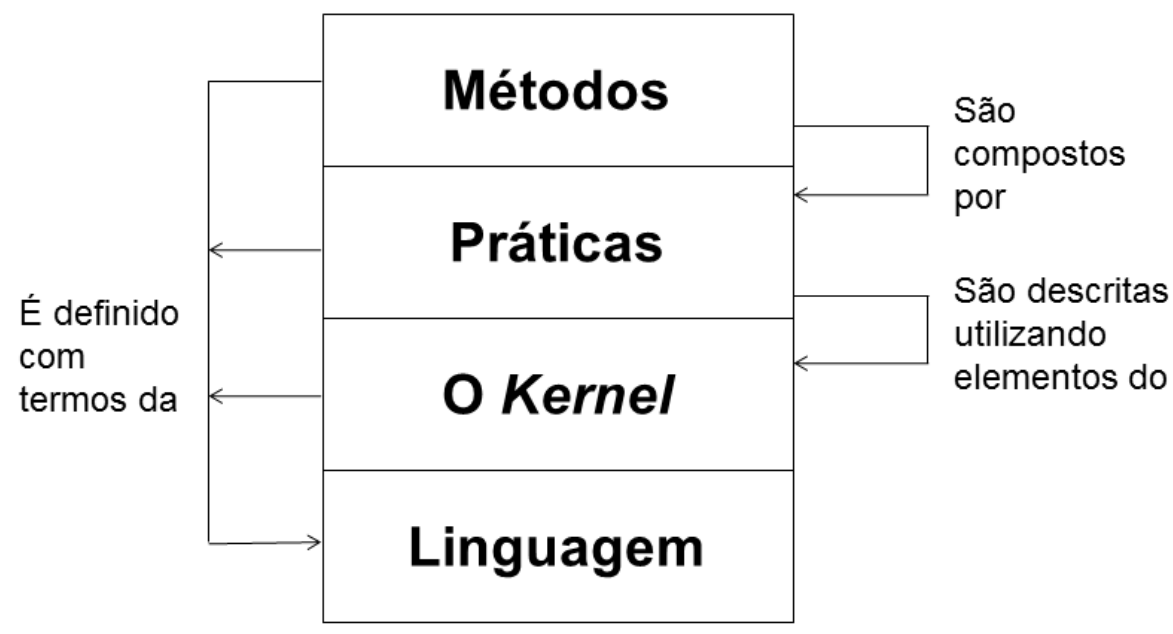

Figura 8 - Arquitetura SEMAT

Fonte: Semat, 2012

\subsubsection{Domínios}

O kernel é dividido em sete alfas principais que são agrupados de acordo com o seu escopo em três grandes domínios de estudo, cliente, solução e empreitada (Figura 9). Observa-se a distribuição de alfas entre os domínios na Figura 10.

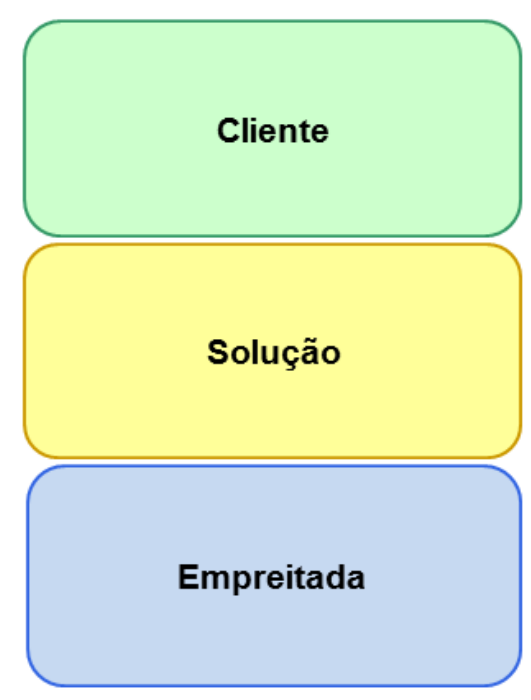

Figura 9 - Domínios do ESSENCE

Fonte: Semat, 2012 


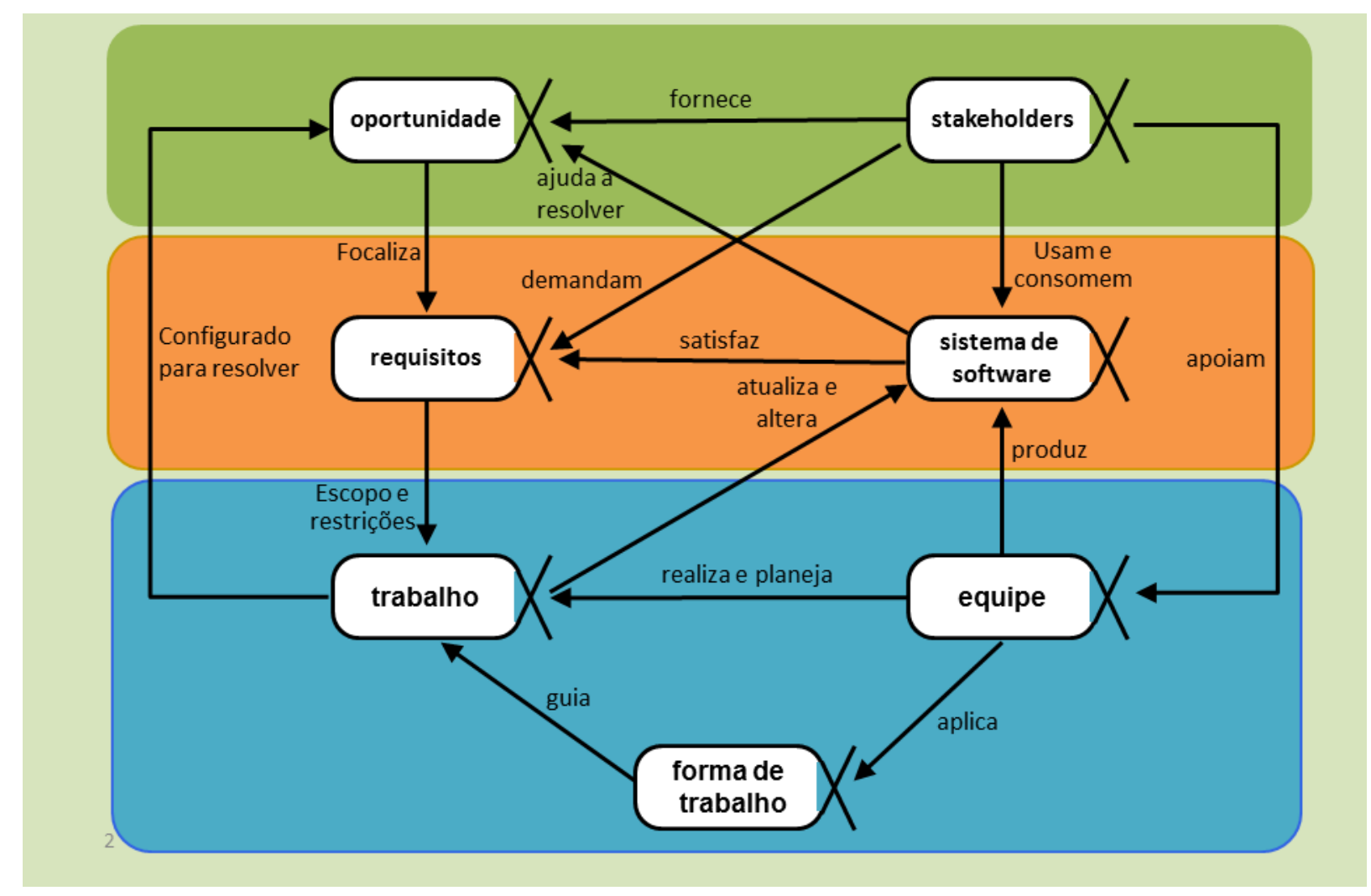

Figura 10 - Alfas do ESSENCE

Fonte: Semat, 2012

O domínio cliente possui dois alfas: oportunidade e stakeholder; e abrange o uso e a exploração do software a ser desenvolvido.

Já o domínio solução envolve a especificação e o desenvolvimento do software em si, possuindo dois alfas: requisitos e sistemas de software.

Por último o domínio empreitada abrange a abordagem que a equipe tem do trabalho, bem como a formação da equipe em si. Essa área possui os alfas trabalho, forma de trabalho e equipe.

Além de serem utilizadas para organizar os alfas por escopo, os domínios têm atividades pré-determinadas que são denominados espaços de atividades (Figura 11). 
Esses espaços de atividades contêm entre outras atividades as de "explorar possibilidades" e de "utilizar o sistema" no âmbito do cliente. "Implementar o sistema", "testar o sistema" e "operar o sistema" na solução.

A área da empreitada possui tipos diversos de atividade, alguma focadas na equipe como coordenação e apoio à equipe, e outras relacionadas ao trabalho como a decisão de em que momento parar o trabalho.

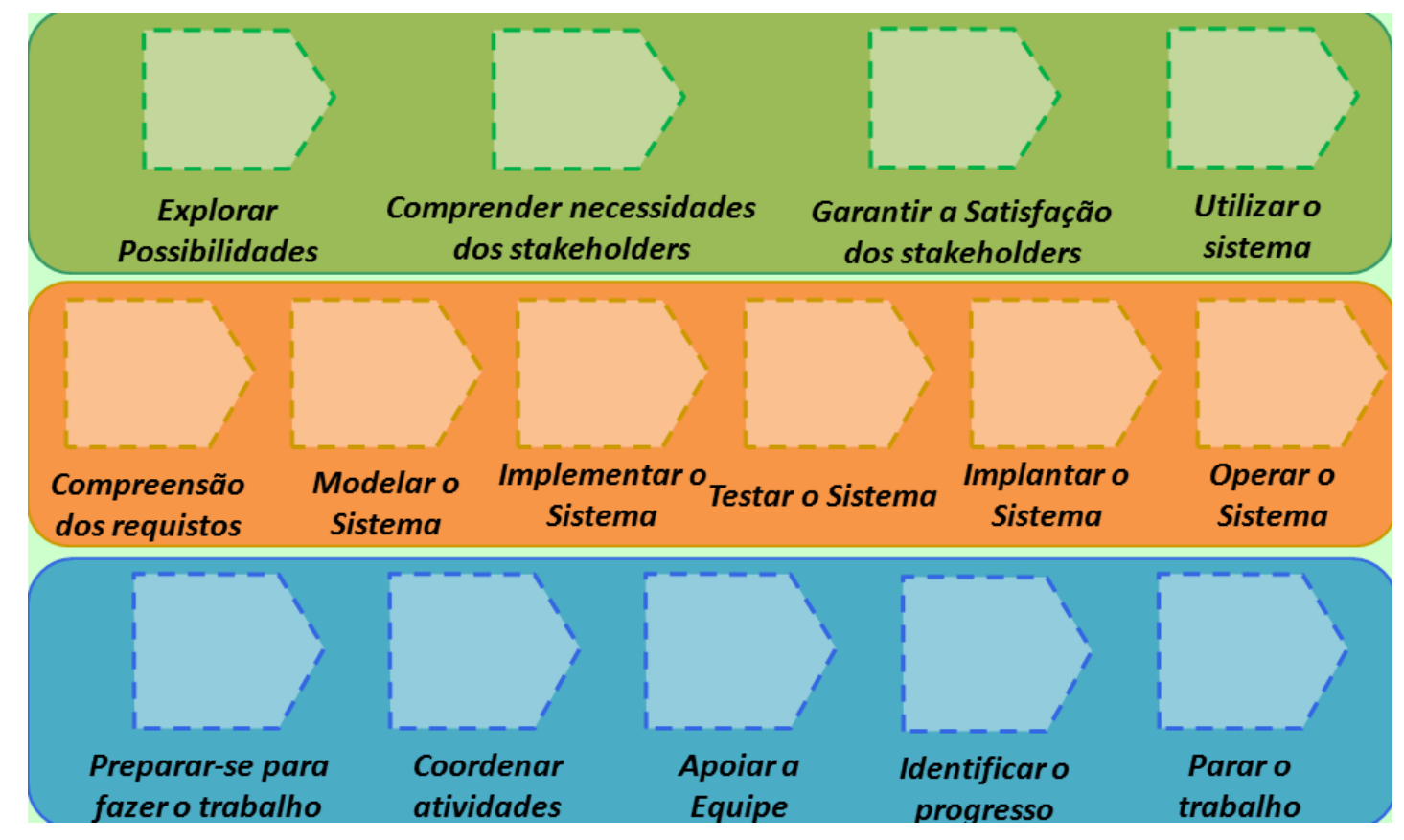

Figura 11 - Espaços de atividades

Fonte: Semat, 2012

\subsubsection{Alfas}

Para cada alfa do SEMAT é atribuído uma lista de estados, que funcionaa como uma ferramenta para indicar a situação atual do desenvolvimento de software e determinar os próximos passos. Cada estado contém uma lista de objetivos a serem alcançados. (JOHNSON; EKSTEDT; JACOBSON, 2012) 
Os alfas são apresentados em forma de cartões contendo os principais requisitos de cada um dos seus estados (Apêndice A - Checklists utilizados pelo SEMAT). A Figura 12 mostra os cartões dos três primeiros estados do alfa Requisitos que contém o que o sistema de software deve realizar para atender aos stakeholders (JACOBSON et al., 2013)

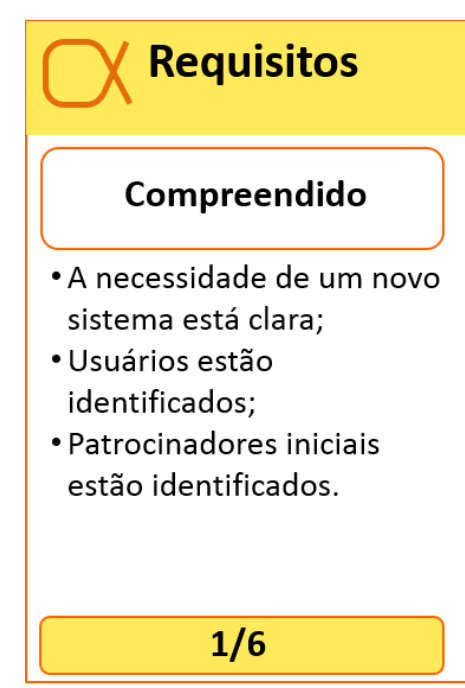

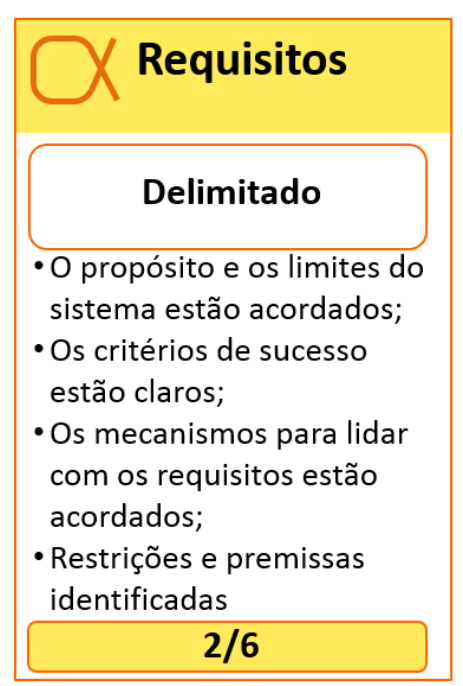

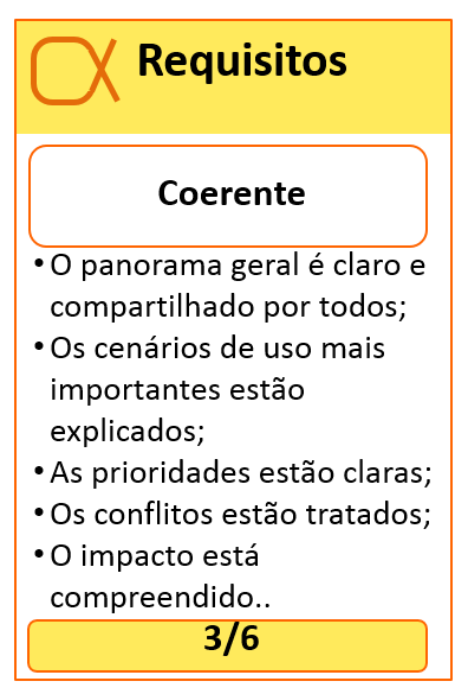

Figura 12 - Cartões do alfa Requisitos

Fonte: Semat, 2013

O conjunto de circunstâncias que tornam apropriado o desenvolvimento ou a alteração de um sistema de software é descrito no alfa oportunidade. Este representa a compreensão compartilhada pela equipe das necessidades dos stakeholders, e auxilia no estabelecimento dos requisitos do novo sistema de software provendo justificativas para o seu desenvolvimento (JACOBSON et al., 2012).

O alfa Stakeholders envolve as pessoas - ou entidades - que afetam ou são afetados pelo seu Sistema de Software. Os stakeholders fornecem a oportunidade e são também fonte dos requisitos do sistema. Devem estar envolvidos durante todo o processo garantindo assim o desenvolvimento de um software aceitável (JACOBSON et al., 2012). 
A evolução do hardware, software e dados utilizados para a criação do produto é descrita pelo alfa Sistema de software, sendo esse o principal resultado da empreitada de engenharia de software (JACOBSON et al., 2012).

Trabalho é o alfa que analisa tudo aquilo que a equipe deve realizar para completar o projeto de software, enquanto o Modo de trabalho consiste no conjunto de práticas usada pela equipe para guiar e apoiar seu trabalho (JACOBSON et al., 2012).

O alfa Equipe considera as pessoas envolvidas no desenvolvimento do sistema de software (JACOBSON et al., 2012).

\subsection{PRÁTICAS ÁGEIS}

A adoção dos métodos ágeis é feita muitas vezes através de suas práticas, e da customização de métodos para as necessidades de cada empresa (JACOBSON; MEYER; SOLEY, 2009), pois apesar de mais de $70 \%$ dos entrevistados na State of Agile Development Survey utilizarem o Scrum, ou derivados dele, no desenvolvimento de software, uma porcentagem significativamente menor utiliza o papel do Product Owner dedicado. (VERSIONONE, 2012)

A mesma pesquisa, apresenta uma lista com as 26 práticas mais utilizadas no desenvolvimento ágil de software (Erro! Fonte de referência não encontrada.).

Quadro 4 - Práticas ágeis mais utilizadas

\begin{tabular}{lcllc}
\hline Prática & Utilização & Prática & Utilização \\
\hline Reunião diária & $85 \%$ & Planejamento da Iteração & $75 \%$ \\
\hline Teste de Unidade & $74 \%$ & Retrospectivas & $72 \%$ \\
\hline Planejamento de Release & $69 \%$ & $\begin{array}{l}\text { Burndows/ Expectativas } \\
\text { baseadas na equipe }\end{array}$ & $67 \%$ \\
\hline Velocity & $58 \%$ & Padronização de Código & $57 \%$ \\
\hline
\end{tabular}




\begin{tabular}{llll}
\hline Integração contínua & $56 \%$ & Builds automatizados & $55 \%$ \\
\hline Product Owner dedicado & $51 \%$ & Integração Dev./QA & $49 \%$ \\
\hline Refatoração & $48 \%$ & Área de trabalho aberta & $43 \%$ \\
\hline TDD & $40 \%$ & TaskBoard Digital & $39 \%$ \\
\hline Mapeamento de histórias & $38 \%$ & Kanban & $32 \%$ \\
\hline Propriedade coletiva & $32 \%$ & Programação pareada & $30 \%$ \\
\hline Testes de aceitação & $27 \%$ & Taskboard analógica & $24 \%$ \\
\hline automatizados & $23 \%$ & Jogos ágeis & $17 \%$ \\
\hline Deployment contínuo & $13 \%$ & BDD & $10 \%$ \\
\hline Cycle Time & & & \\
\hline Fonte: VersionOne, 2012 & & & \\
\hline
\end{tabular}

Fonte: VersionOne, 2012

A Agile Alliance também lista outras práticas ágeis como observado na Figura 13. 


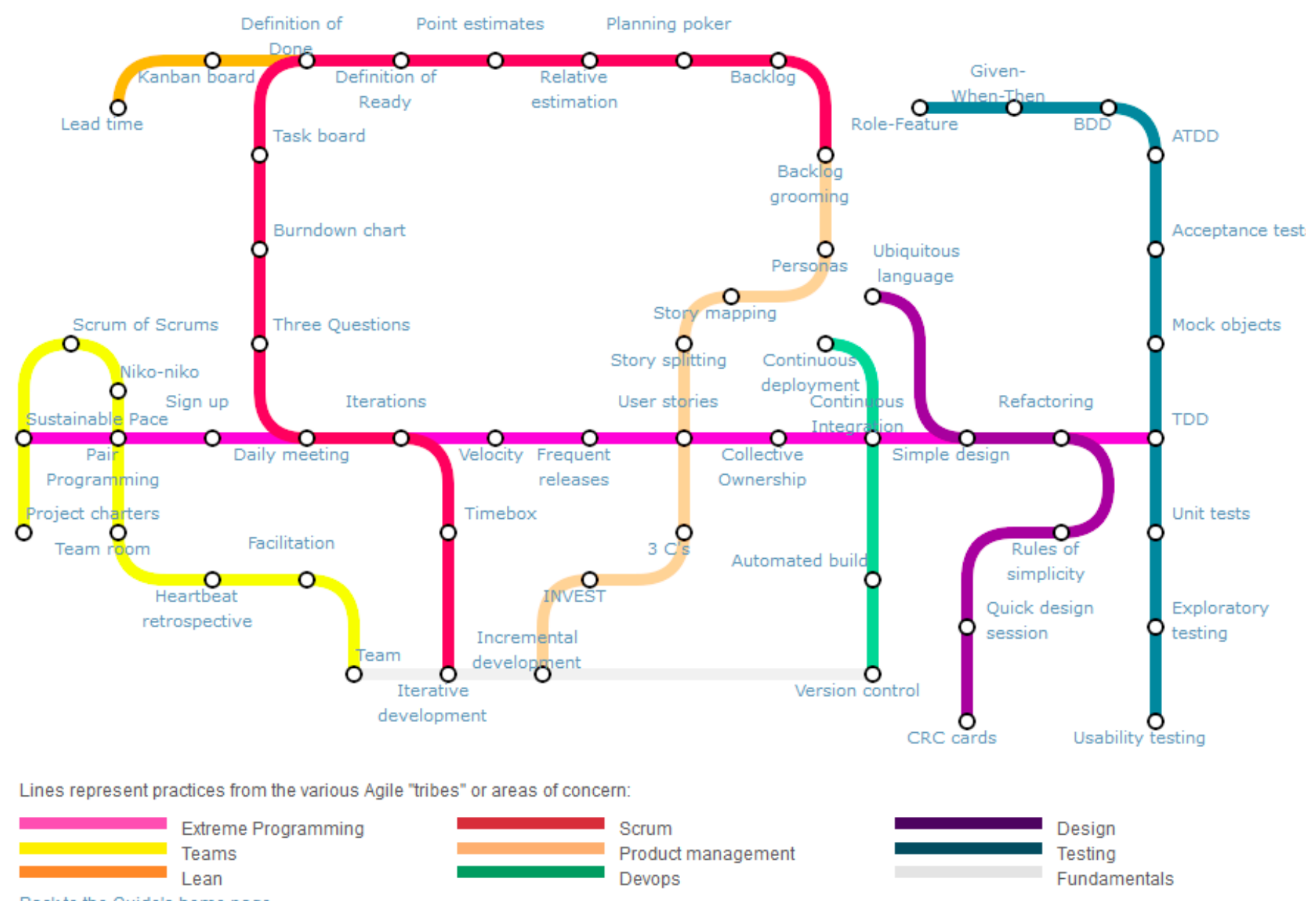

Figura 13 - Mapa das práticas ágeis

Fonte: Agile Alliance, 2013 [site] 
As práticas que não foram citadas no State of Agile Development Survey mas são citadas pela Agile Alliance são:

- Definição de feito;

- Definição de pronto;

- Estimativa por pontos;

- Estimativa relativa;

- Backlog;

- Tratamento do backlog (backlog grooming);

- Personas;

- Divisão de histórias;

- Histórias de usuários;

- Três C's;

- Desenvolvimento incremental;

- Desenvolvimento iterativo;

- Timebox;

- Iterações;

- Três perguntas;

- Controle de versão;

- Linguagem ubíqua;

- Design simples;

- Regras de simplicidade;

- Sessões de design rápido; 
- Cartões CRC;

- Testes exploratórios;

- ATDD;

- Mock objects;

- Dado-quando-então;

- Papel-função-razão;

- Times;

- Facilitação;

- Mapeamento do projeto;

- Ritmo sustentável;

- Seleção voluntária de tarefas;

- Calendário niko-niko;

- Scrum de scrums.

A união das práticas ágeis listadas em ambas as pesquisas totaliza-se 59 práticas regularmente utilizadas. 


\subsubsection{Descrição das práticas}

Nessa seção são descritas brevemente as práticas ágeis para que as suas funções sejam compreendidas no desenvolvimento dos sistemas, e para que possam ser analisadas sob a ótica do SEMAT, da dependabilidade de software e dos guidelines citados nas seções anteriores.

(1) Reunião diária: essa práticas também conhecida como daily scrum é definida como uma reunião curta (cerca de 15 minutos) realizada todos os dias para atualização do andamento do projeto (PAASIVAARA; DURASIEWICZ; LASSENIUS, 2009).

(2) Teste de Unidade: Um teste de unidade é um programa autocontido que checa um aspecto da implementação sendo testada. ("IEEE Standard Glossary of Software Engineering Terminology," 1990)

(3) Planejamento de Release: é a decisão de quais requisitos devem ser entregues em um release específico. (GREER; RUHE, 2004)

(4) Velocity: Ao final de cada iteração o time calcula o total de estimativas das histórias de usuário completadas. Com isso realiza-se a estimativa de quantas iterações serão necessárias para completar o projeto. (ALLEMAN, 2003)

(5) Integração contínua: é o processo automatizado - normalmente realizado diariamente - de unificar os esforços de atores independentes para entregar um sistema completo. (MCCONNEL, 1996)

(6) Product Owner dedicado: responsável por comunicar a visão do que deve ser definido e definir os critérios pelos quais o sistema será avaliado. Responsável por elencar e priorizar os requisitos do sistema no formato de histórias de usuário. (Mahnic, 2012)

(7) Refatoração: Nova escrita do código sem adição de funcionalidades. (Wood, 2013)

(8) Desenvolvimento orientado à testes: é considerado a união de duas práticas 'test-first development' que consiste em escrever os testes de unidade antes que o código necessário para cumprir tais testes seja escrito e refatoração. (Rafique, 2013)

(9) Mapeamento de histórias: prática desenvolvida recentemente que consiste em dividir suas histórias de usuário em duas "dimensões" na horizontal uma 
sequência comportamental do sistema, e na vertical incrementos na sofisticação da função (PATTON, 2005);

(10) Propriedade coletiva: A equipe possui propriedade coletiva do software desenvolvido. Qualquer pessoa pode alterar qualquer parte do código. Porém códigos desenvolvidos só podem ser integrados se todos os testes unitários forem atendidos (MACKENZIE; MONK, 2004);

(11) Testes de aceitação automatizados: A escrita de testes de unidade para serem executados automaticamente a cada nova iteração de desenvolvimento de software (PANZL, 1976);

(12) Implantação contínua: é uma extensão da integração contínua que consiste em automatizar o processo de implantação do software (HUMBLE; READ; NORTH, 2006);

(13) Lead Time: tempo entre a descoberta de um requisito e sua implementação, essa medida é usada de forma equivalente ao velocity por equipes que utilizam Kanban (HÖST; REGNELL; WOHLIN, 2000);

(14) Planejamento da Iteração: Antes do início de cada iteração uma reunião de planejamento é realizada onde o cliente seleciona tarefas que possuem estimativas que totalizam o total de velocity da iteração anterior (HAUGEN, 2006);

(15) Retrospectivas: São reuniões informais realizadas pela equipe de forma a alterar (ou adicionar) alguma nova prática ao funcionamento do processo de desenvolvimento de software (COLLINS; MILLER, 2001);

(16) Burndow chart: diagrama que indica a quantidade de trabalho que resta a ser executada pela equipe (MIRANDA; BOURQUE, 2010);

(17) Padronização de Código: para apoiar a propriedade coletiva do código a equipe desenvolve de maneira uniforme seguindo uma lista de padrões de desenvolvimento (PAULK, 2001);

(18) Builds automatizados: selecionam de acordo com um script as bibliotecas necessárias, arquivos de configuração e códigos fontes e criam um sistema de software funcional (CLARK, 2004);

(19) Integração Dev./QA: em métodos ágeis os desenvolvedores possuem responsabilidade em relação a qualidade do software (VERNER; BABAR, 2004); 
(20) Área de trabalho aberta: pessoas que trabalham juntas, estão alocadas fisicamente juntas, com a geometria do layout refletindo os grupos de trabalho (BRENNAN; CHUGH; KLINE, 2002);

(21) Taskboard Digital: sistema de software onde um grupo pode manter a situação de itens do projeto e atualizá-los (PERRY, 2008);

(22) Kanban: desenvolvido pelo vice presidente da Toyota, possui duas características fundamentais (1) produção just-in-time somente os produtos necessários, no momento necessário em quantidades necessárias e (2) respeito pelas pessoas (SUGIMORI et al., 1977);

(23) Programação pareada: é uma técnica na qual duas pessoas se sentam literalmente lado-a-lado e escrevem um programa no mesmo computador (WRAY, 2010);

(24) Taskboard analógica: local físico onde um grupo mantém a situação atual de itens do projeto (MORAN; SAUND; MELLE, 1999);

(25) Jogos ágeis: jogos utilizados durante a fase de estimativa da dificuldade da implementação da história do usuário (HAUGEN, 2006);

(26) BDD (Behaviour Driven Development): técnica que consiste na automatização de testes de comportamentos esperados do software, sendo que estes comportamentos devem descrever requisitos do sistema (TAVARES et al., 2010);

(27) Definição de feito: a equipe define uma lista de critérios que uma tarefa deve atingir para ser considerada executada e os utiliza consistentemente. Esse conceito apareceu pela primeira vez em um exercício de coaching para praticantes do XP (JAKOBSEN; SUTHERLAND, 2009);

(28) Definição de pronto: análoga a definição de feito, porém os critérios indicam se uma tarefa pode ser considerada pronta para ser desenvolvida evitando muita discussão e retrabalho (JAKOBSEN; SUTHERLAND, 2009);

(29) Estimativa por pontos: estimativas sem relação com unidades reais de tempo utilizadas para evitar confusão entre estimativa e tempo de trabalho (LECHNER, 2008);

(30) Estimativa relativa: estimativa de histórias de usuário (ou casos de uso) realizadas não em unidades absolutas de tempo mas em comparação com outras histórias de usuário (MIRANDA, 2001); 
(31) Backlog: Backlog do produto (ou da Sprint no SCRUM) é uma lista ordenada de tudo que deve ser desenvolvido, e é uma origem única de todas as mudanças que devem ser feitas no sistema(SCHWABER; SUTHERLAND, 2009);

(32) Tratamento do backlog (backlog grooming): é o ato de adicionar detalhes, estimativas e ordenar os itens no backlog (DULLEMOND; VAN GAMEREN; VAN SOLINGEN, 2012);

(33) Personas: Uma persona é um arquétipo de um usuário, descrito cuidadosamente em termos de necessidades, objetivos e tarefas (AOYAMA, 2005);

(34) Divisão de histórias: Uma história de usuário ideal é capaz de ser implementada em no máximo 3 dias. Se as estimativas forem maiores, a história deve ser dividida em uma série de histórias menores (PATTON, 2008);

(35) Histórias de usuários: São descrições curtas e abstratas do que deve ser implementado que servem primariamente como âncoras para maiores discussões com os clientes. Os desenvolvedores discutem os requisites em detalhe com o cliente durante o desenvolvimento (MAURER; MARTEL, 2002);

(36) Três C's: “Cartão, conversa e confirmação”, rotina ágil que inclui um pequeno cartão onde a história fica anotada, esse cartão serve como origem para uma conversa onde todos os detalhes são discutidos e os critérios de aceitação dessa história são anotados em um documento de confirmação (SHARP; ROBINSON; PETRE, 2009);

(37) Desenvolvimento incremental: o projeto é dividido em fatias 'verticais' que adicionam a cada versão funcionalidades visíveis para o usuário (MARTIN, 1999);

(38) Desenvolvimento iterativo: o desenvolvimento é incremental no sentido que atividades podem ser revisitadas em diversos momentos, e é organizado em iterações com objetivos determinados (MARTIN, 1999);

(39) Timebox: a equipe possui uma quantidade de tempo fixa na qual o Sistema deve ser construído, ela possui como entrada uma lista de funções do sistema e como saída um sistema que será avaliado para decidir se está pronto para ser colocado em produção (ABBAS; GRAVELL; WILLS, 2008);

(40) Iterações: no contexto ágil é utilizado para definir uma timebox, usualmente com duração entre 1 e 4 semanas e com duração fixa durante todo o projeto (ABBAS; GRAVELL; WILLS, 2008); 
(41) Três perguntas: na reunião diária, todos os desenvolvedores têm que responder a três perguntas: "O que você realizou ontem? ", "O que você fará hoje? " e "O que está te atrapalhando? " (SUTHERLAND; VIKTOROV, 2007);

(42) Controle de versão: uso de sistemas de controle de versão, para armazenar e reconstruir versões antigas do sistema de software (BALL; KIM; SIY, 1997);

(43) Linguagem ubíqua: linguagem usada para comunicação entre a equipe deve conter conceitos do domínio do negócio combinados com nomes de padrões de design de software utilizados (LANDRE; WESENBERG; OLMHEIM, 2007);

(44) Design simples: define que todo o código desenvolvido deve fazer parte de alguma das tarefas do backlog, em outras palavras - não programe hoje o que será necessário amanhã (FOWLER, 2001);

(45) Regras de simplicidade: a todo momento, o Sistema executa todos os testes, comunica tudo que os desenvolvedores desejam comunicar, não contém código duplicado, e o mínimo possível de classes e métodos (BECK, 1999);

(46) Sessões de design rápido: dois ou mais desenvolvedores se reúnem para uma breve discussão com um quadro branco para decidir questões de arquitetura (JU et al., 2006);

(47) Cartões CRC: cartão contendo o nome da classe, as responsabilidades da mesma, e os colaboradores - outras classes que elas dependem para cumprir suas responsabilidades - com o objetivo de auxiliar na prototipação de uma arquitetura orientada a objetos (BECK; CUNNINGHAM, 1989);

(48) Testes exploratórios: se diferenciam de testes com scripts por darem liberdade para que o responsável pelos testes controle ativamente o projeto do teste, criando novos e melhores testes a partir dos já realizados (BACH, 2003);

(49) ATDD: Análogo ao TDD, envolve a escrita de testes antes do desenvolvimento, porém os testes escritos são testes de aceitação e não teste unitários (HENDRICKSON, 2008);

(50) Mock objects: consiste em instanciar uma versão de um componente específica para testes, que ao invés do comportamento padrão, apenas retorna resultados pré-computados (MACKINNON; FREEMAN; CRAIG, 2001);

(51) Dado-quando-então: a prática consiste em um modelo para escrita de testes de aceitação evitando excesso de textos "dado um contexto, quando um evento ocorre, então um resultado é esperado" (TON, 2007); 
(52) Papel-função-razão: a prática consiste em um modelo para escrita de histórias de usuário evitando excesso de textos ou falta de informações necessárias, o modelo segue a seguinte estrutura, Como um [Papel], Eu desejo [função] para que eu consiga [razão] (SOLís; WANG, 2011);

(53) Equipe: é definida como um sistema social de três ou mais pessoas que pertence a uma organização, e colaboram para um objetivo comum (HOEGL; GEMUENDEN, 2001);

(54) Facilitação: as atividades são coordenadas pelo facilitador que dirige os esforços colaborativos daqueles envolvidos no desenvolvimento, permitindo que as opiniões de todos os participantes façam parte da decisão final (NERUR; MAHAPATRA; MANGALARAJ, 2005);

(55) Mapeamento do projeto: um sumário de alto-nível do projeto, possuindo os principais objetivos, as limitações e os acordos entre os pessoas envolvidas (II, 2001);

(56) Ritmo sustentável: também conhecido como semana de 40 horas, procurar fazer com que o trabalho seja realizado sem horas extras com qualidade em um ritmo sustentável (BARBOSA; LACERDA, [s.d.]);

(57) Seleção voluntária de tarefas: os próprios desenvolvedores selecionam as tarefas que realizarão (COHEN; LINDVALL; COSTA, 2004);

(58) Calendário niko-niko: cada membro da equipe desenha um smile que representa o seu humor naquele dia, deixando visível para os outros membros do time os sentimentos, motivações e o entusiasmo de cada um (WANG et al., 2013);

(59) Scrum de scrums: durante a reunião diária do scrum, cada equipe seleciona um membro para participar de uma segunda reunião (o Scrum de Scrums) para discutir posições entre as equipes (APPELO, 2010).

\section{TAXONOMIA DAS PRÁTICAS ÁGEIS}

Para estudar a interferência das práticas ágeis nos fatores humanos que levam à dependabilidade, as práticas são analisadas para aplicarmos o critério de exclusão. Serão utilizadas no questionário apenas práticas que alterem a dependabilidade através do ambiente. 
Os métodos ágeis já foram analisados e classificados utilizando frameworks como o SWEBOK (FERNANDES; ALMEIDA, 2010). E também classificados com um framework próprio para o estudo de componentes específicos (IACOVELLI; SOUVEYET, 2008). Contudo não foi encontrada nesta revisão nenhuma classificação isolada das práticas ágeis que compõe tais métodos.

Neste item as práticas ágeis são classificadas utilizando 3 frameworks com propósitos diferentes. O ESSENCE será utilizado para organizar as práticas de acordo com seus domínios, permitindo a identificação das práticas relacionadas aos fatores humanos (domínio empreitada). Utiliza-se os métodos tradicionais de aumento da dependabilidade para classificar as práticas diretamente relacionadas ao aumento da dependabilidade do software desenvolvido (AVIZIENIS; LAPRIE, 2004). As guidelines para o desenvolvimento de sistemas com redução de erro humano classificarão as práticas avaliando se colaboram para a construção de um ambiente onde há redução sistêmica do erro humano (RASMUSSEN; VICENTE, 1989).

Cada uma das práticas foi classificada com base no conhecimento do autor, apoiado na literatura.

\subsection{CLASSIFICAÇÃO QUANTO A DEPENDABILIDADE}

Para a classificação quanto a dependabilidade, utilizaremos como base a ideia que a remoção de falhas, a introdução de falhas, alterações no ambiente ou na forma que o software é utilizado influenciam diretamente na dependabilidade. (MUSA, 1987)

As práticas que colaboram com a remoção de falhas como testes de unidade então possuem relação direta com aumento da dependabilidade, enquanto práticas como o calendário niko-niko não possuem relação direta com dependabilidade.

Práticas que colaboram de alguma forma com os meios de obtenção de dependabilidade já levantados nomeadamente, prevenção, tolerância, remoção e previsão de falhas, foram consideradas diretamente relacionadas enquanto as outras indiretamente. 


\section{Práticas relacionadas \\ diretamente com dependabilidade}

\begin{tabular}{|lrl|}
\hline $\begin{array}{l}\text { ATDD } \\
\text { BDD (Behaviour Driven } \\
\text { Development) }\end{array}$ & Área de trabalho aberta & Ritmo sustentável \\
\hline $\begin{array}{l}\text { Builds automatizado } \\
\text { Controle de versão }\end{array}$ & Burndow chart & Seleção voluntária de tarefas \\
\hline Implantação contínua & Calendário niko-niko & Sessões de design rápido \\
\hline Desenvolvimento incremental & Cartões CRC & Taskboard analógica \\
\hline Desenvolvimento iterativo & Dado-quando-então & Taskboard Digital \\
\hline
\end{tabular}

Desenvolvimento orientado a

testes

Definição de pronto

Timebox

Integração contínua

Design simples

Times

\begin{tabular}{llr}
$\begin{array}{l}\text { Integração Dev./QA } \\
\text { Mock objects }\end{array}$ & $\begin{array}{r}\text { Tratamento do backlog (backlog } \\
\text { givão de histórias }\end{array}$ & grooming) \\
\hline Padronização de Código & Estimativa por pontos \\
\hline Programação pareada & Facilitação & Três perguntas \\
\hline Refatoração & Histórias de usuários & Velocity \\
\hline Teste de Unidade & Planejamento de Release \\
\hline Testes de aceitação & Iterã̃es & Product Owner dedicado \\
\hline
\end{tabular}


automatizados

Das 60 práticas analisadas, $17(28,3 \%)$ estão diretamente relacionadas à dependabilidade do software desenvolvido. A quantidade de práticas encontradas relacionadas diretamente com dependabilidade vai de encontro à crítica de que o desenvolvimento de sistemas confiáveis não é possível e que o apoio para o desenvolvimento de software confiável é limitado. (MISRA, 2012)

Esse fato não é, porém, inesperado. Considere-se que um dentre os critérios no manifesto ágil estão o desenvolvimento de software de qualidade e a excelência técnica da equipe. (BECK; BEEDLE; BENNEKUM, 2001)

\subsection{CLASSIFICAÇÃO RELATIVA AOS DOMÍNIOS DO SEMAT}

Utilizando os checklists apresentados como por exemplo na onde vemos as ações necessárias para a evolução da empreitada relativa ao alfa Stakeholders. Podemos ver que a prática "Product Owner dedicado" do Scrum possui relação com esse Alfa, enquanto a prática Jogos Ágeis tem relação com o Alfa Empreitada, por exemplo.

Estes alfas estão organizados em três domínios como mostrado na Figura 9. Todas as práticas de desenvolvimento de software podem ser escritas na linguagem desenvolvida pelo SEMAT, e para tanto devem pertencer a um ou mais alfas. 
Com o mapeamento das práticas em relação aos alfas, podemos categorizar as práticas de acordo com os domínios do SEMAT, permitindo verificar quais práticas afetam diferentes situações no desenvolvimento de software.

Essa classificação foi baseada nas definições das práticas e no conhecimento do autor que permitiram levantar em quais itens dos checklists dos alfas do SEMAT elas seriam efetivas. 
Quadro 6 - Relação entre práticas e domínios do SEMAT

\begin{tabular}{|c|c|}
\hline Empreitada & $\begin{array}{l}\text { Área de trabalho aberta, calendário niko-niko, cartões } \\
\text { CRC, dado-quando-então, facilitação, integração } \\
\text { contínua, jogos ágeis, papel-função-razão, programação } \\
\text { pareada, retrospectivas, reunião diária, ritmo } \\
\text { sustentável, scrum de scrums, seleção voluntária de } \\
\text { tarefas, sessões de design rápido, taskboard analógica, } \\
\text { taskboard Digital, times, três C's, três perguntas e } \\
\text { velocity. }\end{array}$ \\
\hline Solução & $\begin{array}{l}\text { Controle de versão, design simples, divisão de histórias, } \\
\text { mapeamento de histórias, mock objects, padronização } \\
\text { de Código e regras de simplicidade. }\end{array}$ \\
\hline Cliente & Personas e testes de aceitação automatizados. \\
\hline Solução e Empreitada & $\begin{array}{l}\text { Desenvolvimento orientado à testes, Lead Time, product } \\
\text { Owner dedicado, refatoração, teste de Unidade e } \\
\text { timebox. }\end{array}$ \\
\hline Cliente e Empreitada & $\begin{array}{l}\text { Estimativa por pontos, estimativa relativa e linguagem } \\
\text { ubíqua. }\end{array}$ \\
\hline Cliente e Solução & $\begin{array}{l}\text { Builds automatizado, implantação contínua, histórias de } \\
\text { usuários e iterações. }\end{array}$ \\
\hline $\begin{array}{l}\text { Cliente, Solução e } \\
\text { Empreitada }\end{array}$ & $\begin{array}{l}\text { ATDD, backlog, BDD (Behaviour Driven Development), } \\
\text { Burndow chart, Definição de feito, Definição de pronto, } \\
\text { Desenvolvimento incremental, Desenvolvimento } \\
\text { iterativo, Integração Dev./QA, Kanban, Mapeamento do } \\
\text { projeto, Planejamento da Iteração, Planejamento de } \\
\text { Release e Tratamento do backlog (backlog grooming) }\end{array}$ \\
\hline
\end{tabular}


Das práticas estudadas cerca de $38,3 \%$ estão relacionadas a domínio do Cliente enquanto $51,6 \%$ e $73,3 \%$ estão relacionadas aos domínios de Solução e Empreitada, mostrando que a maior parte das práticas estão alinhadas com o desenvolvimento de software de qualidade e no funcionamento da equipe de desenvolvedores. Estes valores mostram que as práticas que são utilizadas estão de acordo com os princípios do manifesto ágil.

Ao menos uma prática foi relacionada a cada um dos alfas do SEMAT, mostrando que as práticas ágeis atuam em todas as áreas consideradas relevantes do desenvolvimento de software.

A quantidade reduzida de práticas relacionadas ao domínio do cliente ilustra a mudança de foco que acontece no desenvolvimento ágil, reduzindo documentação e processos e investindo em programação e na equipe.

\subsection{CLASSIFICAÇÃO EM RELAÇÃO ÀS GUIDELINES}

Em relação as guidelines, a definição da prática e sua função no projeto será comparada a uma das guidelines. As práticas que atingirem objetivos similares aos da guideline serão consideradas.

A prática de integração contínua está relacionada ao guideline 2 pois provê um feedback rápido para o desenvolvedor, reduzindo o tempo entre execução de uma alteração e observação dela no software pelo stakeholder.

Essas práticas podem não estar relacionadas a nenhum dos guidelines propostos, ou a mais de um deles. Na Erro! Fonte de referência não encontrada. serão mostradas as práticas que se relacionam com cada um dos guidelines.

Essa classificação foi baseada no efeito esperado de cada uma das práticas propostas, e na definição de cada um dos guidelines considerando a empreitada de desenvolvimento de software como o sistema a ser projetado. 
Quadro 7 - Relação entre práticas e guidelines de projeto de sistemas

\begin{tabular}{|c|c|}
\hline Guidelines & Práticas \\
\hline Nenhuma & $\begin{array}{l}\text { Área de trabalho aberta, Controle de versão, Facilitação, } \\
\text { Integração Dev./QA, Iterações, Jogos ágeis, Mapeamento de } \\
\text { histórias, Programação pareada, Propriedade coletiva, } \\
\text { Refatoração, Ritmo sustentável, Scrum de scrums, Seleção } \\
\text { voluntária de tarefas, Testes de usabilidade, Testes } \\
\text { exploratórios, Timebox, Times, Três C's }\end{array}$ \\
\hline 1 & $\begin{array}{l}\text { ATDD, BDD (Behaviour Driven Development), Definição de feito, } \\
\text { Definição de pronto, Desenvolvimento incremental, } \\
\text { Desenvolvimento iterativo, Design simples, Estimativa por } \\
\text { pontos, Estimativa relativa, Lead Time, Mock objects, } \\
\text { Planejamento da Iteração, Planejamento de Release, Regras de } \\
\text { simplicidade, Retrospectivas, Testes de aceitação } \\
\text { automatizados }\end{array}$ \\
\hline 2 & $\begin{array}{l}\text { Builds automatizado, Integração contínua, Reunião diária, Três } \\
\text { perguntas }\end{array}$ \\
\hline 3 & $\begin{array}{l}\text { ATDD, Backlog, BDD (Behaviour Driven Development), } \\
\text { Desenvolvimento incremental, Divisão de histórias, Histórias de } \\
\text { usuários, Kanban, Planejamento da Iteração, Product Owner } \\
\text { dedicado, Sessões de design rápido, Taskboard analógica, } \\
\text { Taskboard Digital, Tratamento do backlog (backlog grooming) }\end{array}$ \\
\hline 4 & $\begin{array}{l}\text { Builds automatizado, Sessões de design rápido, Testes de } \\
\text { aceitação automatizados }\end{array}$ \\
\hline 5 & $\begin{array}{l}\text { ATDD, BDD (Behaviour Driven Development), Builds } \\
\text { automatizado, Burndow chart, Calendário niko-niko, Implantação } \\
\text { contínua, Desenvolvimento orientado à testes, Kanban, } \\
\text { Taskboard analógica, Taskboard Digital, Teste de Unidade, } \\
\text { Testes de aceitação automatizados }\end{array}$ \\
\hline
\end{tabular}




\begin{tabular}{|l|l|}
\hline 6 & Kanban, Taskboard analógica, Taskboard Digital \\
\hline 7 & $\begin{array}{l}\text { BDD (Behaviour Driven Development), Burndow chart, Cartões } \\
\text { CRC, Dado-quando-então, Definição de feito, Definição de } \\
\text { pronto, Desenvolvimento orientado à testes, Kanban, } \\
\text { Linguagem ubíqua, Mapeamento do projeto, Papel-função- } \\
\text { razão, Personas, Taskboard analógica, Taskboard Digital }\end{array}$ \\
\hline 8 & $\begin{array}{l}\text { Velocity } \\
\text { Dado-quando-então, Histórias de usuários, Papel-função-razão }\end{array}$ \\
\hline 10 & $\begin{array}{l}\text { Burndow chart, Dado-quando-então, Definição de feito, } \\
\text { Definição de pronto, Divisão de histórias, Histórias de usuários, } \\
\text { Kanban, Padronização de Código, Papel-função-razão, } \\
\text { Personas, Taskboard analógica, Taskboard Digital, Tratamento } \\
\text { do backlog (backlog grooming) }\end{array}$ \\
\hline
\end{tabular}

Das práticas levantadas nesse estudo, 30\% não estão relacionadas com nenhuma das formas de desenvolvimento de sistema com redução de erro humano proposta por Rasmussen, porém a grande maioria é capaz de contribuir com pelo menos um dos guidelines mencionados.

Das práticas relacionadas a algum dos guidelines pelo menos 30 delas, não estão diretamente relacionadas com a prevenção de falhas, são práticas consideradas indiretamente relacionadas a dependabilidade na seção 3.1. Esse resultado apoia a ideia que práticas ágeis são capazes de desenvolver softwares de alta confiabilidade.

\subsection{CLASSIFICAÇÃO CRUZADA}

Com o objetivo de estudar o efeito indireto de certas práticas na dependabilidade do software desenvolvido, foram selecionadas cinco práticas entre as analisadas. O critério para a seleção das práticas envolve: não estar relacionada diretamente com 
a dependabilidade, atuar exclusivamente no domínio empreitada do SEMAT e estar relacionada a um dos guidelines propostos.

As práticas que se encontram nessa situação são:

- Calendário niko-niko

- Cartões CRC

- Dado-quando-então

- Papel-função-razão

- Retrospectivas

- Reunião diária

- Sessões de design rápido

- Taskboard analógica

- Taskboard Digital

- Três perguntas

- Velocity

Dessas, as práticas reunião diária, calendário niko-niko, retrospectivas, sessões de design rápido e taskboards foram selecionados para o questionário, por seu uso ser de fácil identificação no ambiente de trabalho. 


\section{EFEITO DAS PRÁTICAS NA DEPENDABILIDADE DE SOFTWARE}

O efeito das práticas na dependabilidade do software desenvolvido será realizado de forma indireta, através da percepção dos desenvolvedores quanto aos comportamentos que são relacionados a redução de erro humano. A presença destes comportamentos será utilizada como indicador de redução de erro humano.

\subsection{CASUÍSTICA}

A amostra foi composta por 136 profissionais envolvidos com desenvolvimento de software, indiferente das práticas adotadas no ambiente de trabalho dos mesmos. Não foram aplicados critérios de exclusão para empresas que não utilizam métodos ágeis.

Os profissionais foram contatados através de grupos em redes sociais e e-mail, dos quais 125 aceitaram participar do presente estudo.

\subsection{MÉTODO}

Para validação da hipótese que algumas práticas ágeis podem alterar a qualidade do software - especificamente a dependabilidade - através de alterações ambientais com influência no sistema de desenvolvimento de software, um questionário foi preparado para levantar dados de uma população que utiliza métodos ágeis sobre essas práticas.

O questionário utilizado foi dividido em cinco seções, a primeira com o objetivo de descrever a população estudada. Na segunda seção foi questionado o uso das práticas levantadas a partir da classificação realizada no capítulo anterior. Foram selecionadas práticas que pertencem ao domínio "empreitada" do ESSENCEKERNEL, que não possuem relação direta com dependabilidade de software e que auxiliam no cumprimento de um dos guidelines de redução de erro humano. 
As práticas selecionadas foram: reunião diária, retrospectivas, sessões de design rápido, calendário niko-niko e taskboard (tanto analógica quanto digital).

Nesta seção foram usadas escalas Likert com valores de 0 (Não utilizado / desconheço) a 7 (Muito utilizado), nessa escala os valores possuem uma ordem de classificação, mas os intervalos entre eles não podem ser considerados iguais. Por isso, o uso da medida de média e testes paramétricos são inapropriados para esses dados. (JAMIESON, 2004)

A terceira seção do questionário teve como objetivo avaliar o cumprimento dos guidelines mostrados no capítulo 2, para cada um dos guidelines foi criada uma sentença correlacionando o mesmo ao ambiente de desenvolvimento de software. $E$ para cada uma das sentenças foi questionada a opinião do desenvolvedor entre "discordo totalmente" e "concordo totalmente", novamente utilizando a escala Likert. As questões que tratam de cada Guideline estão ilustradas no Quadro 8.

Quadro 8 - Perguntas relacionadas aos guidelines

\begin{tabular}{|r|r|}
\hline Guidelines & Questões \\
\hline 2 & 12,18 \\
\hline 3 & 13,19 \\
\hline 5 & $14,15,20,21$ \\
\hline 6 & 16,22 \\
\hline 9 & 17,23 \\
\hline
\end{tabular}

$\mathrm{Na}$ quarta seção do questionário, foi avaliada a percepção da colaboração das práticas no cumprimento dos guidelines questionados, com a opção para o sujeito adicionar práticas que não estavam na lista pré-selecionada. As opções foram randomizadas para cada uma das perguntas.

A última seção do questionário permite que o desenvolvedor dê sua opinião sobre o efeito das práticas no desenvolvimento de software.

O questionário foi disponibilizado utilizando uma ferramenta do Google Drive ${ }^{\circledR}$. Os dados foram tratados utilizando a versão 13.0 do software SigmaPlot®. 


\subsubsection{Análise estatística}

Para analisar o impacto da adoção das práticas ágeis nos fatores observados pelos guidelines os entrevistados foram divididos em grupos de acordo com os scores de utilização das práticas ágeis.

Para cada prática, foram considerados dois grupos com 31 sujeitos cada: o grupo com scores acima do quartil superior e o grupo com scores abaixo do quartil inferior. Os entrevistados que apresentaram scores entre os quartis foram excluídos da análise.

Para cada prática, foram comparados os scores dos dois grupos para as afirmações relativas aos guidelines afetados pelas práticas de acordo com a classificação realizada no capítulo 3 (Quadro 9).

Quadro 9 - Relações entre práticas e guidelines

\begin{tabular}{|l|r|}
\hline Prática & Guidelines \\
\hline Reunião diária & 2 \\
\hline Retrospectivas & 2,9 \\
\hline Sessões de Design Rápido & 3 \\
\hline Calendário niko-niko & 5 \\
\hline Taskboards & $3,5,6$ \\
\hline
\end{tabular}

A somatória dos scores das práticas foi utilizada para criar dois grupos: um com alto uso do conjunto de práticas ágeis analisado (Grupo A) e um com baixo uso das práticas ágeis (Grupo B).

O Grupo A é composto por indivíduos com scores com valor acima do quartil superior desse conjunto de dados, enquanto o Grupo B é composto por indivíduos com scores com valor abaixo do quartil inferior. 
Ambos os grupos foram comparados em relação à todas as afirmações referentes aos guidelines presentes no questionário.

Para os testes estatísticos entre os grupos foi utilizado o teste $U$ de Mann-Whitney.

\subsection{RESULTADOS}

A Tabela 1 ilustra os sujeitos que responderam a respeito da experiência com desenvolvimento de software (Questão 3), a maioria dos entrevistados possui acima de 4 anos de experiência.

Tabela 1 - Experiência em desenvolvimento de software

Tempo

Número absoluto Frequência relativa (\%)

Menos de 1 ano 17

Entre 1 e 3 anos

40

32,0

Entre 4 e 10 anos

53

42,4

Mais de 10 anos

15

12

Observou-se que $54 \%$ dos entrevistados consideram a dependabilidade uma das características relevantes ao software desenvolvido em suas empresas (Questão 6).

Quanto ao tamanho das empresas pesquisadas (Questão 4), 60,8\% dos entrevistados trabalham em pequenas e microempresas (Tabela 2).

Tabela 2 - Número de funcionários no local de trabalho

Quantidade

Até 5

Entre 6 e 20

Entre 21 e 50

Entre 51 e 150

Mais de 150
Número absoluto Frequência relativa (\%)

\begin{tabular}{rr}
32 & 25,6 \\
31 & 24,8 \\
13 & 10,4 \\
12 & 9,6 \\
37 & 29,6 \\
\hline
\end{tabular}

Mais de $90 \%$ dos entrevistados concordam que práticas ágeis colaboram com o aumento da dependabilidade do software desenvolvido (Questão 24), porém 43,2\% não utilizam nenhuma metodologia ágil conhecida no mercado (Questão 5). A 
metodologia com maior adoção foi o SCRUM, sendo utilizado por 51 entrevistados, como ilustrado na Tabela 3.

Tabela 3 - Metodologias habitualmente utilizadas

Metodologia

Agile RUP

Crystal

Feature Driven

Development

Programação eXtrema SCRUM

Outros

Nenhuma
Número absoluto Frequência relativa (\%)

\begin{tabular}{rr}
4 & 3,2 \\
3 & 2,4 \\
2 & 1,6 \\
& \\
8 & 6,4 \\
51 & 40,8 \\
3 & 2,4 \\
54 & 43,2 \\
\hline
\end{tabular}

\subsubsection{Utilização de práticas ágeis}

$\mathrm{Na}$ Tabela 4 estão apresentados os resultados para as práticas reunião diária, calendário niko-niko e retrospectivas (Questões 7,8 e 9).

Tabela 4 - Quartis da escala Likert para utilização de práticas ágeis

\section{Questão 7}

Primeiro quartil

Terceiro quartil

Mediana

$$
6,5
$$$$
3
$$

Questão 8

Questão 9

0

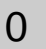

0

5

\section{2}

$\mathrm{Na}$ Tabela 5 estão os resultados para sessões de design rápido e taskboard (Questões 10 e 11), além da somatória do score das cinco práticas.

Tabela 5 - Quartis da escala Likert para utilização de práticas ágeis (continuação) Questão 10 Questão 11

Somatório

\section{Primeiro quartil}

Terceiro quartil

Mediana

0

5

3

1

7

5 
O Gráfico 2 mostra a distribuição do score na escala Likert para cada uma das práticas presentes no questionário. $\mathrm{O}$ eixo horizontal do gráfico mostra a prática avaliada e na legenda, temos o valor do score para a questão.

A prática calendário niko-niko obteve 107 respostas "0", e três respostas com score "7". Enquanto a prática Taskboards 50 desenvolvedores responderam que utilizam com frequência a prática.

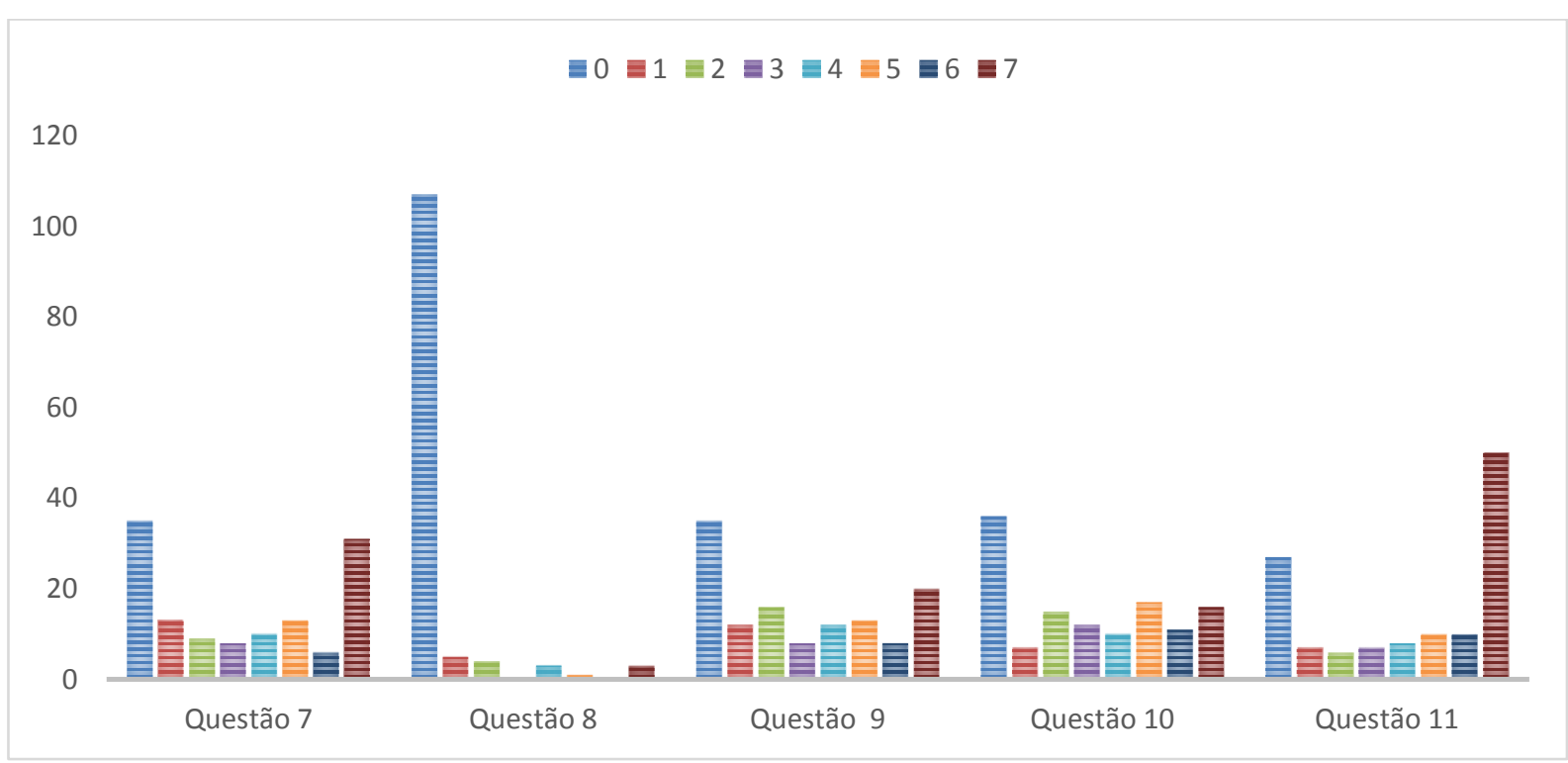

Gráfico 2 - Utilização de práticas ágeis

\subsubsection{Percepção dos guidelines}

O Gráfico 3 ilustra a percepção dos sujeitos sobre cada uma das afirmações relativas aos guidelines. 


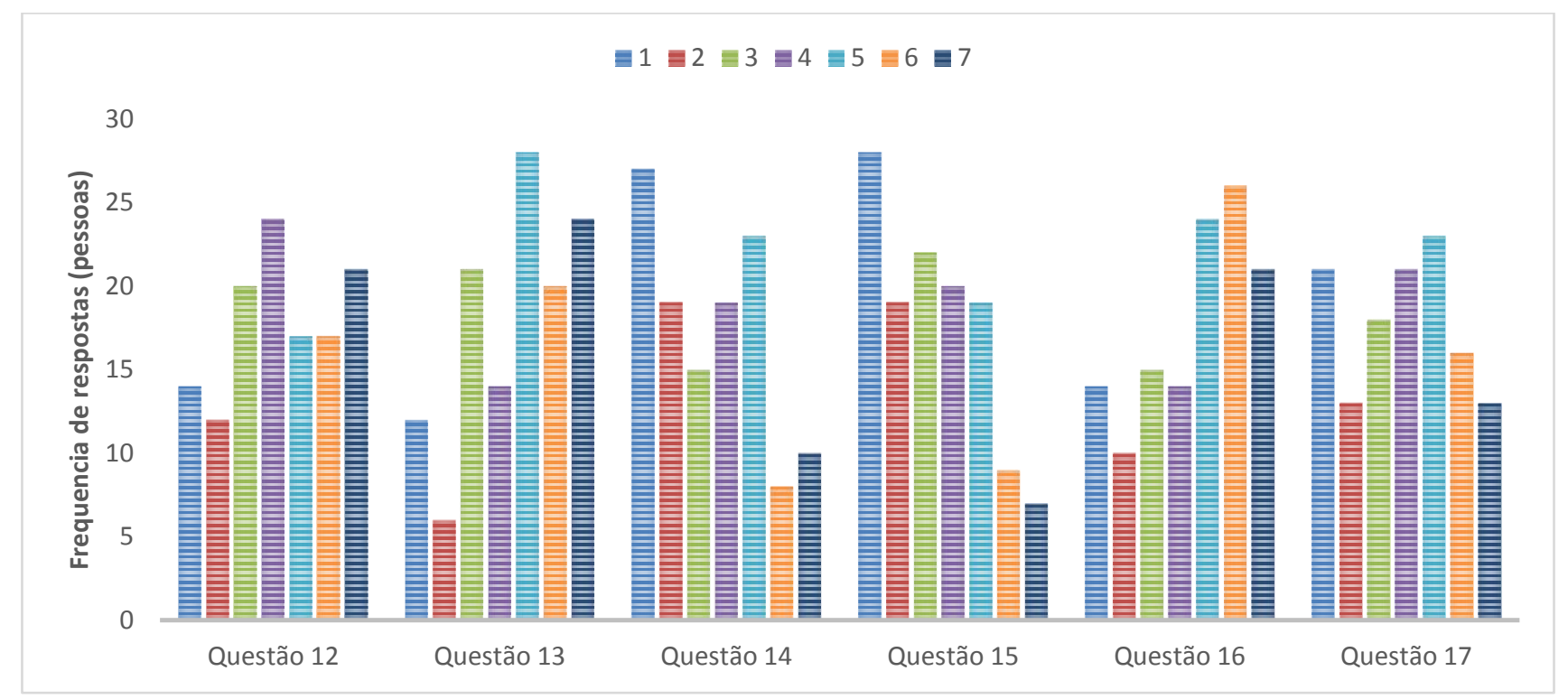

Gráfico 3 - Percepção dos guidelines

A afirmação questão 15, referente a afirmação "A situação da equipe pode ser avaliada de forma automática", relacionada ao Guideline 5 obteve o maior número de respostas "1" e possui o menor valor para o quartil inferior (Tabela 7).

Nenhuma afirmação apresentou score superior a 6 no terceiro quartil como mostrado na Tabela 6 e Tabela 7.

Tabela 6 - Quartis da escala Likert para afirmações relativas aos guidelines

Questão 12

Questão 13

Questão 14

\begin{tabular}{llll}
\hline Primeiro quartil & 3 & 3 & 2 \\
Terceiro quartil & 6 & 6 & 5 \\
Mediana & 4 & 5 & 3
\end{tabular}

Tabela 7 - Quartis da escala Likert para afirmações relativas aos guidelines (continuação) Questão 15 Questão 16

Questão 17

\begin{tabular}{llll}
\hline Primeiro quartil & 2 & 3 & 2 \\
Terceiro quartil & 5 & 6 & 5 \\
Mediana & 3 & 5 & 4
\end{tabular}


A quarta seção do questionário (questões 18 a 23) obteve a opinião dos desenvolvedores quanto à relação entre as práticas selecionadas e as afirmações dos guidelines.

A frequência das respostas para cada uma das questões é ilustrada no Gráfico 4.

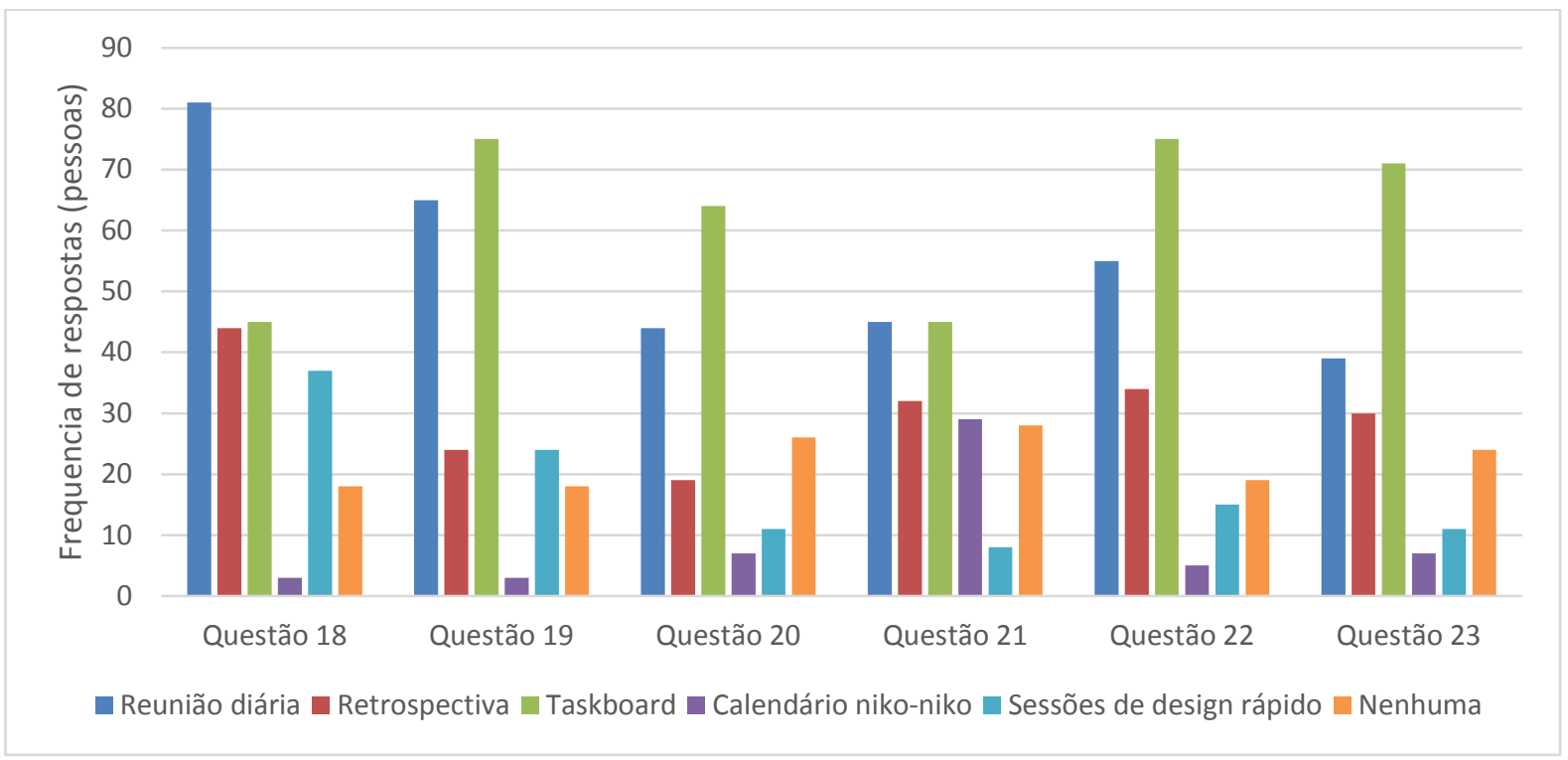

Gráfico 4 - Respostas às questões 18 a 23

\subsubsection{Reunião Diária}

Em relação à essa prática observou-se uma mediana igual a 6 para o grupo com respostas acima do quartil superior e 3 para o grupo com respostas abaixo do quartil inferior. A diferença dos valores nos dois grupos foi significativa com $p<0,001$.

\subsubsection{Sessões de Design Rápido}

Foi analisado o impacto dessa prática ao Guideline 3. A mediana dos grupos foi novamente 6 e 3 , respectivamente, e a diferença entre os resultados foi estatisticamente significante com $p<0,001$.

\subsubsection{Taskboards}


Novamente os grupos com maior e menor utilização foram comparados, mas foram realizadas 3 comparações pois a prática de taskboards foi relacionada a 3 guidelines diferentes.

Em relação ao Guideline 3 as medianas foram 6 e 3 respectivamente. Para 0 Guideline 5 foi utilizada a soma de dois scores, e as medianas foram iguais a 10 e 2 respectivamente. E finalmente para o Guideline 6 foram obtidas medianas 6 e 3 respectivamente. Todas as diferenças foram estatisticamente significantes, com $p<$ 0,001 .

\subsubsection{Calendário Niko-Niko}

Para comparar os grupos que mais utilizam e menos utilizam essa prática com o Guideline 5 foram utilizados os dados de duas perguntas diferentes da seção 3 somadas as perguntas 14 e 15 .

As medianas foram 3 para o grupo com menor utilização e 9 para o grupo com maior utilização, com diferença significativa e $p<0,001$.

\subsubsection{Retrospectiva}

Foi analisado o impacto dessa prática nos guidelines 2 e 9. Na comparação com o Guideline 2 as medianas foram de 6 para o grupo que reportou maior utilização da prática e de 3 para o grupo com menor utilização, esses valores são diferentes com $p<0,001$. Na comparação com o Guideline 9 os valores foram de 5 e 2 respectivamente e a diferença foi também estatisticamente significante com $\mathrm{p}<$ 0,001 .

\subsubsection{Pacote de práticas}

As respostas dos dois grupos foram comparadas em todas as afirmações, e os resultados são reportados na Tabela 8. 
Tabela 8 - Mediana do score dos guidelines para os grupos com uso intenso e uso baixo do pacote de práticas analisado

\begin{tabular}{lrrr}
\hline Afirmação & Mediana (Grupo A) & Mediana (Grupo B) & p \\
\hline Questão 12 & 6 & 3 & $<0,001$ \\
Questão 13 & 6 & 3 & $<0,001$ \\
Questão 14 & 5 & 3 & $<0,001$ \\
Questão 15 & 5 & 3 & $<0,001$ \\
Questão 16 & 6 & 3 & $<0,001$ \\
Questão 17 & 5 & 3 & $<0,001$ \\
\hline
\end{tabular}

\subsection{DISCUSSÃO}

A prática Taskboard (Questão 11) foi a que conseguiu mediana com valor mais alto (cinco) resultado que conflita com seu resultado em uma pesquisa no Brasil em 2012 onde era utilizada por $32,2 \%$ dos entrevistados. Ainda de acordo com a mesma pesquisa Retrospectivas e Reunião Diária (Questões 9 e 7, respectivamente) estavam entre as práticas mais utilizadas (68\% e $63,9 \%$, respectivamente) enquanto na análise obtiveram medianas de valores 3 e 2 apontando para um uso menor dessas práticas no grupo estudado. (MELO; SANTOS; CORBUCCI, 2012)

A prática Sessões de Design Rápido não aparece na lista das práticas mais utilizadas na pesquisa realizada no Brasil, nem na pesquisa mundial realizada. Porém obteve mediana 3 com o nosso grupo. (VERSIONONE, 2012)

A prática Calendário Niko-Niko não teve presença expressiva no questionário aplicado nesse trabalho, e também não foi mencionada nos questionários encontrados na literatura.

A prática de reunião diária foi relacionada por mais de $50 \%$ dos desenvolvedores à dois guidelines diferentemente da classificação realizada no capítulo 3. O Guideline 3 que trata de priorização de tarefas não foi relacionado a essa prática na taxonomia realizada pelo autor, porém foi apontado por $53 \%$ da população como efeito dessa prática. 
As práticas de retrospectiva, calendário niko-niko e sessões de design rápido não foram apontadas por uma quantidade significativa dos desenvolvedores como capazes de colaborar com nenhum dos guidelines estudados.

A prática do calendário niko-niko foi mais fortemente relacionada $(23 \%)$ com o Guideline 5 que aborda o monitoramento com consciência marginal de ações independentes.

A prática Taskboards foi relacionada à quatro guidelines diferentes por mais da metade dos sujeitos enquanto na taxonomia foram relacionadas a três guidelines na taxonomia realizada nas práticas ágeis. O Guideline 9 foi relacionado pelos sujeitos, porém não foi relacionado na classificação realizada pelo autor.

As práticas analisadas mostraram ser capazes de melhorar os aspectos do ambiente relacionados à elas. Em todos os casos, o grupo com maior adoção das práticas ágeis conseguiu resultado melhor para os guidelines analisados.

Esse resultado positivo vai de encontro à opinião de especialistas que afirmam que as práticas ágeis não são capazes de desenvolver sistemas de software com alta dependabilidade e que pode causar a redução da qualidade. (MISRA, 2012)

Alguns autores apontam que os mecanismos utilizados pelos métodos ágeis para controle de qualidade não são adequados para o desenvolvimento de sistemas críticos. Essas práticas não foram consideradas no presente estudo, mas o impacto das práticas no ambiente mostram que a adoção de práticas ágeis possuem efeitos benéficos na qualidade do software. (TURK; FRANCE; RUMPE, 2002)

Considerando ainda o conjunto de práticas escolhido para o questionário obtivemos um resultado positivo para todos os itens considerados, mostrando que a utilização de práticas ágeis aumenta o feedback, a percepção da situação do projeto entre outras características necessárias para a criação de um sistema com redução do erro humano. Fatores ambientais são historicamente relacionados ao desempenho dos desenvolvedores. Essas práticas abordam uma falha existente nos métodos tradicionais de aumento da dependabilidade - a falta de consideração aos fatores humanos. (DEMARCO; LISTER, 1985; SANDHOF; FILGUEIRAS, 2006) 
Uma das principais preocupações na adoção de práticas ágeis é a redução da qualidade do sistema de software produzido ( $20,8 \%$ no Brasil e $9 \%$ no mundo), porém a adoção das práticas ágeis foi correlacionada com maior aderência à guidelines para redução do erro humano que promovem aumento na qualidade do software. (MELO; SANTOS; CORBUCCI, 2012; VERSIONONE, 2012) 


\section{CONSIDERAÇÕES FINAIS}

Em meio às percepções obtidas com a classificação das práticas e com o questionário foi possível observar que as práticas ágeis permeiam todas as etapas fundamentais do desenvolvimento de software.

Além disso, os resultados ajudam a reduzir as críticas em relação à capacidade de se realizar projetos de alta dependabilidade. Grande parte das práticas ágeis atuam diretamente na redução de erro do software.

Foi verificado que o uso de práticas relativas aos fatores humanos do desenvolvimento de software, quando utilizadas com frequência, levam ao desenvolvimento de um ambiente de desenvolvimento de software com as características necessárias para redução de erro humano e aumento da dependabilidade do software desenvolvido.

\subsection{CONTRIBUIÇÕES}

Dentre as contribuições desse trabalho para o estudo das práticas de desenvolvimento de software é possível destacar:

(1) Classificação das práticas ágeis mais comuns sob a ótica da iniciativa SEMAT, encontrando os alfas que relacionados a cada uma das práticas;

(2) Classificação das práticas ágeis em relação à dependabilidade de software, ilustrando quais práticas atuam diretamente no aumento dessa característica da qualidade;

(3) Classificação das práticas ágeis a partir dos guidelines do Design de Interface Ecológica, mostrando que as práticas ágeis possuem um efeito fundamental na redução de erro humano no sistema de desenvolvimento de software;

(4) Verificação através de questionário do efeito das práticas ágeis nos pontos propostos pelo design de interface ecológica, mostrando que as práticas ágeis trazem benefícios à redução de erro humano. 


\subsection{TRABALHOS FUTUROS}

Os resultados obtidos na classificação utilizando a literatura e as definições das práticas ágeis devem passar por um processo de verificação, seja com consulta a especialistas ou com o desenvolvimento de uma metodologia mais confiável.

Quanto ao impacto das práticas na dependabilidade, os resultados obtidos nesse trabalho foram indiretos, conseguidos através de questionários. Novas pesquisas devem ser realizadas para aprofundar e validar esses resultados, utilizando critérios mais diretos como avaliar a quantidade de falhas encontradas no código fonte do software.

Trabalhos abordando outros subgrupos de práticas ágeis devem ser realizados, com o objetivo de aumentar a quantidade de práticas de desenvolvimento de software analisadas com uma metodologia capaz de ser reproduzida.

O desenvolvimento de uma metodologia capaz de avaliar de forma eficiente o impacto de práticas no ambiente de trabalho, e consequentemente, no software desenvolvido é um trabalho que se faz necessário. Essa metodologia deve ser baseada em uma maior compreensão do ser humano, das interações entre eles, e das tarefas que envolvem o desenvolvimento de software. 


\section{Referências}

ABBAS, N.; GRAVELL, A.; WILLS, G. Historical roots of Agile methods: where did "Agile thinking" come from? Agile Processes in Software Engineering and Extreme Programming, p. 94-103, 2008.

ALLEMAN, G. Making agile development work in a government contracting environment-measuring velocity with earned value. Agile Development Conference, 2003. ADC 2003. Proceedings of the, 2003.

AMBLER, S. Survey says... agile has crossed the chasm. DR DOBBS JOURNAL, p. 6-10, 2007.

AOYAMA, M. Persona-and-scenario based requirements engineering for software embedded in digital consumer products. Requirements Engineering, 2005.

Proceedings. 13th IEEE International Conference on., p. 85-94, 2005.

APPELO, J. Management 3.0: leading Agile developers, developing Agile leaders. [s.I.] Pearson Education, 2010.

AVIZIENIS, A.; LAPRIE, J. Basic concepts and taxonomy of dependable and secure computing. Dependable and Secure Computing, IEEE Transactions on, v. 1, n. 1, p. 11-33, 2004.

AVIZIENIS, A.; LAPRIE, J.; RANDELL, B. Fundamental concepts of dependability. [s.l: s.n.].

BACH, J. Exploratory Testing Explained. Online: http://www. satisfice. com/articles/et-article. pdf, p. 1-10, 2003.

BALL, T.; KIM, J.; SIY, H. P. If your version control system could talk. ICSE Workshop on Process Modelling and Empirical Studies of Software Engineering, 1997.

BARBOSA, A.; LACERDA, G. Estudo Investigativo da Adoção do CMMI e das Metodologias Ágeis em Empresas Brasileiras. [s.d.].

BASSI, D. L. Experiências com desenvolvimento ágil. 2008.

BECK, K. Embracing change with extreme programming. Computer, n. c, p. 70-77, 1999.

BECK, K. Extreme Programming Explained: Embrace Change. [s.I.] AddisonWesley Professional, 2000.

BECK, K.; BEEDLE, M.; BENNEKUM, A. VAN. Manifesto for agile software development. Disponível em: <http://agilemanifesto.org/>. Acesso em: 3 set. 2013. 
BECK, K.; CUNNINGHAM, W. A laboratory for teaching object oriented thinking. ACM Sigplan Notices, p. 1-7, 1989.

BOEHM, B.; BROWN, J.; LIPOW, M. Quantitative evaluation of software quality. Proceedings of the 2nd international conference on Software engineering, $p$. 592-605, 1976.

BOGNER, M. The how and why of incident investigation: implications for health information technology. [s.I.] Springer Berlin Heidelberg, 2007.

BRENNAN, A.; CHUGH, J. S.; KLINE, T. Traditional versus Open Office Design: A Longitudinal Field Study. Environment and Behavior, v. 34, n. 3, p. 279-299, 1 maio 2002.

BURNS, C. M.; JAMIESON, G. A. Evaluation of Ecological Interface design for nuclear process control: Situation awareness effects. Human Factors: The Journal of the Human Factors and Ergonomics Society, v. 50, n. 4, p. 663-679, 2008.

CAYOT-CONSTANTIN, S. et al. [Assessment of the usefulness to use a software supervising continuous infusion rates of drugs administered with pumps in ICU and estimation of the frequency of rate of administration errors]. Annales françaises d'anesthèsie et de rèanimation, v. 29, n. 3, p. 204-8, mar. 2010.

CLARK, M. Pragmatic Project Automation: How to Build, Deploy and Monitor Java Apps. [s.I.] The Pragmatic Programmers, 2004.

COCKBURN, A.; HIGHSMITH, J. Agile software development, the people factor. Computer, n. November, p. 131-133, 2001.

COHEN, D.; LINDVALL, M.; COSTA, P. An introduction to agile methods. Advances in computers, v. 62, n. 03, p. 1-66, 2004.

COLLINS, C.; MILLER, R. Adaptation: XP Style. Submitted as a paper to XP, 2001.

DEMARCO, T.; LISTER, T. Programmer performance and the effects of the workplace. Proceedings of the 8th international conference on Software engineering, p. 268-272, 1985.

DULLEMOND, K.; VAN GAMEREN, B.; VAN SOLINGEN, R. Supporting distributed software engineering in a fully distributed organization. Cooperative and Human Aspects of Software Engineering (CHASE), 2012 5th International Workshop on., p. 30-36, jun. 2012.

FERNANDES, J. M.; ALMEIDA, M. Classification and Comparison of Agile Methods. 2010 Seventh International Conference on the Quality of Information and Communications Technology, p. 391-396, set. 2010.

FOWLER, M. Is design dead? SOFTWARE DEVELOPMENT-SAN FRANCISCO-, p. 1-14, 2001. 
GREER, D.; RUHE, G. Software release planning: an evolutionary and iterative approach. Information and Software Technology, v. 46, n. 4, p. 243-253, mar. 2004.

HAUGEN, N. An empirical study of using planning poker for user story estimation. Agile Conference, 2006, 2006.

HENDRICKSON, E. Driving development with tests: ATDD and TDD. Quality Tree Software, Inc. http://www. qualitytree. com, p. 1-9, 2008.

HOEGL, M.; GEMUENDEN, H. Teamwork quality and the success of innovative projects: A theoretical concept and empirical evidence. Organization science, v. 12, n. 4, p. 435-449, 2001.

HÖST, M.; REGNELL, B.; WOHLIN, C. Using students as subjects-a comparative study of students and professionals in lead-time impact assessment. Empirical Software Engineering, v. 5, n. 3, p. 201-214, 2000.

HUMBLE, J.; READ, C.; NORTH, D. The deployment production line. Agile Conference, 2006, p. 113-118, 2006.

IACOVELLI, A.; SOUVEYET, C. Framework for Agile Methods Classification. MoDISE-EUS, p. 91-102, 2008.

IEEE Standard Dictionary of Measures to Produce Reliable Software. IEEE Std 982.1-1988, , 1989.

IEEE Standard Glossary of Software Engineering Terminology. IEEE Std 610.121990, , 1990.

II, I. Immunizing Against Predictable Project Failure - Charters and Chartering as a baseline for Change. STQE, n. January, 2001.

JACOBSON, I. et al. The Essence of Software Engineering : The SEMAT Kernel. Queue, v. 10, n. 10, p. 40, 2012.

JACOBSON, I. et al. The essence of software Engineering: applying the SEMAT kernel. [s.I.] Addison-Wesley, 2013.

JACOBSON, I.; MEYER, B. Methods Need Theory. Dr. Dobb’s Journal, 2009.

JACOBSON, I.; MEYER, B.; SOLEY, R. The SEMAT initiative: A call for action. Dr. Dobb's Journal, v. 10, 2009.

JAKOBSEN, C. R.; SUTHERLAND, J. Scrum and CMMI - Going from Good to Great. 2009 Agile Conference, p. 333-337, ago. 2009.

JAMIESON, S. Likert scales: how to (ab)use them. Medical education, v. 38, n. 12, p. 1217-8, dez. 2004. 
JOHNSON, P.; EKSTEDT, M.; JACOBSON, I. Where's the Theory for Software Engineering? IEEE Software, v. 29, n. 5, p. 96-96, set. 2012.

JU, W. et al. Thinking with Erasable Ink : Ad-hoc Whiteboard Use in Collaborative Design. CDR Technical Report, 2006.

KRUCHTEN, P. Contextualizing agile software development. Journal of Software: Evolution and Process, v. 25, n. 4, p. 351-361, 2013.

LANDRE, E.; WESENBERG, H.; OLMHEIM, J. Agile enterprise software development using domain-driven design and test first. Companion to the 22nd ACM SIGPLAN conference on Object oriented programming systems and applications companion - OOPSLA '07, p. 983, 2007.

LECHNER, M. XP Team Psychology-An Inside View. PPIG 2008: Psychology of Programming Interest Group, 2008.

LEWIN, K.; HEIDER, F.; HEIDER, G. Principles of Topological Psychology. [s.I.] Read Books, 1936.

LIESOWSKA, A. British Airways Boeing 747 makes safe emergency News landing after failure of navigation equipment. Disponível em:

<http://siberiantimes.com/other/others/news/british-airways-boeing-747-makes-safeemergency-landing-in-irkutsk-after-failure-of-navigation-equipment/>. Acesso em: 1 set. 2013.

MACKENZIE, A.; MONK, S. From Cards to Code: How Extreme Programming ReEmbodies Programming as a Collective Practice. Computer Supported Cooperative Work (CSCW), v. 13, n. 1, p. 91-117, mar. 2004.

MACKINNON, T.; FREEMAN, S.; CRAIG, P. Endo-Testing : Unit Testing with Mock Objects. Extreme programming examined, p. 287-301, 2001.

MAMUDI, S. Nasdaq Shuts Trading for Three Hours After Computer Error. Disponível em: <http://www.bloomberg.com/news/2013-08-22/nasdaq-shuts-tradingfor-three-hours-in-latest-computer-error.html>. Acesso em: 1 set. 2013.

MARTIN, R. Iterative and incremental development (iid). C++ Report, n. lid, 1999.

MAURER, F.; MARTEL, S. Extreme programming: Rapid development for Webbased applications. IEEE Internet computing, v. 6, n. 1, p. 86-90, 2002.

MCCONNEL, S. Daily Build and Smoke Test. Best Practices IEEE, v. 13, n. 4, p. 144-144, 1996.

MEADOWS, D.; WRIGHT, D. Thinking in systems: A primer. [s.I.] Chelsea Green Publishing, 2008. 
MELO, C.; SANTOS, V.; CORBUCCI, H. Métodos ágeis no Brasil: estado da prática em times e organizações. Relatório Técnico RT-MAC-2012-03. Departamento de Ciência da Computação. IME-USP, 2012.

MIRANDA, E. Improving Subjective Estimates Using Paired Comparisons. Software, IEEE, v. 18, n. 1, p. 87-91, 2001.

MIRANDA, E.; BOURQUE, P. Agile monitoring using the line of balance. Journal of Systems and Software, v. 83, n. 7, p. 1205-1215, jul. 2010.

MISRA, S. Agile software development practices: evolution, principles, and criticisms. International Journal of Quality \& Reliability Management, v. 29, n. 9, p. 972980, 2012.

MORAN, T.; SAUND, E.; MELLE, W. VAN. Design and technology for Collaborage: collaborative collages of information on physical walls. Proceedings of the 12th annual ACM symposium on User interface software and technology, p. 197206, 1999.

MUSA, J. Software quality and reliability basics. Proceedings of the 1987 Fall Joint Computer Conference on Exploring technology: today and tomorrow, p. 114$115,1987$.

NERUR, S.; MAHAPATRA, R.; MANGALARAJ, G. Challenges of migrating to agile methodologies. Communications of the ACM, v. 48, n. 5, p. 72-78, 1 maio 2005.

NORMAN, D. Design rules based on analyses of human error. Communications of the ACM, v. 26, n. 4, p. 254-258, 1983.

OMG. Essence-Kernel and Language for Software Engineering Methods. [s.I.] Object Management Group (OMG), 2013. Disponível em: < http://www.omg.org/cgibin/doc?ad/13-02-01>. Acesso em: 25 ago. 2014.

PAASIVAARA, M.; DURASIEWICZ, S.; LASSENIUS, C. Using Scrum in Distributed Agile Development: A Multiple Case Study. Global Software Engineering, 2009. ICGSE 2009. Fourth IEEE International Conference on, p. 195-204, jul. 2009.

PANZL, D. Test procedures: A new approach to software verification. Proceedings of the 2nd international conference on Software engineering, 1976.

PATTON, J. It's All in How You Slice It. Better Software Magazine, January, 2005.

PATTON, J. User Story Mapping, 2008. Disponível em: <http://www.cs.northwestern.edu/academics/courses/394/slides/spr12/Patton Building Better Products Using.pdf>. Acesso em: 20 ago. 2014

PAULK, M. Extreme programming from a CMM perspective. Software, IEEE, v. 18, n. 6, p. 19-26, 2001. 
PERRY, T. Drifting Toward Invisibility: The Transition to the Electronic Task Board. Agile, 2008. AGILE'08. Conference, p. 496-500, 2008.

RASMUSSEN, J.; VICENTE, K. J. Coping with human errors through system design: implications for ecological interface design. International Journal of Man-Machine Studies, v. 31, n. 5, p. 517-534, nov. 1989.

REASON, J. Human error: models and management. BMJ: British Medical Journal, v. 320, n. March, p. 4-6, 2000.

SANDHOF, K.; FILGUEIRAS, L. Defeitos de software como erros humanos. II Workshop WOSES, p. 75-84, 2006.

SCHWABER, K.; SUTHERLAND, J. Guia do SCRUM..., Rafael Sabbagh. Dísponivel em: http://www. scrum. ..., 2009. Disponível em:

<http://scholar.google.com/scholar?hl=en\&btnG=Search\&q=intitle:Guia+do+Scrum\#0 >. Acesso em: 25 maio. 2013

SHARP, H.; ROBINSON, H.; PETRE, M. The role of physical artefacts in agile software development: Two complementary perspectives. Interacting with

Computers, v. 21, n. 1-2, p. 108-116, jan. 2009.

SIMONETTE, M. J.; SPINA, E. THE HUMAN SIDE OF SOFTWARE DEVELOPMENT - Teamwork as Sociotechnical Systems. In: Software

Engineering: Methods, Modeling and Teaching. [s.I.] Sello Editorial - Pontificia Universidad Católica del Perú, 2010. v. 2p. 21-28.

SOLÍS, C.; WANG, X. A study of the characteristics of behaviour driven development. Software Engineering and Advanced Applications (SEAA), 2011 37th EUROMICRO Conference on, p. 383-387, 2011.

SUGIMORI, Y. et al. Toyota production system and Kanban system Materialization of just-in-time and respect-for-human system. International Journal of Production Research, v. 15, n. 6, p. 553-564, jan. 1977.

SUTHERLAND, J.; VIKTOROV, A. Distributed scrum: Agile project management with outsourced development teams. System Sciences, 2007. HICSS 2007. 40th Annual Hawaii International Conference on, 2007.

TAVARES, $\mathrm{H}$. et al. A tool stack for implementing Behaviour-Driven Development in Python Language. arXiv preprint arXiv:1007.1722, p. 279-284, 2010.

TON, H. A Strategy for Balancing Business Value and Story Size. Agile 2007 (Agile 2007), p. 279-284, ago. 2007.

TURK, D.; FRANCE, R.; RUMPE, B. Limitations of agile software processes. Third International Conference on eXtreme Programming and Agile Processes in Software Engineering (XP 2002), p. 43-46, 2002. 
VERNER, J.; BABAR, M. A. Software quality and agile methods. Proceedings of the 28th Annual International Computer Software and Applications Conference, 2004. COMPSAC 2004., p. 520-525, 2004.

VERSIONONE. State of Agile Development Survey, 2012.

VICENTE, K. Ecological interface design: Progress and challenges. Human Factors: The Journal of the Human Factors and Ergonomics Society, v. 44, n. 1, p. 62-78, 2002.

WANG, X. et al. Traverse the landscape of the mind by walking: an exploration of a new brainstorming practice. p. 1-12, 2013.

WHITWORTH, E.; BIDDLE, R. The social nature of agile teams. Agile Conference (AGILE), 2007, p. 26-36, ago. 2007.

WOOD, S.; MICHAELIDES, G.; THOMSON, C. Successful extreme programming: Fidelity to the methodology or good teamworking? Information and Software Technology, v. 55, n. 4, p. 660-672, abr. 2013.

WRAY, S. How pair programming really works. Software, IEEE, v. 27, n. 1, p. 50-55, 2010. 


\section{Glossário}

Dependabilidade: Significa a probabilidade do sistema de software não apresentar erros por um tempo determinado em situações determinadas.

Prática: É uma técnica bem definida, ou um conjunto de regras a serem seguidas pelos desenvolvedores.

Método: Um conjunto de práticas usualmente utilizado.

Erro humano: Qualquer ação realizada sem a intenção do autor, que levam ao sistema para uma situação de erro. 


\section{Apêndice A - Checklists utilizados pelo SEMAT}

O ESSENCE, desenvolvido pelo SEMAT, associa para cada alfa um conjunto prédefinido de estados, que contém checklists que representam a evolução do desenvolvimento.

As tabelas abaixo, descrevem todos os itens de cada um dos alfas do SEMAT, e foram utilizadas para relacionar as práticas ágeis a cada um dos alfas.

Quadro 10 - Checklist do alfa oportunidade

Estado Checklist

Identificada

Solução

necessária
- Uma ideia para uma forma de melhorar o trabalho como é realizado atualmente, aumentar o valor de mercado ou aplicar um sistema de software novo ou inovador é identificada;

- Pelo menos um dos stakeholders deseja investir em compreender melhor a oportunidade e o valor associado ao trata-la;

- Os outros stakeholders que compartilham a oportunidade foram identificados.

- Os stakeholders na oportunidade e na solução proposta foram identificados;

- As necessidades dos stakeholders que geraram a oportunidade foram estabelecidas;

- Qualquer problema subjacente e suas causas foram identificadas;

- Foi confirmado que uma solução baseada em software é necessária; 
- Pelo menos uma solução baseada em software foi proposta.

Valor

estabelecido

Viável

- Uma solução foi esboçada;

- Os indicativos mostram que a solução pode ser desenvolvida e implantada;

- Os riscos associados com a solução são aceitáveis e gerenciáveis;

- Os custos estimados da solução são menores que o valor antecipado da oportunidade;

- Os motivos para o desenvolvimento de uma solução baseada em software são compreendidos por todos os membros;

- Está claro que a busca da oportunidade é viável. utilizável endereça 


\begin{tabular}{ll}
\hline & demonstrativamente a oportunidade está disponível; \\
- Os stakeholders concordam que vale a pena implantar & a solução disponível; \\
- Os stakeholders estão satisfeitos que a solução \\
produzida endereça a oportunidade. \\
Benefício \\
- A solução começou a acumular benefícios para os \\
- stakeholders; \\
O perfil de retorno sobre investimento é pelo menos \\
tão bom quando antecipado;
\end{tabular}

Fonte: Semat, 2012

Quadro 11 - Checklist do Alfa stakeholders

\begin{tabular}{|c|c|}
\hline Estado & Checklist \\
\hline \multirow[t]{3}{*}{ Reconhecido } & $\begin{array}{l}\text { - Todos os diferentes grupos de stakeholders } \\
\text { que são, ou serão, afetados pelo } \\
\text { desenvolvimento e operação do sistema de } \\
\text { software estão identificados; }\end{array}$ \\
\hline & $\begin{array}{l}\text { - Existe um consenso de que grupos de } \\
\text { stakeholders serão representados. No mínimo, } \\
\text { os grupos de stakeholders que financiam, } \\
\text { utilizam, dão suporte, e mantém o sistema } \\
\text { devem ser considerados. }\end{array}$ \\
\hline & $\begin{array}{l}\text { - As responsabilidades dos representantes dos } \\
\text { stakeholders estão definidas. }\end{array}$ \\
\hline \multirow[t]{2}{*}{ Representado } & - Os representantes \\
\hline & concordam em assumir suas \\
\hline
\end{tabular}




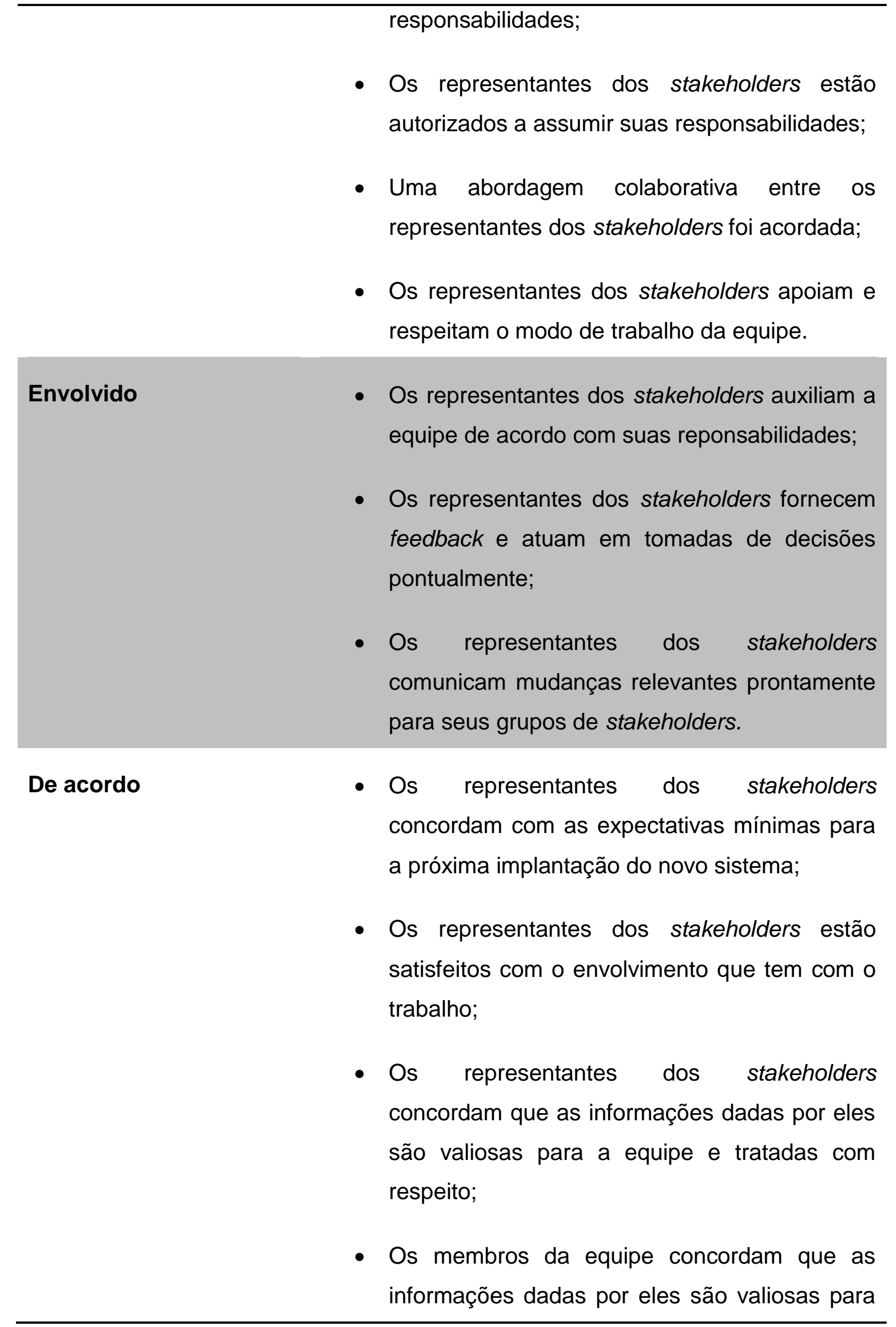




\begin{tabular}{|c|c|}
\hline & $\begin{array}{l}\text { os representantes dos stakeholders e tratadas } \\
\text { com respeito; }\end{array}$ \\
\hline & $\begin{array}{l}\text { - Os representantes dos stakeholders } \\
\text { concordam em como suas diferentes } \\
\text { prioridades e perspectivas estão sendo } \\
\text { balanceadas para prover uma direção clara a } \\
\text { equipe. }\end{array}$ \\
\hline $\begin{array}{l}\text { Satisfeito } \\
\text { implementação }\end{array}$ & $\begin{array}{l}\text { - Os representantes dos stakeholders dão } \\
\text { feedback para o sistema da perspectiva do seu } \\
\text { grupo de stakeholders; } \\
\text { - Os representantes dos stakeholders confirmam } \\
\text { que eles concordam que o sistema está pronto } \\
\text { para ser implantado. }\end{array}$ \\
\hline Satisfeito pelo uso & $\begin{array}{l}\text { - Stakeholders estão utilizando o novo sistema e } \\
\text { provendo feedback de suas experiências; } \\
\text { - Os stakeholders confirmam que o novo sistema } \\
\text { atende as suas expectativas. }\end{array}$ \\
\hline
\end{tabular}

Fonte: Semat, 2012

Quadro 12 - Checklist do alfa requisitos

\begin{tabular}{ll}
\hline Estado & Checklist \\
\hline Concebido & $\begin{array}{l}\text { O conjunto inicial de stakeholders concorda que um } \\
\text { sistema será produzido; }\end{array}$ \\
- & Os stakeholders que irão utilizar o sistema foram \\
identificados; & Os stakeholders que irão financiar o trabalho inicial \\
& do novo sistema foram identificados;
\end{tabular}


- Existe uma oportunidade clara para o novo sistema abordar.

Delimitado

- Os stakeholders envolvidos no desenvolvimento do novo sistema foram identificados;

- Os stakeholders concordam na proposta do novo sistema;

- Está clara a definição de sucesso para o novo sistema;

- Os stakeholders possuem um entendimento da extensão da solução proposta;

- A forma como requisitos serão descritos foi concordada;

- Os mecanismos para gerenciamento de requisitos estão estabelecidos;

- O esquema de priorização está claro;

- Limites estão identificados e considerados;

- As premissas foram claramente informadas.

Coerente

- Os requisitos foram levantados e compartilhados entre a equipe e os stakeholders;

- A origem dos requisitos está clara;

- O racional por trás dos requisitos está claro;

- Requisitos conflitantes são identificados e tratados;

- Os requisitos comunicam as características essenciais do sistema a ser entregue; 
- Os cenários de uso mais importantes para o sistema podem ser explicados;

- O impacto da implementação dos requisitos é compreendido;

- A equipe compreende o que deve ser entregue e concorda em entregar isso.

\section{Aceitável}

\section{Endereçado}

- O suficiente dos requisitos foi endereçado para que - sistema resultante seja aceitável para os stakeholders;

- Os stakeholders aceitam que os requisitos refletem de forma acurada o que o sistema faz e o que o sistema não faz;

- O conjunto de requisitos implementados provê um valor claro para os stakeholders;

- O sistema que implementa os requisitos é aceito pelos stakeholders e sua implantação vale a pena. 


\section{Cumprido}

Fonte: Semat, 2012
- Os stakeholders aceitam que os requisitos capturam de forma acurada o que é necessário para satisfazer as necessidades de um novo sistema;

- Não existem requisitos notáveis impedindo o sistema de ser considerado satisfatório para todos os requisitos;

- O sistema é aceito pelos stakeholders como satisfatório para todos os requisitos.

Quadro 13 - Checklist do alfa sistema de software

Estado

Arquitetura

selecionada

\section{Checklist}

- Os critérios a serem utilizados para a escolha da arquitetura foram aceitos;

- As plataformas de hardware foram identificadas;

- As tecnologias e linguagens de programação a serem utilizadas foram selecionadas;

- Os limites do sistema são conhecidos;

- Decisões significativas sobre a organização do sistema foram tomadas;

- Decisões de compra, construção e reuso foram feitas.

- Características arquiteturais chave já foram demonstradas;

- O sistema pode ser exercido e seu desempenho pode 


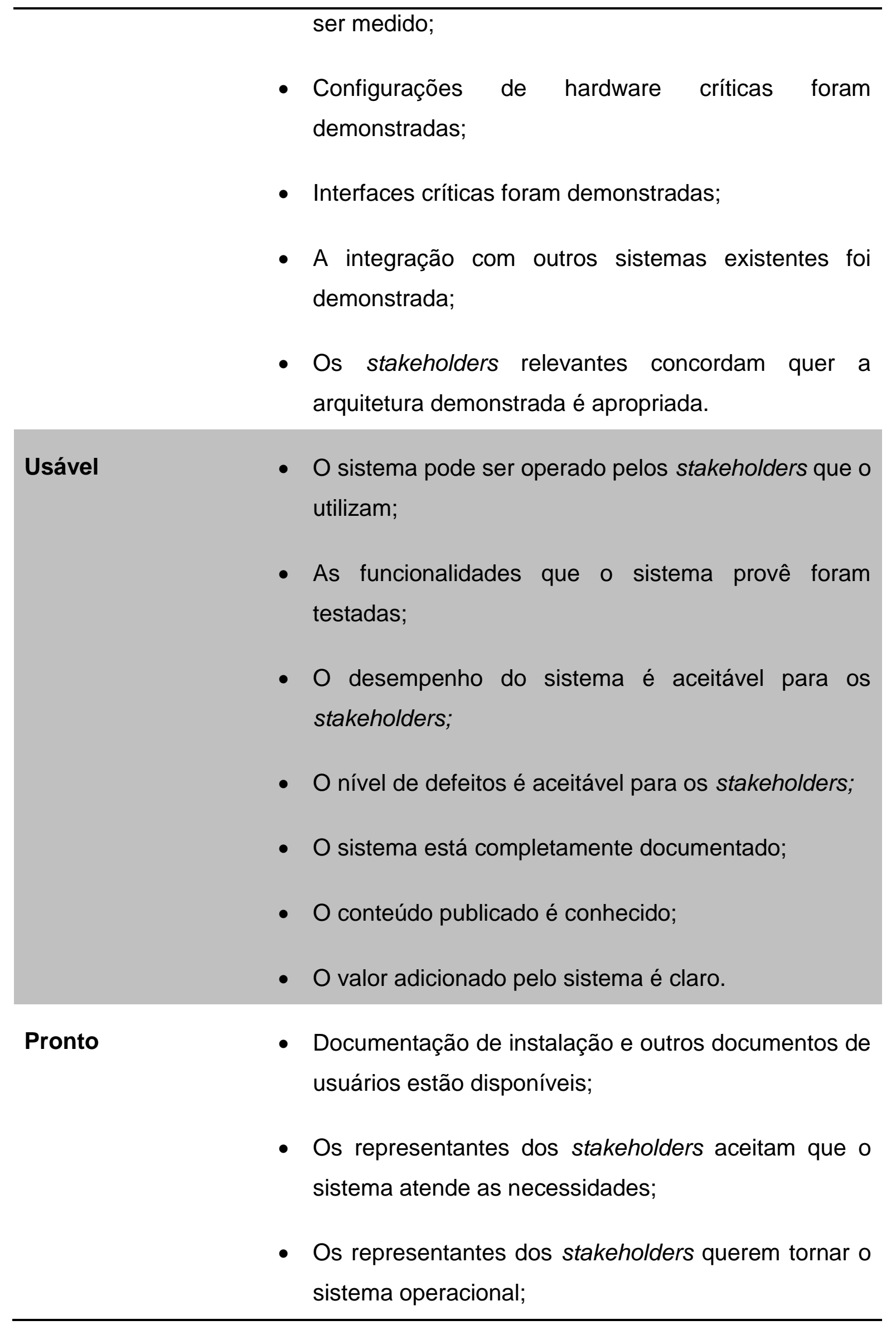


- Suporte operacional está alocado.

\section{Operacional}

Aposentado

Quadro 14 - Checklist do alfa trabalho

\section{Estado}

Iniciado

Fonte: Semat, 2012

- Atualizações do sistema não serão mais produzidas. serviço acordados.

- Pelo menos um exemplar do sistema está completamente operacional;

- O sistema é completamente apoiado nos níveis de serviço acordados.

- O sistema foi substituído ou descontinuado;

- O sistema não é mais suportado;

- Não existem stakeholders oficiais que ainda utilizem o sistema; 
identificado;

- Os stakeholders que irão aceitar os resultados são conhecidos;

- A fonte de financiamento é clara;

- As prioridades do trabalho são claras.

\section{Preparado}

- Compromisso é assumido;

- Custo e esforço do trabalho são estimados;

- Disponibilidade de recursos é compreendida;

- Políticas e procedimentos de governança estão claros;

- Exposição aos riscos é compreendida;

- Critérios de aceitação são definidos e acordados com o cliente;

- O trabalho é dividido o suficiente para que um trabalho produtivo se inicie;

- Tarefas foram identificadas e priorizadas pelas equipes e stakeholders;

- Um plano crível está instalado;

- Financiamento para o início do trabalho está estabelecido;

- A equipe, ou pelo menos alguns membros da equipe, estão prontos para iniciar o trabalho;

- Pontos de integração e entrega são definidos. 


\section{Começado*}

- Trabalho de desenvolvimento foi iniciado;

- Progresso do trabalho é monitorado;

- O trabalho está sendo dividido em itens que possuem definições claras de 'prontos';

- Membros da equipe estão aceitando e progredindo em tarefas.

Sob controle

- Tarefas estão sendo completadas;

- Trabalho não planejado está sob controle;

- Riscos estão sob controle, o impacto e probabilidade de sua ocorrência foram minimizados a níveis aceitáveis;

- Estimativas são revisadas para refletir o desempenho da equipe;

- Medidas estão disponíveis para mostrar progresso e velocity;

- Retrabalho está sob controle;

- Tarefas são consistentemente completas no prazo e dentro de suas expectativas.

\section{Concluído}

- Todas as tarefas notáveis são de manutenção administrativa ou relacionadas a preparação da próxima peça de trabalho;

- Os resultados do trabalho foram alcançados;

- Os stakeholders aceitaram o sistema de software resultante. 


\section{Encerrado}

Encerrado

- As lições aprendidas foram descriminadas, registradas e discutidas;

- Métricas foram disponibilizadas;

- Tudo foi arquivado;

- O orçamento foi reconciliado e fechado;

- A equipe foi liberada;

- Não existem tarefas notáveis incompletas.

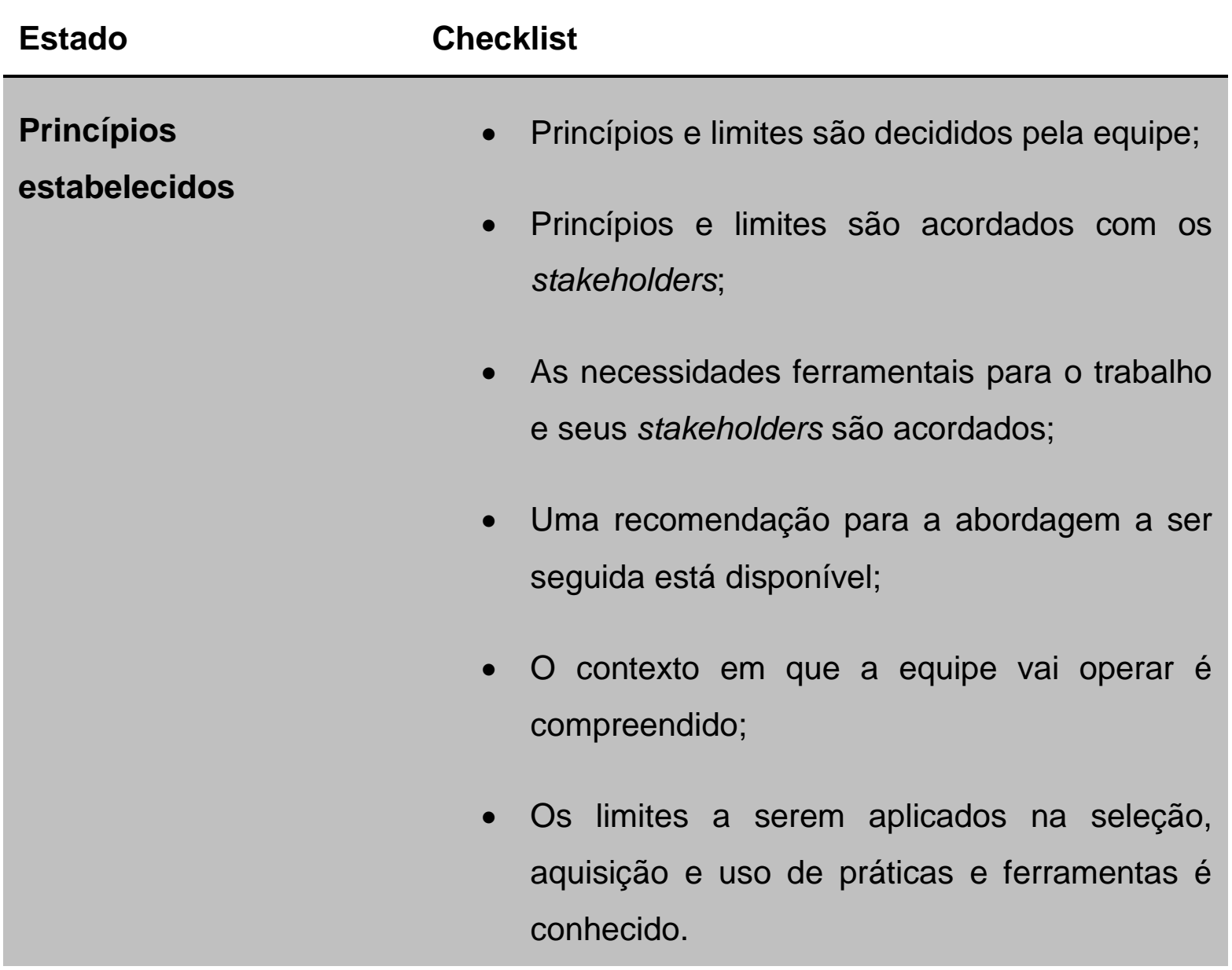

\section{Fundamentos}

- As práticas e ferramentas chaves que forma a 


\begin{tabular}{|c|c|}
\hline estabelecidos & $\begin{array}{l}\text { fundação do modo de trabalho foram } \\
\text { selecionadas; }\end{array}$ \\
\hline & $\begin{array}{l}\text { - São acordadas práticas suficientes para o } \\
\text { início do trabalho pela equipe; }\end{array}$ \\
\hline & $\begin{array}{l}\text { - Todas as práticas e ferramentas não } \\
\text { negociáveis foram identificadas; }\end{array}$ \\
\hline & $\begin{array}{l}\text { - As lacunas que existem entre as práticas e } \\
\text { ferramentas que são necessárias e as práticas } \\
\text { e ferramentas que estão disponíveis foi } \\
\text { analisado e compreendido; }\end{array}$ \\
\hline & $\begin{array}{l}\text { - As lacunas de capacidade que existem entre o } \\
\text { que é necessário para executar o modo de } \\
\text { trabalho e o nível de capacidade da equipe foi } \\
\text { analisado e compreendido; }\end{array}$ \\
\hline & $\begin{array}{l}\text { - As práticas e ferramentas selecionadas foram } \\
\text { integradas de tal forma a formar um modo de } \\
\text { trabalho utilizável. }\end{array}$ \\
\hline Em uso & $\begin{array}{l}\text { - As práticas e ferramentas estão sendo } \\
\text { utilizadas para fazer trabalhos reais; }\end{array}$ \\
\hline & $\begin{array}{l}\text { - O uso das práticas e ferramentas } \\
\text { selecionadas é inspecionado regularmente; }\end{array}$ \\
\hline & $\begin{array}{l}\text { - As práticas e ferramentas estão sendo } \\
\text { adaptadas ao contexto da equipe; }\end{array}$ \\
\hline & $\begin{array}{l}\text { - O uso de práticas e ferramentas é apoiado } \\
\text { pela equipe; }\end{array}$ \\
\hline & $\begin{array}{l}\text { - Procedimentos para avaliar o feedback do } \\
\text { modo de trabalho da equipe foram }\end{array}$ \\
\hline
\end{tabular}




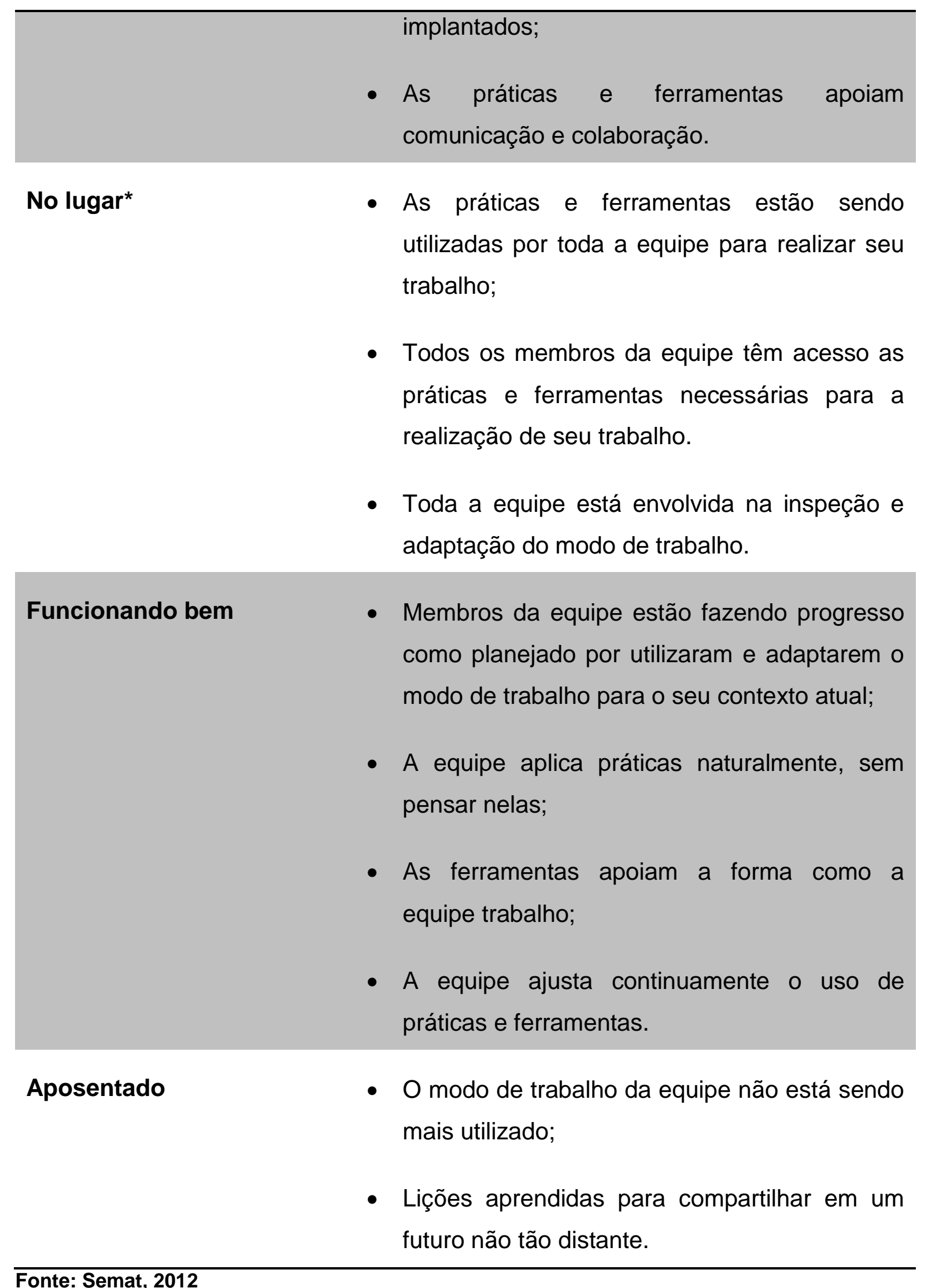

Fonte: Semat, 2012 


\begin{tabular}{|c|c|}
\hline Estado & Checklist \\
\hline \multirow[t]{10}{*}{ Iniciada } & $\begin{array}{l}\text { - A missão da equipe foi definida em termos de } \\
\text { oportunidades e resultados; }\end{array}$ \\
\hline & $\begin{array}{l}\text { - Restrições para a operação da equipe são } \\
\text { conhecidas; }\end{array}$ \\
\hline & $\begin{array}{l}\text { - Mecanismos para o crescimento da equipe } \\
\text { foram estabelecidos; }\end{array}$ \\
\hline & - A composição da equipe está definida; \\
\hline & $\begin{array}{l}\text { - Qualquer restrição em como e onde o trabalho } \\
\text { será desempenhado está definida; }\end{array}$ \\
\hline & $\begin{array}{l}\text { - As responsabilidades da equipe são } \\
\text { delineadas; }\end{array}$ \\
\hline & $\begin{array}{l}\text { - As competências necessárias são } \\
\text { identificadas; }\end{array}$ \\
\hline & - O tamanho da equipe está determinado; \\
\hline & - Regras de governança estão determinadas; \\
\hline & - O modelo de liderança foi escolhido. \\
\hline \multirow[t]{2}{*}{ Formada } & $\begin{array}{l}\text { - Responsabilidades individuais estão } \\
\text { compreendidas; }\end{array}$ \\
\hline & $\begin{array}{l}\text { - Uma quantidade suficiente de membros da } \\
\text { equipe foi recrutada para permitir o progresso } \\
\text { do trabalho; }\end{array}$ \\
\hline
\end{tabular}




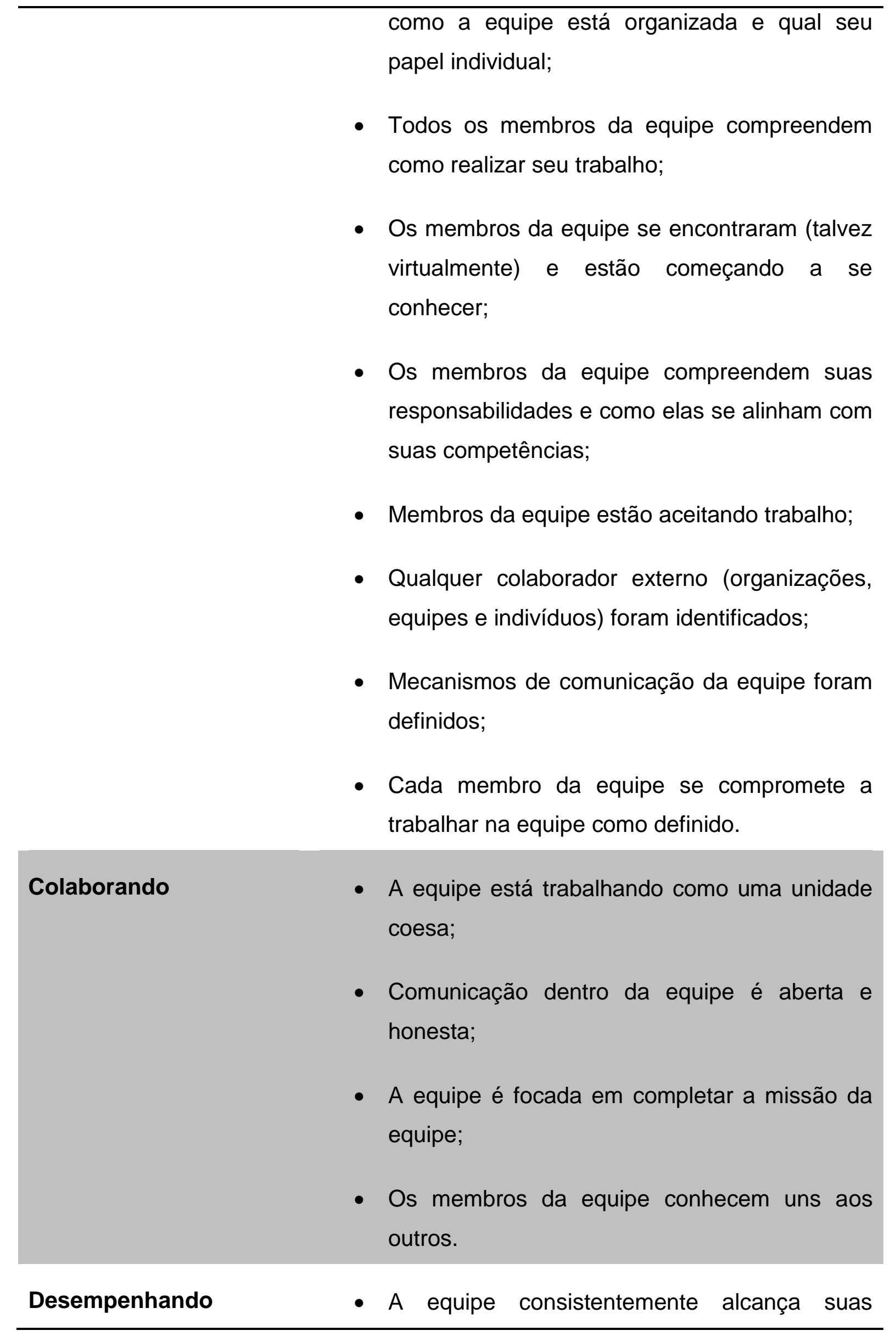


metas;

- A equipe se adapta continuamente a mudanças de contexto;

- A equipe identifica e aborda problemas sem auxílio externo;

- Progresso efetivo está sendo alcançado com o mínimo de backtracking e reworking evitáveis;

- Trabalho perdido, e o potencial para trabalho perdido são eliminados continuamente;

\section{Suspendida}

- As responsabilidades da equipe foram completadas ou passadas para outra;

- Os membros da equipe estão disponíveis para serem designados a outras equipes;

- Nenhum esforço está sendo colocado pela equipe para o cumprimento da missão.

Fonte: Semat, 2012 


\section{Apêndice B - Questionário}

\section{Dependabilidade ágil}

Dependabilidade diz respeito a habilidade para entregar um serviço comprovadamente confiável, é um conceito que abrange disponibilidade, confiabilidade, integridade, segurança e manutenabilidade

Este questionário visa avaliar a percepção do envolvimento de práticas ágeis com modificações no ambiente de trabalho que podem colaborar com a redução de erros

1. Você a ceita participar deste questionário?

Todas as respostas desse questionário serão usadas apenas para fim de pesquisa, sendo o resultado utilizado em um trabalho de mestrado para a Universidade de São Paulo.

Mark only one oval.

Aceito

Não aceito Stop filling out this form.

\section{Sobre o desenvolvedor}

Perguntas sobre você e seu local de trabalho, para auxiliar na identificação da população do estudo.

2. Qual a sua função na empresa?

3. Há quanto tempo trabalha com desenvolvimento de software?

Mark only one oval.

Menos de 1 ano

Entre 1 e 3 anos

4 e 10 anos

Mais de 10 anos

4. Quantos funcionários existem na sua empresa? Mark only one oval.

Até 5

Entre 6 e 20

Entre 21 e 50

Entre 51 e 150

Mais de 150 
5. Você usa habitualmente alguma dessas metodologias ágeis?

Mark only one oval.

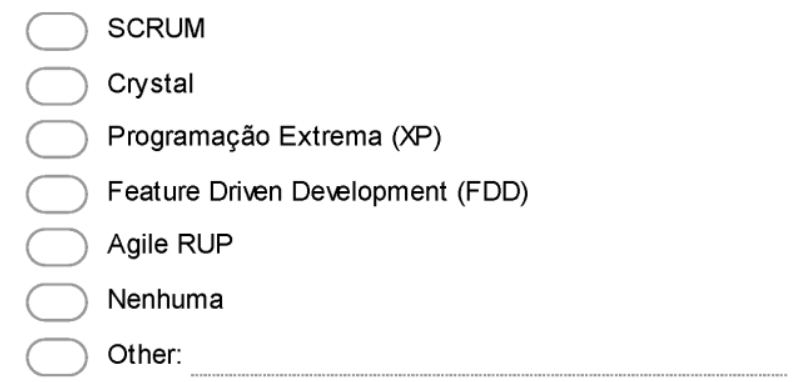

6. A empresa onde trabalha desenvolve software que possui dependabilidade como um dos requisitos principais?

Mark only one oval.

$\int \operatorname{Sim}$

Não

\section{Adoção de práticas ágeis}

Para responder as questões seguintes utilize como referência o último projeto em que você trabalhou ou está trabalhando.

Nas próximas questões relacione a utilização das práticas ágeis mencionadas de "Não utilizado / desconheço" até "Muito utilizado".

Essas práticas foram selecionadas por serem práticas que atuam exclusivamente na equipe e suas interações.

\section{Reunião diária}

Reunião curta - cerca de 15 minutos - para atualização do andamento do projeto

Mark only one oval.

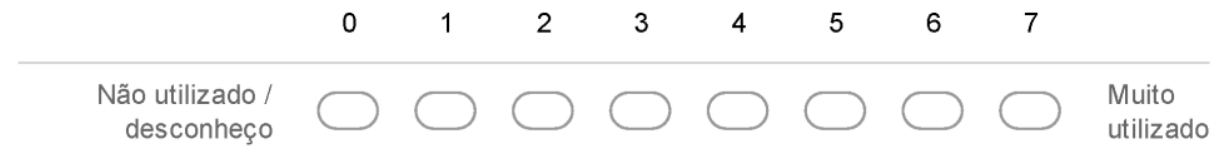

8. Calendário niko-niko

Calendário utilizado para informar o humor dos membros da equipe, atualizado diariamente. Mark only one oval.

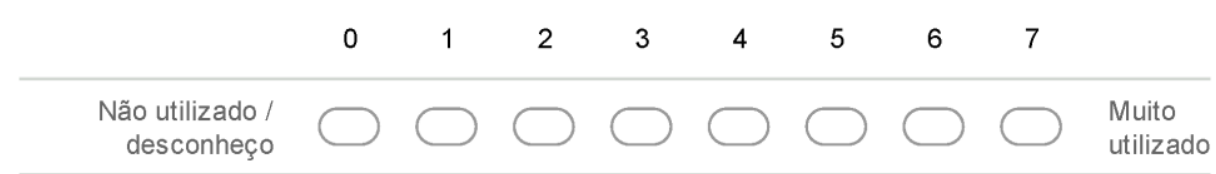




\section{Retrospectivas}

São reuniões informais realizadas pela equipe de forma a alterar (ou adicionar) alguma prática ao funcionamento do processo de desenvolvimento de software

Mark only one oval.

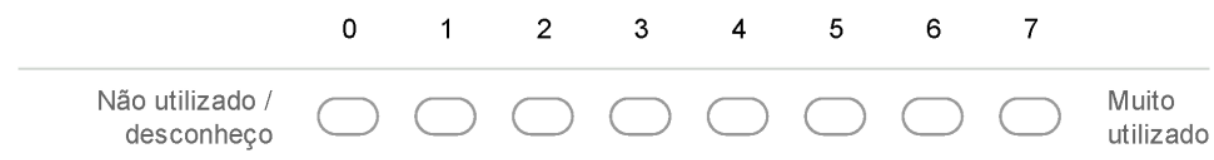

10. Sessões de design rápido

Dois ou mais desenvolvedores se reúnem para uma breve discussão com um quadro branco para decidir questões de arquitetura

Mark only one oval.

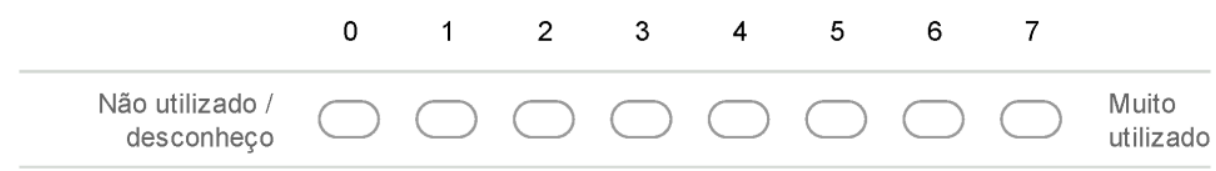

\section{Taskboard}

Tabela normalmente fixada na parede (porém pode ser digital) que indica a situação das tarefas da equipe, divididas por exemplo em: "a fazer", "em desenvolvimento" e "pronta"

Mark only one oval.

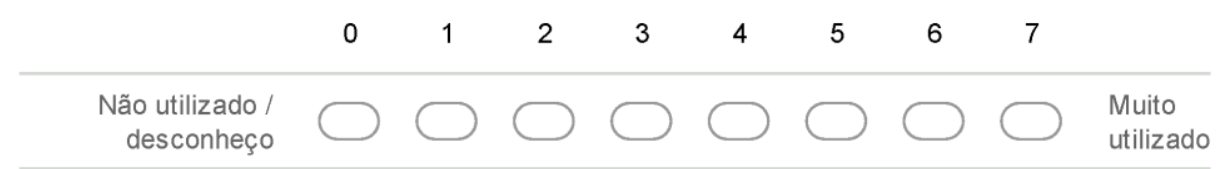

\section{Percepções sobre o ambiente de trabalho}

Perguntas com relação à sua percepção da realidade das seguintes questões no seu dia-a-dia

Responda qual o grau de concordância de "Discordo totalmente" a "Concordo totalmente" para as afirmações realizadas abaixo.

12. Você possui um feedback das ações que está realizando antes de sua finalização Mark only one oval.

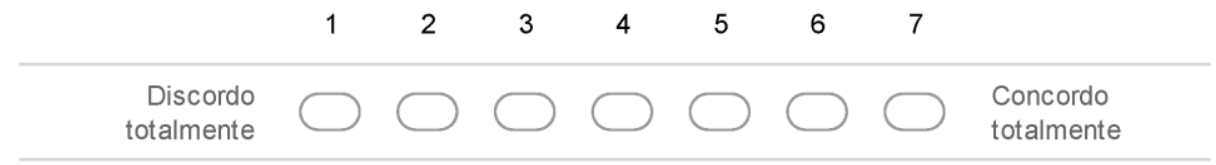

13. As próximas tarefas e suas respectivas prioridades estão cla ras

Mark only one oval.

\begin{tabular}{lllllllll} 
& 1 & 2 & 3 & 4 & 5 & 6 & 7 \\
$\begin{array}{c}\text { Discordo } \\
\text { totalmente }\end{array}$ & $\square$ & $\square$ & & \\
\hline $\begin{array}{l}\text { Concordo } \\
\text { totalmente }\end{array}$
\end{tabular}


14. A situação do projeto pode ser avaliada de forma automática Mark only one oval.

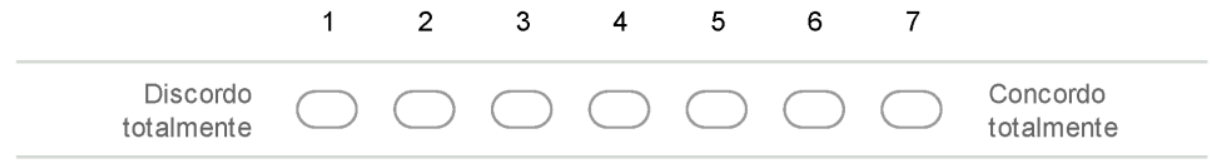

15. A situação da equipe pode ser avaliada de forma automática Mark only one oval.

\begin{tabular}{lllllllll} 
& 1 & 2 & 3 & 4 & 5 & 6 & 7 \\
$\begin{array}{r}\text { Discordo } \\
\text { totalmente }\end{array}$ & $\square$ & $\square$ & $\square$ & \\
\hline $\begin{array}{l}\text { Concordo } \\
\text { totalmente }\end{array}$
\end{tabular}

16. As ta refas podem ser utilizadas para determinar o andamento do projeto Mark only one oval.

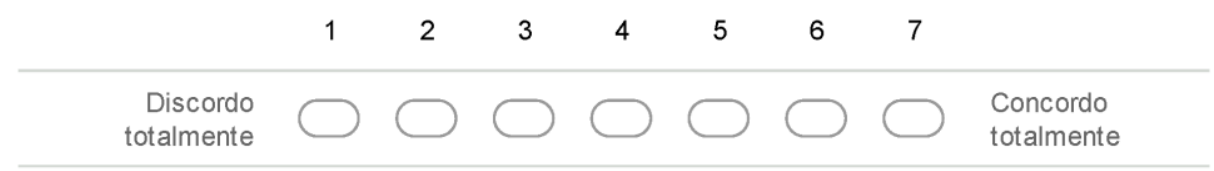

17. A informação do andamento do sistema é mostrada de forma efetiva e exteriorizada Mark only one oval.

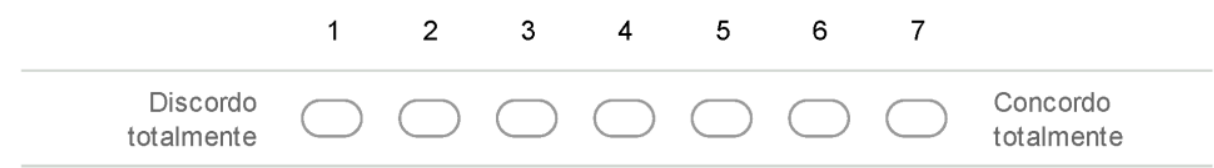

\section{Percepções sobre o ambiente de trabalho (continuação)}

Agora, para cada sentença relacionada ao ambiente de trabalho, selecione quais práticas auxiliam (ou poderiam auxiliar) para que o que foi descrito seja alcançado.

18. Você possui um feedback das ações que está realizando antes de sua finalização Check all that apply.
Sessões de design rápido
$\square$ Taskboard
$\square$ Retrospectivas
—Reunião Diária
$\square$ Calendário niko-niko
Other: 
19. As próximas tarefas e suas respectivas prioridades estão cla ras Check all that apply.

$\square$ Retrospectivas

$\square$ Taskboard

$\square$ Calendário niko-niko

$\square$ Reunião Diária

$\square$ Sessões de design rápido

$\square$ Other:

20. A situação do projeto pode ser avaliada de forma automática Check all that apply.

Reunião Diária

Taskboard

$\square$ Retrospectivas

Calendário niko-niko

Sessões de design rápido

$\square$ Other:

21. A situação da equipe pode ser avaliada de forma automática Check all that apply.

$\square$ Reunião Diária

Retrospectivas

$\square$ Taskboard

Calendário niko-niko

$\square$ Sessões de design rápido

$\square$ Other:

22. As tarefas podem ser utilizadas para determinar o andamento do projeto Check all that apply.

Retrospectivas

Calendário niko-niko

Reunião Diária

Sessões de design rápido

Taskboard

Other: 
23. A informação do andamento do sistema é mostrada de forma efetiva e exteriorizada Check all that apply.
Sessões de design rápido
$\square$ Retrospectivas
$\square$ Reunião Diária
$\square$ Taskboard
$\square$ Calendário niko-niko
$\square$ Other:

\section{Percepção sobre práticas ágeis}

24. Você acha que práticas ágeis, como as mencionadas, auxiliam no aumento da dependabilidade do software desenvolvido?

Mark only one oval.

Sim

Não

25. Na sua opinião quais práticas ágeis auxiliam o aumento da dependabilidade? Liste aqui as práticas ágeis que você considera capazes de aumentar a dependabilidade.
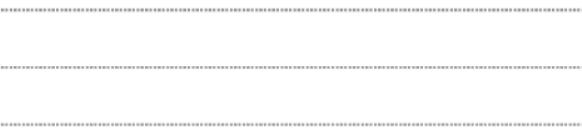

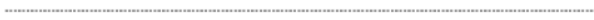

26. Na sua opinião por que práticas ágeis auxiliam no aumento da dependabilidade?

Google Forms 


\section{Apêndice C - Respostas dos desenvolvedores}

\begin{tabular}{|c|c|c|c|c|c|c|}
\hline ID & Questão 1 & Questão 2 & Questão 3 & Questão 4 & Questão 5 & Questão 6 \\
\hline 1 & Não aceito & & & & & \\
\hline 2 & Não aceito & & & & & \\
\hline 3 & Não aceito & & & & & \\
\hline 4 & Não aceito & & & & & \\
\hline 5 & Não aceito & & & & & \\
\hline 6 & Não aceito & & & & & \\
\hline 7 & Não aceito & & & & & \\
\hline 8 & Não aceito & & & & & \\
\hline 9 & Não aceito & & & & & \\
\hline 10 & Não aceito & & & & & \\
\hline 11 & Não aceito & & & & & \\
\hline 12 & Aceito & $\begin{array}{l}\text { análise e } \\
\text { desenvolvimento }\end{array}$ & 4 e 10 anos & Mais de 150 & Nenhuma & Não \\
\hline 13 & Aceito & Analista & 4 e 10 anos & Mais de 150 & SCRUM & Não \\
\hline 14 & Aceito & Analista de Negócios & 4 e 10 anos & $\begin{array}{l}\text { Entre } 51 \text { e } \\
150\end{array}$ & SCRUM & Não \\
\hline 15 & Aceito & $\begin{array}{l}\text { Analista de Qualidade } \\
\text { de Software }\end{array}$ & 4 e 10 anos & Mais de 150 & SCRUM & Sim \\
\hline 16 & Aceito & analista de sistemas & $\begin{array}{l}\text { Entre } 1 \text { e } 3 \\
\text { anos }\end{array}$ & Mais de 150 & Crystal & Sim \\
\hline 17 & Aceito & analista de sistemas & 4 e 10 anos & Mais de 150 & SCRUM & Sim \\
\hline 18 & Aceito & Analista de Sistemas & $\begin{array}{l}\text { Entre } 1 \text { e } 3 \\
\text { anos }\end{array}$ & Mais de 150 & Nenhuma & Não \\
\hline 19 & Aceito & $\begin{array}{l}\text { Analista de Sistemas } \\
\text { (desenvolver) }\end{array}$ & 4 e 10 anos & Mais de 150 & Nenhuma & Não \\
\hline 20 & Aceito & $\begin{array}{l}\text { Analista de Sistemas } \\
\text { (desenvolver) }\end{array}$ & 4 e 10 anos & Mais de 150 & Nenhuma & Não \\
\hline 21 & Aceito & $\begin{array}{l}\text { Analista } \\
\text { Desenvolvedor Pleno }\end{array}$ & 4 e 10 anos & Mais de 150 & Nenhuma & Sim \\
\hline 22 & Aceito & $\begin{array}{l}\text { Analista e } \\
\text { Desenvolvedor }\end{array}$ & $\begin{array}{l}\text { Entre } 1 \text { e } 3 \\
\text { anos }\end{array}$ & Mais de 150 & SCRUM & Sim \\
\hline 23 & Aceito & Analista Programador & 4 e 10 anos & Entre 6 e 20 & Nenhuma & Não \\
\hline 24 & Aceito & analista programador & $\begin{array}{l}\text { Mais de } 10 \\
\text { anos }\end{array}$ & $\begin{array}{l}\text { Entre } 51 \text { e } \\
150\end{array}$ & SCRUM & Não \\
\hline 25 & Aceito & Analista Senior & $\begin{array}{l}\text { Mais de } 10 \\
\text { anos }\end{array}$ & Mais de 150 & Nenhuma & Não \\
\hline 26 & Aceito & Analista sistema & 4 e 10 anos & $\begin{array}{l}\text { Entre } 51 \text { e } \\
150\end{array}$ & SCRUM & Não \\
\hline 27 & Aceito & Arquiteto de Software & $\begin{array}{l}\text { Mais de } 10 \\
\text { anos }\end{array}$ & $\begin{array}{l}\text { Entre } 51 \text { e } \\
150\end{array}$ & SCRUM & Não \\
\hline 28 & Aceito & Arquiteto de Soluções & $\begin{array}{l}\text { Mais de } 10 \\
\text { anos }\end{array}$ & Mais de 150 & SCRUM & Sim \\
\hline 29 & Aceito & $\begin{array}{l}\text { Auxiliar de Analista de } \\
\text { Suporte } \\
\text { Computacional }\end{array}$ & $\begin{array}{l}\text { Menos de } 1 \\
\text { ano }\end{array}$ & Mais de 150 & $\begin{array}{l}\text { Feature Driven } \\
\text { Development } \\
\text { (FDD) }\end{array}$ & Sim \\
\hline 30 & Aceito & back-end & $\begin{array}{l}\text { Menos de } 1 \\
\text { ano }\end{array}$ & Até 5 & Nenhuma & Não \\
\hline 31 & Aceito & CEO & 4 e 10 anos & Entre 6 e 20 & SCRUM & Não \\
\hline
\end{tabular}




\begin{tabular}{|c|c|c|c|c|c|c|}
\hline 32 & Aceito & CEO & $\begin{array}{l}\text { Menos de } 1 \\
\text { ano }\end{array}$ & Até 5 & Nenhuma & Não \\
\hline 33 & Aceito & Consultor & 4 e 10 anos & Entre 6 e 20 & SCRUM & Sim \\
\hline 34 & Aceito & СТО & 4 e 10 anos & Até 5 & Nenhuma & Sim \\
\hline 35 & Aceito & СТО & $\begin{array}{l}\text { Entre } 1 \text { e } 3 \\
\text { anos }\end{array}$ & Até 5 & Nenhuma & Não \\
\hline 36 & Aceito & СТO & $\begin{array}{l}\text { Entre } 1 \text { e } 3 \\
\text { anos }\end{array}$ & Até 5 & Nenhuma & Não \\
\hline 37 & Aceito & $\begin{array}{l}\text { Cuidar e Gerenciar da } \\
\text { parte tecnica } \\
\text { (programação, } \\
\text { hardware e rede) }\end{array}$ & $\begin{array}{l}\text { Menos de } 1 \\
\text { ano }\end{array}$ & Entre 6 e 20 & Agile RUP & Sim \\
\hline 38 & Aceito & Desenvolvedor & 4 e 10 anos & Mais de 150 & $\begin{array}{l}\text { Misto de Scrum } \\
\text { e XP }\end{array}$ & Sim \\
\hline 39 & Aceito & Desenvolvedor & $\begin{array}{l}\text { Entre } 1 \text { e } 3 \\
\text { anos }\end{array}$ & Até 5 & SCRUM & Não \\
\hline 40 & Aceito & Desenvolvedor & 4 e 10 anos & Mais de 150 & Nenhuma & Sim \\
\hline 41 & Aceito & Desenvolvedor & 4 e 10 anos & Mais de 150 & $\begin{array}{l}\text { Programação } \\
\text { Extrema (XP) }\end{array}$ & Sim \\
\hline 42 & Aceito & Desenvolvedor & $\begin{array}{l}\text { Entre } 1 \text { e } 3 \\
\text { anos }\end{array}$ & $\begin{array}{l}\text { Entre } 51 \text { e } \\
150\end{array}$ & SCRUM & Sim \\
\hline 43 & Aceito & Desenvolvedor & 4 e 10 anos & Mais de 150 & Nenhuma & Não \\
\hline 44 & Aceito & Desenvolvedor & $\begin{array}{l}\text { Entre } 1 \text { e } 3 \\
\text { anos }\end{array}$ & $\begin{array}{l}\text { Entre } 21 \text { e } \\
50\end{array}$ & SCRUM & \\
\hline 45 & Aceito & Desenvolvedor & $\begin{array}{l}\text { Entre } 1 \text { e } 3 \\
\text { anos }\end{array}$ & Até 5 & Nenhuma & Não \\
\hline 46 & Aceito & Desenvolvedor & $\begin{array}{l}\text { Entre } 1 \text { e } 3 \\
\text { anos }\end{array}$ & Mais de 150 & Nenhuma & Não \\
\hline 47 & Aceito & Desenvolvedor & $\begin{array}{l}\text { Mais de } 10 \\
\text { anos }\end{array}$ & Entre 6 e 20 & SCRUM & Sim \\
\hline 48 & Aceito & Desenvolvedor & 4 e 10 anos & $\begin{array}{l}\text { Entre } 51 \text { e } \\
150\end{array}$ & SCRUM & Sim \\
\hline 49 & Aceito & Desenvolvedor & 4 e 10 anos & Entre 6 e 20 & Agile RUP & Sim \\
\hline 50 & Aceito & Desenvolvedor & 4 e 10 anos & Entre 6 e 20 & SCRUM & Sim \\
\hline 51 & Aceito & Desenvolvedor & $\begin{array}{l}\text { Entre } 1 \text { e } 3 \\
\text { anos }\end{array}$ & Até 5 & Nenhuma & Não \\
\hline 52 & Aceito & $\begin{array}{l}\text { Desenvolvedor } \\
\text {.NET/Javascript }\end{array}$ & $\begin{array}{l}\text { Menos de } 1 \\
\text { ano }\end{array}$ & $\begin{array}{l}\text { Entre } 21 \text { e } \\
50\end{array}$ & SCRUM & Sim \\
\hline 53 & Aceito & $\begin{array}{l}\text { Desenvolvedor Back } \\
\text { End }\end{array}$ & $\begin{array}{l}\text { Menos de } 1 \\
\text { ano }\end{array}$ & Entre 6 e 20 & Nenhuma & Não \\
\hline 54 & Aceito & $\begin{array}{l}\text { Desenvolvedor } \\
\text { Magento }\end{array}$ & $\begin{array}{l}\text { Entre } 1 \text { e } 3 \\
\text { anos }\end{array}$ & Entre 6 e 20 & SCRUM & Não \\
\hline 55 & Aceito & Desenvolvedor Pleno & $\begin{array}{l}\text { Entre } 1 \text { e } 3 \\
\text { anos }\end{array}$ & Mais de 150 & SCRUM & Sim \\
\hline 56 & Aceito & Desenvolvedor Python & 4 e 10 anos & Mais de 150 & Nenhuma & Não \\
\hline 57 & Aceito & Desenvolvedor Web & $\begin{array}{l}\text { Entre } 1 \text { e } 3 \\
\text { anos }\end{array}$ & Até 5 & Nenhuma & Não \\
\hline 58 & Aceito & Desenvolvedor Web & $\begin{array}{l}\text { Entre } 1 \text { e } 3 \\
\text { anos }\end{array}$ & Entre 6 e 20 & Nenhuma & Sim \\
\hline 59 & Aceito & Desenvolvedor Web & 4 e 10 anos & Até 5 & Nenhuma & Não \\
\hline 60 & Aceito & Desenvolvedor Web & $\begin{array}{l}\text { Entre } 1 \text { e } 3 \\
\text { anos }\end{array}$ & $\begin{array}{l}\text { Entre } 21 \text { e } \\
50\end{array}$ & Nenhuma & Não \\
\hline & Aceito & $\begin{array}{l}\text { Desenvolvimento } \\
\text { Front-End }\end{array}$ & $\begin{array}{l}\text { Entre } 1 \text { e } 3 \\
\text { anos }\end{array}$ & $\begin{array}{l}\text { Entre } 21 \text { e } \\
50\end{array}$ & SCRUM & Não \\
\hline
\end{tabular}




\begin{tabular}{|c|c|c|c|c|c|c|}
\hline 62 & Aceito & Desenvovedor & $\begin{array}{l}\text { Entre } 1 \text { e } 3 \\
\text { anos }\end{array}$ & Entre 6 e 20 & Nenhuma & Não \\
\hline 63 & Aceito & Developer & 4 e 10 anos & $\begin{array}{l}\text { Entre } 51 \text { e } \\
150\end{array}$ & SCRUM & Sim \\
\hline 64 & Aceito & Developer Senior & $\begin{array}{l}\text { Entre } 1 \text { e } 3 \\
\text { anos }\end{array}$ & $\begin{array}{l}\text { Entre } 21 \text { e } \\
50\end{array}$ & Crystal & Sim \\
\hline 65 & Aceito & Diretor & $\begin{array}{l}\text { Mais de } 10 \\
\text { anos }\end{array}$ & Até 5 & SCRUM & Não \\
\hline 66 & Aceito & $\begin{array}{l}\text { Diretor de projeto e } \\
\text { analista }\end{array}$ & 4 e 10 anos & Até 5 & SCRUM & Sim \\
\hline 67 & Aceito & $\begin{array}{l}\text { Engenheiro de } \\
\text { Software }\end{array}$ & $\begin{array}{l}\text { Entre } 1 \text { e } 3 \\
\text { anos }\end{array}$ & Entre 6 e 20 & $\begin{array}{l}\text { Programação } \\
\text { Extrema (XP) }\end{array}$ & Sim \\
\hline 68 & Aceito & Engenheiro Eletrônico & $\begin{array}{l}\text { Mais de } 10 \\
\text { anos }\end{array}$ & Entre 6 e 20 & Nenhuma & Sim \\
\hline 69 & Aceito & $\begin{array}{l}\text { Especialista Soluções } \\
\text { Web }\end{array}$ & 4 e 10 anos & Mais de 150 & Agile RUP & Sim \\
\hline 70 & Aceito & Estagiario & $\begin{array}{l}\text { Entre } 1 \text { e } 3 \\
\text { anos }\end{array}$ & Mais de 150 & Nenhuma & Não \\
\hline 71 & Aceito & Estagiário & $\begin{array}{l}\text { Menos de } 1 \\
\text { ano }\end{array}$ & Mais de 150 & Nenhuma & Sim \\
\hline 72 & Aceito & Estagiário & $\begin{array}{l}\text { Menos de } 1 \\
\text { ano }\end{array}$ & Entre 6 e 20 & Nenhuma & Sim \\
\hline 73 & Aceito & Estudante & $\begin{array}{l}\text { Menos de } 1 \\
\text { ano }\end{array}$ & Até 5 & Nenhuma & Não \\
\hline 74 & Aceito & Front-end Developer & 4 e 10 anos & Até 5 & Nenhuma & Sim \\
\hline 75 & Aceito & Gerente & $\begin{array}{l}\text { Entre } 1 \text { e } 3 \\
\text { anos }\end{array}$ & $\begin{array}{l}\text { Entre } 51 \text { e } \\
150\end{array}$ & SCRUM & Sim \\
\hline 76 & Aceito & Gerente de Projeto & 4 e 10 anos & Entre 6 e 20 & Agile RUP & Não \\
\hline 77 & Aceito & gerente de projeto & $\begin{array}{l}\text { Mais de } 10 \\
\text { anos }\end{array}$ & Entre 6 e 20 & SCRUM & Sim \\
\hline 78 & Aceito & gerente de projetos & 4 e 10 anos & Mais de 150 & SCRUM & Não \\
\hline 79 & Aceito & Gerente de Projetos & 4 e 10 anos & Entre 6 e 20 & Nenhuma & Não \\
\hline 80 & Aceito & Gerente de Projetos & 4 e 10 anos & Entre 6 e 20 & Nenhuma & Não \\
\hline 81 & Aceito & gerente de ti & $\begin{array}{l}\text { Mais de } 10 \\
\text { anos }\end{array}$ & Entre 6 e 20 & SCRUM & Não \\
\hline 82 & Aceito & Gerente de TI & $\begin{array}{l}\text { Mais de } 10 \\
\text { anos }\end{array}$ & $\begin{array}{l}\text { Entre } 21 \text { e } \\
50\end{array}$ & Crystal & Sim \\
\hline 83 & Aceito & $\begin{array}{l}\text { Gerente/Desenvolved } \\
\text { or }\end{array}$ & 4 e 10 anos & Entre 6 e 20 & SCRUM & Sim \\
\hline 84 & Aceito & Gestor de Projetos & 4 e 10 anos & $\begin{array}{l}\text { Entre } 21 \text { e } \\
50\end{array}$ & SCRUM & Não \\
\hline 85 & Aceito & IFSertão & 4 e 10 anos & Mais de 150 & SCRUM & Não \\
\hline 86 & Aceito & $\begin{array}{l}\text { Lead Software } \\
\text { Engineer }\end{array}$ & 4 e 10 anos & Mais de 150 & SCRUM & Sim \\
\hline 87 & Aceito & Líder técnico & $\begin{array}{l}\text { Mais de } 10 \\
\text { anos }\end{array}$ & $\begin{array}{l}\text { Entre } 51 \mathrm{e} \\
150\end{array}$ & $\begin{array}{l}\text { Programação } \\
\text { Extrema (XP) }\end{array}$ & Não \\
\hline 88 & Aceito & Líder técnico & 4 e 10 anos & Mais de 150 & SCRUM & Não \\
\hline 89 & Aceito & Prog & $\begin{array}{l}\text { Menos de } 1 \\
\text { ano }\end{array}$ & $\begin{array}{l}\text { Entre } 21 \text { e } \\
50\end{array}$ & Nenhuma & Sim \\
\hline 90 & Aceito & Programador & 4 e 10 anos & Até 5 & $\begin{array}{l}\text { Programação } \\
\text { Extrema (XP) }\end{array}$ & Sim \\
\hline 91 & Aceito & Programador & $\begin{array}{l}\text { Entre } 1 \text { e } 3 \\
\text { anos }\end{array}$ & Mais de 150 & SCRUM & Não \\
\hline 92 & Aceito & Programador & 4 e 10 anos & Até 5 & Programação & Sim \\
\hline
\end{tabular}


Extrema (XP)

\begin{tabular}{|c|c|c|c|c|c|c|}
\hline 93 & Aceito & Programador & 4 e 10 anos & Até 5 & Nenhuma & Não \\
\hline 94 & Aceito & Programador & $\begin{array}{l}\text { Entre } 1 \text { e } 3 \\
\text { anos }\end{array}$ & Até 5 & SCRUM & Não \\
\hline 95 & Aceito & programador & 4 e 10 anos & Até 5 & Nenhuma & Não \\
\hline 96 & Aceito & Programador & $\begin{array}{l}\text { Entre } 1 \text { e } 3 \\
\text { anos }\end{array}$ & Até 5 & Nenhuma & Sim \\
\hline 97 & Aceito & programador & 4 e 10 anos & Mais de 150 & Nenhuma & Não \\
\hline 98 & Aceito & Programador & $\begin{array}{l}\text { Entre } 1 \text { e } 3 \\
\text { anos }\end{array}$ & Até 5 & SCRUM & Sim \\
\hline 99 & Aceito & Programador & $\begin{array}{l}\text { Menos de } 1 \\
\text { ano }\end{array}$ & Até 5 & Nenhuma & Não \\
\hline 100 & Aceito & Programador & $\begin{array}{l}\text { Entre } 1 \text { e } 3 \\
\text { anos }\end{array}$ & $\begin{array}{l}\text { Entre } 21 \text { e } \\
50\end{array}$ & SCRUM & Não \\
\hline 101 & Aceito & Programador & $\begin{array}{l}\text { Entre } 1 \text { e } 3 \\
\text { anos }\end{array}$ & $\begin{array}{l}\text { Entre } 51 \text { e } \\
150\end{array}$ & SCRUM & Sim \\
\hline 102 & Aceito & Programador & $\begin{array}{l}\text { Entre } 1 \text { e } 3 \\
\text { anos }\end{array}$ & Entre 6 e 20 & SCRUM & Sim \\
\hline 103 & Aceito & Programador & $\begin{array}{l}\text { Entre } 1 \text { e } 3 \\
\text { anos }\end{array}$ & Até 5 & SCRUM & Sim \\
\hline 104 & Aceito & Programador & 4 e 10 anos & Mais de 150 & Nenhuma & Sim \\
\hline 105 & Aceito & Programador & 4 e 10 anos & Até 5 & JavaScript & Não \\
\hline 106 & Aceito & Programador & $\begin{array}{l}\text { Entre } 1 \text { e } 3 \\
\text { anos }\end{array}$ & $\begin{array}{l}\text { Entre } 21 \mathrm{e} \\
50\end{array}$ & $\begin{array}{l}\text { Processo } \\
\text { customizado }\end{array}$ & Sim \\
\hline 107 & Aceito & Programador & $\begin{array}{l}\text { Menos de } 1 \\
\text { ano }\end{array}$ & $\begin{array}{l}\text { Entre } 21 \text { e } \\
50\end{array}$ & SCRUM & Sim \\
\hline 108 & Aceito & Programador & $\begin{array}{l}\text { Entre } 1 \text { e } 3 \\
\text { anos }\end{array}$ & Até 5 & Nenhuma & Não \\
\hline 109 & Aceito & Programador & 4 e 10 anos & Mais de 150 & Nenhuma & Não \\
\hline 110 & Aceito & Programador Junior & $\begin{array}{l}\text { Menos de } 1 \\
\text { ano }\end{array}$ & Entre 6 e 20 & SCRUM & Sim \\
\hline 111 & Aceito & Programador PHP & $\begin{array}{l}\text { Entre } 1 \text { e } 3 \\
\text { anos }\end{array}$ & Mais de 150 & $\begin{array}{l}\text { Programação } \\
\text { Extrema (XP) }\end{array}$ & Não \\
\hline 112 & Aceito & programador web & $\begin{array}{l}\text { Entre } 1 \text { e } 3 \\
\text { anos }\end{array}$ & Entre 6 e 20 & SCRUM & Não \\
\hline 113 & Aceito & Programadora & 4 e 10 anos & Mais de 150 & SCRUM & Sim \\
\hline 114 & Aceito & Programdor Web & 4 e 10 anos & Entre 6 e 20 & Nenhuma & Não \\
\hline 115 & Aceito & Project Manager & 4 e 10 anos & Até 5 & $\begin{array}{l}\text { Programação } \\
\text { Extrema (XP) }\end{array}$ & Sim \\
\hline 116 & Aceito & Sócio Proprietário & 4 e 10 anos & Até 5 & Nenhuma & Não \\
\hline 117 & Aceito & Software Engineer & 4 e 10 anos & $\begin{array}{l}\text { Entre } 21 \text { e } \\
50\end{array}$ & SCRUM & Não \\
\hline 118 & Aceito & Software engineering & $\begin{array}{l}\text { Mais de } 10 \\
\text { anos }\end{array}$ & Entre 6 e 20 & Nenhuma & Não \\
\hline 119 & Aceito & suporte e treinamento & $\begin{array}{l}\text { Entre } 1 \text { e } 3 \\
\text { anos }\end{array}$ & Até 5 & $\begin{array}{l}\text { Programação } \\
\text { Extrema (XP) }\end{array}$ & Não \\
\hline 120 & Aceito & SUPORTE TECNICO & $\begin{array}{l}\text { Menos de } 1 \\
\text { ano }\end{array}$ & $\begin{array}{l}\text { Entre } 51 \text { e } \\
150\end{array}$ & Nenhuma & Sim \\
\hline 121 & Aceito & testador & 4 e 10 anos & Entre 6 e 20 & SCRUM & Sim \\
\hline 122 & Aceito & $\mathrm{TI}$ & $\begin{array}{l}\text { Menos de } 1 \\
\text { ano }\end{array}$ & $\begin{array}{l}\text { Entre } 21 \text { e } \\
50\end{array}$ & Nenhuma & Não \\
\hline 123 & Aceito & Web developer & $\begin{array}{l}\text { Mais de } 10 \\
\text { anos }\end{array}$ & Entre 6 e 20 & Nenhuma & Não \\
\hline
\end{tabular}




\begin{tabular}{|c|c|c|c|c|c|c|}
\hline 124 & Aceito & Web Master & $\begin{array}{l}\text { Entre } 1 \text { e } 3 \\
\text { anos }\end{array}$ & Até 5 & SCRUM & Não \\
\hline 125 & Aceito & & $\begin{array}{l}\text { Entre } 1 \text { e } 3 \\
\text { anos }\end{array}$ & Mais de 150 & Nenhuma & Não \\
\hline 126 & Aceito & & $\begin{array}{l}\text { Mais de } 10 \\
\text { anos }\end{array}$ & Mais de 150 & Nenhuma & Sim \\
\hline 127 & Aceito & & $\begin{array}{l}\text { Menos de } 1 \\
\text { ano }\end{array}$ & Entre 6 e 20 & SCRUM & Sim \\
\hline 128 & Aceito & & 4 e 10 anos & Mais de 150 & SCRUM & Não \\
\hline 129 & Aceito & & 4 e 10 anos & Entre 6 e 20 & SCRUM & Sim \\
\hline 130 & Aceito & & 4 e 10 anos & $\begin{array}{l}\text { Entre } 51 \text { e } \\
150\end{array}$ & SCRUM & Não \\
\hline 131 & Aceito & & 4 e 10 anos & Até 5 & Nenhuma & Sim \\
\hline 132 & Aceito & & $\begin{array}{l}\text { Entre } 1 \text { e } 3 \\
\text { anos }\end{array}$ & Até 5 & Nenhuma & Sim \\
\hline 133 & Aceito & & $\begin{array}{l}\text { Mais de } 10 \\
\text { anos }\end{array}$ & Mais de 150 & $\begin{array}{l}\text { Feature Driven } \\
\text { Development } \\
\text { (FDD) }\end{array}$ & Sim \\
\hline 134 & Aceito & & $\begin{array}{l}\text { Menos de } 1 \\
\text { ano }\end{array}$ & Entre 6 e 20 & Nenhuma & Não \\
\hline 135 & Aceito & & $\begin{array}{l}\text { Entre } 1 \text { e } 3 \\
\text { anos }\end{array}$ & Entre 6 e 20 & Nenhuma & Não \\
\hline 136 & Aceito & & $\begin{array}{l}\text { Entre } 1 \text { e } 3 \\
\text { anos }\end{array}$ & Até 5 & Nenhuma & Não \\
\hline
\end{tabular}

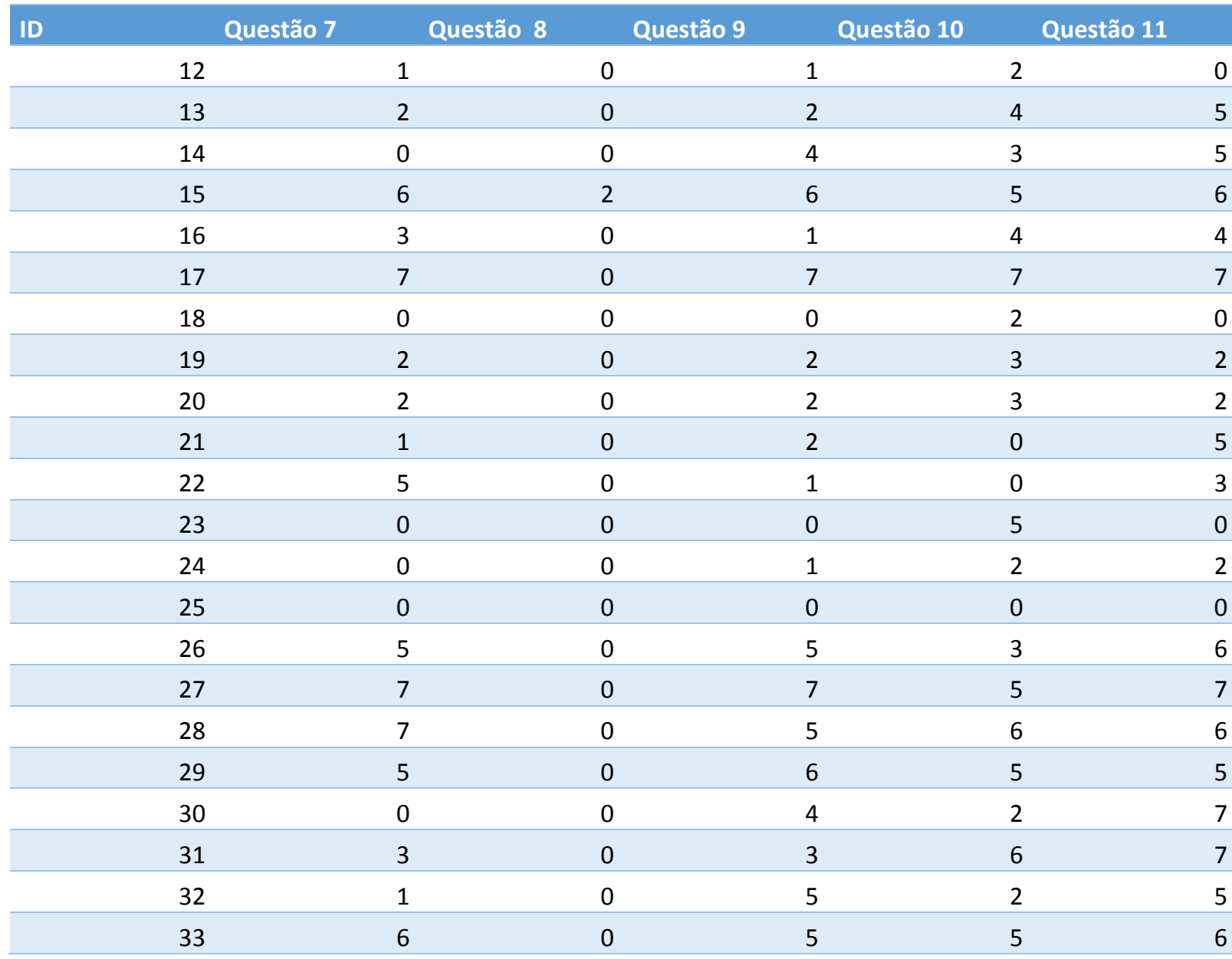




\begin{tabular}{|c|c|c|c|c|c|}
\hline 34 & 4 & 0 & 0 & 7 & 5 \\
\hline 35 & 0 & 0 & 0 & 0 & 1 \\
\hline 36 & 0 & 0 & 0 & 0 & 1 \\
\hline 37 & 7 & 4 & 5 & 7 & 7 \\
\hline 38 & 7 & 1 & 6 & 2 & 7 \\
\hline 39 & 7 & 7 & 2 & 3 & 7 \\
\hline 40 & 0 & 0 & 0 & 2 & 7 \\
\hline 41 & 5 & 0 & 6 & 2 & 5 \\
\hline 42 & 7 & 0 & 4 & 2 & 7 \\
\hline 43 & 0 & 0 & 1 & 1 & 1 \\
\hline 44 & 7 & 0 & 2 & 3 & 7 \\
\hline 45 & 0 & 0 & 0 & 0 & 0 \\
\hline 46 & 0 & 0 & 0 & 0 & 0 \\
\hline 47 & 1 & 0 & 1 & 0 & 7 \\
\hline 48 & 7 & 0 & 7 & 5 & 7 \\
\hline 49 & 2 & 0 & 3 & 6 & 4 \\
\hline 50 & 7 & 0 & 7 & 5 & 7 \\
\hline 51 & 7 & 0 & 6 & 5 & 2 \\
\hline 52 & 7 & 0 & 0 & 4 & 7 \\
\hline 53 & 5 & 0 & 1 & 2 & 3 \\
\hline 54 & 7 & 0 & 7 & 0 & 7 \\
\hline 55 & 7 & 1 & 7 & 4 & 7 \\
\hline 56 & 0 & 0 & 0 & 0 & 0 \\
\hline 57 & 1 & 0 & 0 & 0 & 0 \\
\hline 58 & 4 & 0 & 4 & 6 & 7 \\
\hline 59 & 0 & 0 & 2 & 0 & 0 \\
\hline 60 & 6 & 0 & 2 & 1 & 1 \\
\hline 61 & 6 & 0 & 5 & 2 & 7 \\
\hline 62 & 5 & 0 & 0 & 0 & 3 \\
\hline 63 & 7 & 0 & 4 & 6 & 7 \\
\hline 64 & 7 & 2 & 2 & 2 & 7 \\
\hline 65 & 6 & 2 & 5 & 7 & 6 \\
\hline 66 & 2 & 4 & 3 & 4 & 7 \\
\hline 67 & 7 & 0 & 7 & 5 & 7 \\
\hline 68 & 0 & 0 & 3 & 0 & 0 \\
\hline 69 & 0 & 0 & 0 & 0 & 0 \\
\hline 70 & 5 & 0 & 4 & 6 & 5 \\
\hline 71 & 1 & 0 & 5 & 6 & 3 \\
\hline 72 & 0 & 0 & 5 & 5 & 5 \\
\hline 73 & 0 & 0 & 0 & 0 & 0 \\
\hline 74 & 0 & 0 & 0 & 0 & 0 \\
\hline 75 & 2 & 0 & 7 & 7 & 7 \\
\hline 76 & 3 & 0 & 6 & 3 & 7 \\
\hline 77 & 7 & 0 & 7 & 7 & 7 \\
\hline 78 & 4 & 0 & 6 & 4 & 4 \\
\hline
\end{tabular}




\begin{tabular}{|c|c|c|c|c|c|}
\hline 79 & 2 & 0 & 2 & 3 & 5 \\
\hline 80 & 2 & 0 & 5 & 6 & 7 \\
\hline 81 & 1 & 0 & 0 & 0 & 7 \\
\hline 82 & 7 & 0 & 0 & 7 & 0 \\
\hline 83 & 7 & 0 & 6 & 6 & 7 \\
\hline 84 & 5 & 1 & 7 & 7 & 4 \\
\hline 85 & 0 & 0 & 0 & 0 & 0 \\
\hline 86 & 7 & 0 & 7 & 7 & 7 \\
\hline 87 & 4 & 2 & 7 & 7 & 7 \\
\hline 88 & 7 & 0 & 7 & 5 & 7 \\
\hline 89 & 4 & 0 & 4 & 5 & 7 \\
\hline 90 & 7 & 0 & 5 & 6 & 7 \\
\hline 91 & 5 & 0 & 0 & 2 & 2 \\
\hline 92 & 0 & 0 & 0 & 5 & 7 \\
\hline 93 & 5 & 0 & 4 & 4 & 4 \\
\hline 94 & 4 & 0 & 1 & 1 & 1 \\
\hline 95 & 0 & 0 & 0 & 0 & 0 \\
\hline 96 & 2 & 0 & 4 & 0 & 4 \\
\hline 97 & 0 & 0 & 0 & 0 & 3 \\
\hline 98 & 1 & 0 & 0 & 5 & 7 \\
\hline 99 & 0 & 0 & 0 & 0 & 1 \\
\hline 100 & 0 & 0 & 1 & 0 & 7 \\
\hline 101 & 0 & 0 & 7 & 4 & 0 \\
\hline 102 & 3 & 0 & 2 & 0 & 6 \\
\hline 103 & 0 & 0 & 1 & 3 & 7 \\
\hline 104 & 0 & 0 & 0 & 0 & 0 \\
\hline 105 & 7 & 7 & 7 & 5 & 7 \\
\hline 106 & 3 & 0 & 5 & 0 & 7 \\
\hline 107 & 7 & 0 & 7 & 0 & 7 \\
\hline 108 & 3 & 0 & 2 & 1 & 0 \\
\hline 109 & 0 & 0 & 0 & 3 & 0 \\
\hline 110 & 7 & 1 & & 7 & 7 \\
\hline 111 & 7 & 4 & 7 & 3 & 7 \\
\hline 112 & 1 & 0 & 2 & 1 & 7 \\
\hline 113 & 7 & 0 & 0 & 0 & 7 \\
\hline 114 & 1 & 0 & 5 & 7 & 6 \\
\hline 115 & 4 & 0 & 4 & 4 & 4 \\
\hline 116 & 1 & 0 & 1 & 3 & 0 \\
\hline 117 & 7 & 0 & 3 & 5 & 7 \\
\hline 118 & 4 & 0 & 3 & 4 & 4 \\
\hline 119 & 3 & 0 & 3 & 2 & 6 \\
\hline 120 & 0 & 0 & 0 & 0 & 0 \\
\hline 121 & 7 & 0 & 7 & 7 & 7 \\
\hline 122 & 1 & 1 & 2 & 2 & 3 \\
\hline 123 & 4 & & 2 & 1 & 2 \\
\hline
\end{tabular}




\begin{tabular}{|llllll}
124 & 0 & 0 & 0 & & 1 \\
\hline 125 & 6 & 0 & 4 & 5 & 3 \\
\hline 126 & 0 & 0 & 2 & 0 & 0 \\
\hline 127 & 5 & 5 & 3 & 6 & 6 \\
\hline 128 & 4 & 0 & 4 & 0 & 7 \\
\hline 129 & 5 & & 1 & 7 & 7 \\
\hline 130 & 7 & 0 & 7 & 7 & 0 \\
\hline 131 & 0 & 0 & 0 & 0 & 0 \\
\hline 132 & 1 & 0 & 0 & 1 & 7 \\
\hline 133 & 5 & 7 & 7 & 7 & 0 \\
\hline 134 & 0 & 0 & 0 & 0 & 7 \\
\hline 135 & 0 & 0 & 0 & 0 & 0 \\
\hline 136 & 3 & 0 & 0 & 0 & \\
\hline
\end{tabular}

ID \begin{tabular}{lllll|l}
\hline Questão 12 & Questão 13 & Questão 14 & Questão 15 & Questão 16 & Questão 17
\end{tabular}

\begin{tabular}{|c|c|c|c|c|c|c|}
\hline 12 & 5 & 5 & 1 & 1 & 5 & 1 \\
\hline 13 & 3 & 3 & 2 & 3 & 3 & 2 \\
\hline 14 & 1 & 3 & 1 & 1 & 5 & 3 \\
\hline 15 & 3 & 6 & 6 & 5 & 5 & 5 \\
\hline 16 & 5 & 6 & 3 & 3 & 5 & 5 \\
\hline 17 & 4 & 6 & 5 & 5 & 6 & 5 \\
\hline 18 & 3 & 4 & 1 & 1 & 1 & 1 \\
\hline 19 & 5 & 5 & 3 & 3 & 3 & 2 \\
\hline 20 & 5 & 5 & 3 & 3 & 3 & 2 \\
\hline 21 & 2 & 3 & 4 & 3 & 6 & 3 \\
\hline 22 & 4 & 6 & 5 & 5 & 5 & 5 \\
\hline 23 & 5 & 7 & 1 & 1 & 3 & 1 \\
\hline 24 & 2 & 4 & 4 & 3 & 4 & 4 \\
\hline 25 & 4 & 1 & 1 & 1 & 1 & 1 \\
\hline 26 & 2 & 1 & 2 & 2 & 3 & 2 \\
\hline 27 & 7 & 7 & 5 & 7 & 7 & 5 \\
\hline 28 & 3 & 5 & 2 & 3 & 7 & 3 \\
\hline 29 & 7 & 6 & 1 & 1 & 1 & 4 \\
\hline 30 & 3 & 1 & 7 & 2 & 6 & 6 \\
\hline 31 & 6 & 4 & 3 & 1 & 6 & 4 \\
\hline 32 & 5 & 5 & 2 & 2 & 5 & 5 \\
\hline 33 & 4 & 5 & 5 & 5 & 5 & 5 \\
\hline 34 & 4 & 5 & 3 & 2 & 6 & 5 \\
\hline 35 & 6 & 3 & 2 & 2 & 2 & 4 \\
\hline 36 & 6 & 3 & 2 & 2 & 2 & 4 \\
\hline 37 & 7 & 7 & 5 & 5 & 5 & 7 \\
\hline 38 & 4 & 4 & 4 & 2 & 2 & 3 \\
\hline 39 & 7 & 7 & 3 & 3 & 7 & 7 \\
\hline 40 & 1 & 1 & 1 & 1 & 1 & 1 \\
\hline
\end{tabular}




\begin{tabular}{|c|c|c|c|c|c|c|}
\hline 41 & 4 & 3 & 2 & 2 & 5 & 5 \\
\hline 42 & 6 & 7 & 5 & 6 & 7 & 7 \\
\hline 43 & 4 & 5 & 5 & 6 & 3 & 2 \\
\hline 44 & 6 & 6 & 5 & 5 & 6 & 6 \\
\hline 45 & 1 & 1 & 1 & 1 & 1 & 1 \\
\hline 46 & 7 & 7 & 1 & 4 & 4 & 7 \\
\hline 47 & 7 & 5 & 1 & 2 & 7 & 4 \\
\hline 48 & 1 & 7 & 4 & 4 & 7 & 7 \\
\hline 49 & 4 & 6 & 5 & 3 & 6 & 5 \\
\hline 50 & 7 & 7 & 3 & 3 & 5 & 6 \\
\hline 51 & 3 & 6 & 5 & 5 & 4 & 4 \\
\hline 52 & 6 & 5 & 5 & 5 & 6 & 6 \\
\hline 53 & 4 & 4 & 4 & 3 & 5 & 3 \\
\hline 54 & 7 & 7 & 7 & 7 & 7 & 7 \\
\hline 55 & 6 & 5 & 5 & 5 & 4 & 6 \\
\hline 56 & 3 & 6 & 2 & 2 & 6 & 2 \\
\hline 57 & 3 & 4 & 1 & 1 & 3 & 2 \\
\hline 58 & 6 & 7 & 7 & 6 & 6 & 6 \\
\hline 59 & 2 & 3 & 1 & 1 & 1 & 1 \\
\hline 60 & 4 & 3 & 4 & 4 & 6 & 3 \\
\hline 61 & 5 & 4 & & 4 & 5 & 2 \\
\hline 62 & 2 & 2 & & & 1 & 1 \\
\hline 63 & 6 & 6 & 4 & 5 & 5 & 4 \\
\hline 64 & 3 & 3 & & 3 & 3 & 3 \\
\hline 65 & 4 & 5 & 3 & 3 & 3 & 5 \\
\hline 66 & 5 & 7 & 5 & 5 & 4 & 5 \\
\hline 67 & 7 & 7 & 7 & 6 & 6 & 5 \\
\hline 68 & 4 & 4 & 4 & 4 & 4 & 4 \\
\hline 69 & 1 & 3 & 1 & 1 & 1 & 4 \\
\hline 70 & 4 & 6 & 3 & 4 & 6 & 4 \\
\hline 71 & 4 & 5 & 4 & 5 & 7 & 4 \\
\hline 72 & 4 & 5 & 4 & 4 & 4 & 4 \\
\hline 73 & 1 & 7 & 1 & 1 & 7 & 1 \\
\hline 74 & 3 & 3 & 1 & 1 & 3 & 3 \\
\hline 75 & 7 & 6 & 2 & 5 & 6 & 7 \\
\hline 76 & 3 & 4 & 3 & 4 & 5 & 3 \\
\hline 77 & 1 & 7 & 7 & 7 & 7 & 7 \\
\hline 78 & 6 & 7 & 7 & 6 & 7 & 7 \\
\hline 79 & 5 & 3 & 3 & 2 & 5 & 3 \\
\hline 80 & 3 & 6 & 2 & 3 & 7 & 6 \\
\hline 81 & 7 & 7 & 4 & 4 & 5 & 5 \\
\hline 82 & 7 & 5 & 5 & 5 & 6 & 3 \\
\hline 83 & 7 & 6 & 6 & 6 & 6 & 4 \\
\hline 84 & 4 & 5 & 3 & 5 & 4 & 3 \\
\hline 85 & 1 & 1 & 1 & 1 & 1 & 1 \\
\hline
\end{tabular}




\begin{tabular}{|c|c|c|c|c|c|c|}
\hline 86 & 3 & 7 & 7 & 7 & 7 & 7 \\
\hline 87 & 6 & 5 & 5 & 4 & 5 & 5 \\
\hline 88 & 5 & 6 & 4 & 4 & 5 & 6 \\
\hline 89 & 7 & 7 & 7 & 7 & 7 & 7 \\
\hline 90 & 6 & 5 & 4 & 4 & 6 & 5 \\
\hline 91 & 6 & 6 & 5 & 5 & 7 & 4 \\
\hline 92 & 2 & 3 & 1 & 1 & 6 & 5 \\
\hline 93 & 4 & 4 & 4 & 3 & 4 & 1 \\
\hline 94 & 2 & 3 & 1 & 1 & 2 & 1 \\
\hline 95 & 4 & 1 & 1 & 1 & 1 & 1 \\
\hline 96 & 3 & 2 & 2 & 3 & 6 & 6 \\
\hline 97 & 1 & 1 & 2 & 1 & 1 & 1 \\
\hline 98 & 7 & 5 & 5 & 4 & 4 & 6 \\
\hline 99 & 4 & 2 & 2 & 2 & 2 & 2 \\
\hline 100 & 5 & 5 & 1 & 1 & 7 & 2 \\
\hline 101 & 1 & 5 & 6 & 1 & 5 & 4 \\
\hline 102 & 5 & 7 & 6 & 3 & 7 & 7 \\
\hline 103 & 2 & 5 & 1 & 2 & 5 & 6 \\
\hline 104 & 1 & 2 & 4 & 3 & 4 & 1 \\
\hline 105 & 7 & 7 & 6 & 6 & 7 & 6 \\
\hline 106 & 7 & 7 & 4 & 4 & 6 & 5 \\
\hline 107 & 6 & 5 & 3 & 4 & 6 & 6 \\
\hline 108 & 2 & 3 & 3 & 3 & 3 & 3 \\
\hline 109 & 1 & 1 & 1 & 1 & 1 & 1 \\
\hline 110 & 4 & 1 & 3 & 5 & & 6 \\
\hline 111 & 4 & 7 & 5 & 4 & 7 & 5 \\
\hline 112 & 6 & 5 & 4 & 3 & 2 & 1 \\
\hline 113 & 1 & 4 & 1 & 1 & 1 & 4 \\
\hline 114 & 5 & 4 & 2 & 2 & 3 & 2 \\
\hline 115 & 7 & 7 & 7 & 7 & 7 & 7 \\
\hline 116 & 3 & 3 & 2 & 2 & 2 & 1 \\
\hline 117 & 3 & 6 & 6 & 4 & 6 & 5 \\
\hline 118 & 3 & 3 & 5 & 2 & 4 & 3 \\
\hline 119 & 4 & 3 & 4 & 4 & 4 & 4 \\
\hline 120 & 3 & 2 & & 3 & 3 & 1 \\
\hline 121 & 7 & 6 & 5 & 4 & 6 & 6 \\
\hline 122 & 5 & 3 & 2 & 2 & 6 & 4 \\
\hline 123 & 5 & 3 & 2 & 2 & 2 & 2 \\
\hline 124 & 7 & 7 & 6 & 5 & 5 & 4 \\
\hline 125 & 2 & 4 & 1 & 1 & 3 & 1 \\
\hline 126 & 5 & 3 & 2 & 1 & 2 & 2 \\
\hline 127 & 6 & 4 & 5 & 4 & 6 & 6 \\
\hline 128 & 1 & 5 & 5 & 2 & 5 & 5 \\
\hline 129 & 7 & 5 & 6 & 6 & 6 & 5 \\
\hline 130 & 6 & 5 & 5 & 5 & 5 & 4 \\
\hline
\end{tabular}




\begin{tabular}{|lllllll|}
\hline 131 & 2 & 1 & 1 & 1 & 2 & 3 \\
\hline 132 & 3 & 1 & 2 & 3 & 3 & 3 \\
\hline 133 & 5 & 6 & 7 & 7 & 7 & 3 \\
\hline 134 & 4 & 6 & 1 & 1 & 4 & 5 \\
\hline 135 & 2 & 5 & 4 & 6 & 5 & 3 \\
\hline 136 & 3 & 2 & 1 & 1 & 1 & 1 \\
\hline
\end{tabular}

\begin{tabular}{|c|c|c|c|c|c|c|}
\hline ID & Questão 18 & Questão 19 & Questão 20 & Questão 21 & Questão 22 & Questão 23 \\
\hline 12 & $\begin{array}{l}\text { Reunião } \\
\text { Diária, } \\
\text { Taskboard }\end{array}$ & $\begin{array}{l}\text { Reunião Diária, } \\
\text { Retrospectivas, } \\
\text { Taskboard }\end{array}$ & Taskboard & Taskboard & $\begin{array}{l}\text { Reunião Diária, } \\
\text { Retrospectivas, } \\
\text { Taskboard }\end{array}$ & $\begin{array}{l}\text { Reunião Diária, } \\
\text { Retrospectivas, } \\
\text { Taskboard }\end{array}$ \\
\hline 13 & $\begin{array}{l}\text { Reunião } \\
\text { Diária, } \\
\text { Retrospectiva } \\
\text { s }\end{array}$ & $\begin{array}{l}\text { Reunião Diária, } \\
\text { Taskboard }\end{array}$ & $\begin{array}{l}\text { Reunião Diária, } \\
\text { Taskboard }\end{array}$ & $\begin{array}{l}\text { Reunião Diária, } \\
\text { Calendário } \\
\text { niko-niko }\end{array}$ & $\begin{array}{l}\text { Reunião Diária, } \\
\text { Retrospectivas, } \\
\text { Taskboard }\end{array}$ & $\begin{array}{l}\text { Calendário } \\
\text { niko-niko, } \\
\text { Taskboard }\end{array}$ \\
\hline 14 & $\begin{array}{l}\text { Retrospectiva } \\
\mathrm{S}\end{array}$ & $\begin{array}{l}\text { Sessões de } \\
\text { design rápido }\end{array}$ & Taskboard & Taskboard & $\begin{array}{l}\text { Sessões de } \\
\text { design rápido }\end{array}$ & Taskboard \\
\hline 15 & $\begin{array}{l}\text { Reunião } \\
\text { Diária, } \\
\text { Taskboard }\end{array}$ & $\begin{array}{l}\text { Reunião Diária, } \\
\text { Sessões de } \\
\text { design rápido, } \\
\text { Taskboard, } \\
\text { Sessão de design } \\
\text { colaborativa }\end{array}$ & $\begin{array}{l}\text { Reunião Diária, } \\
\text { Retrospectivas, } \\
\text { Taskboard }\end{array}$ & $\begin{array}{l}\text { Calendário } \\
\text { niko-niko }\end{array}$ & Taskboard & Retrospectivas \\
\hline 16 & $\begin{array}{l}\text { Reunião } \\
\text { Diária }\end{array}$ & Reunião Diária & Reunião Diária & Retrospectivas & Reunião Diária & Retrospectivas \\
\hline 17 & $\begin{array}{l}\text { Reunião } \\
\text { Diária, } \\
\text { Taskboard }\end{array}$ & $\begin{array}{l}\text { Reunião Diária, } \\
\text { Taskboard }\end{array}$ & Taskboard & Retrospectivas & $\begin{array}{l}\text { Reunião Diária, } \\
\text { Taskboard }\end{array}$ & Taskboard \\
\hline 18 & $\begin{array}{l}\text { Sessões de } \\
\text { design } \\
\text { rápido, } \\
\text { Taskboard }\end{array}$ & Taskboard & Taskboard & $\begin{array}{l}\text { Calendário } \\
\text { niko-niko }\end{array}$ & $\begin{array}{l}\text { Retrospectivas, } \\
\text { Taskboard }\end{array}$ & Taskboard \\
\hline 19 & $\begin{array}{l}\text { Reunião } \\
\text { Diária, } \\
\text { Retrospectiva } \\
\text { s }\end{array}$ & $\begin{array}{l}\text { Reunião Diária, } \\
\text { Sessões de } \\
\text { design rápido }\end{array}$ & & & $\begin{array}{l}\text { Reunião Diária, } \\
\text { Retrospectivas, } \\
\text { Sessões de } \\
\text { design rápido, } \\
\text { Taskboard }\end{array}$ & $\begin{array}{l}\text { Reunião Diária, } \\
\text { Taskboard }\end{array}$ \\
\hline 20 & $\begin{array}{l}\text { Reunião } \\
\text { Diária, } \\
\text { Retrospectiva } \\
\text { s }\end{array}$ & $\begin{array}{l}\text { Reunião Diária, } \\
\text { Sessões de } \\
\text { design rápido }\end{array}$ & & & $\begin{array}{l}\text { Reunião Diária, } \\
\text { Retrospectivas, } \\
\text { Sessões de } \\
\text { design rápido, } \\
\text { Taskboard }\end{array}$ & $\begin{array}{l}\text { Reunião Diária, } \\
\text { Taskboard }\end{array}$ \\
\hline \multicolumn{7}{|l|}{21} \\
\hline 22 & $\begin{array}{l}\text { Reunião } \\
\text { Diária, } \\
\text { Retrospectiva } \\
\text { s }\end{array}$ & Taskboard & Taskboard & $\begin{array}{l}\text { Reunião Diária, } \\
\text { Retrospectivas }\end{array}$ & $\begin{array}{l}\text { Reunião Diária, } \\
\text { Taskboard }\end{array}$ & Taskboard \\
\hline 23 & & Taskboard & & & Taskboard & \\
\hline 24 & $\begin{array}{l}\text { Reunião } \\
\text { Diária }\end{array}$ & Taskboard & $\begin{array}{l}\text { Sessões de } \\
\text { design rápido }\end{array}$ & Taskboard & Reunião Diária & $\begin{array}{l}\text { Calendário } \\
\text { niko-niko }\end{array}$ \\
\hline \multicolumn{7}{|l|}{25} \\
\hline 26 & $\begin{array}{l}\text { Reunião } \\
\text { Diária, }\end{array}$ & Taskboard & & & & \\
\hline
\end{tabular}


Taskboard

Reunião

Diária,

Retrospectiva Reunião Diária,

$\mathrm{s}$, Sessões de Retrospectivas,

design Taskboard,

rápido, Reunião de

27 Taskboard

Planejamento

Reunião Diária,

Retrospectivas, Reunião Diária,

Reunião

28 Diária

Reunião Diária

Taskboard

Taskboard

Taskboard

Taskboard

Taskboard

Taskboard Taskboard

Reunião

Diária,

Reunião Diária,

Taskboard

Reunião Diária,

Retrospectivas,

Sessões de Sessões de

29 design rápido

design rápido

Retrospectiva

$s$, Sessões de

design

Reunião Diária,

rápido,

Sessões de

Calendário

design rápido,

niko-niko,

Taskboard

Calendário

30 Taskboard

Taskboard

niko-niko

Retrospectivas

Sessões de

design

rápido,

Retrospectivas, Retrospectivas,

31 Taskboard

Taskboard

Taskboard

Taskboard

Taskboard

Taskboard

Reunião

Diária,

Sessões de

Reunião Diária,

Reunião Diária,

32 design rápido Reunião Diária

Calendário

Sessões de

Reunião Diária niko-niko

design rápido

Reunião Diária,

Sessões de

Reunião

design rápido,

Reunião Diária,

33 Diária

Taskboard

Taskboard

Taskboard

Reunião Diária Reunião Diária

Reunião

34 Diária

Taskboard

Taskboard

Taskboard

Taskboard

Taskboard

Sessões de

design

Sessões de

rápido,

design rápido,

35 Taskboard

Taskboard

Calendário

Sessões de

design

Sessões de

rápido,

design rápido,

niko-niko

Taskboard

Taskboard

36 Taskboard

Taskboard

Calendário

Reunião

niko-niko

Taskboard Taskboard

Diária,

Reunião Diária,

Retrospectiva Retrospectivas,

s, JAD

Sessões de

37 adaptados

design rápido

ão Diaria,

Retrospectivas,

Calendário Sessões de

niko-niko,

design rápido,

Taskboard

Taskboard

Reunião Diária

Reunião Diária,

38 Desk checks

Taskboard

Build wall

Retrospectivas

Taskboard

Taskboard

Reunião

39 Diária

Retrospectivas

Calendário

Reunião Diária,

40 none

none

Taskboard niko-niko

Retrospectivas

Taskboard

Reunião

Diária,

Reunião Diária,

none

none

none

none

Retrospectiva Retrospectivas,

Reunião Diária, Reunião Diária, Reunião Diária, Reunião Diária,

41 s, Taskboard

Taskboard

Retrospectivas, Retrospectivas,

Taskboard

Taskboard

Taskboard

Taskboard 


\begin{tabular}{|c|c|c|c|c|c|c|}
\hline 42 & $\begin{array}{l}\text { Reunião } \\
\text { Diária, } \\
\text { Sessões de } \\
\text { design } \\
\text { rápido, } \\
\text { Taskboard }\end{array}$ & $\begin{array}{l}\text { Reunião Diária, } \\
\text { Taskboard }\end{array}$ & $\begin{array}{l}\text { Reunião Diária, } \\
\text { Sessões de } \\
\text { design rápido, } \\
\text { Taskboard }\end{array}$ & $\begin{array}{l}\text { Reunião Diária, } \\
\text { Calendário } \\
\text { niko-niko }\end{array}$ & Taskboard & $\begin{array}{l}\text { Reunião Diária, } \\
\text { Taskboard }\end{array}$ \\
\hline 43 & $\begin{array}{l}\text { Reunião } \\
\text { Diária, } \\
\text { Retrospectiva } \\
\text { s, Sessões de } \\
\text { design rápido }\end{array}$ & $\begin{array}{l}\text { Reunião Diária, } \\
\text { Sessões de } \\
\text { design rápido }\end{array}$ & $\begin{array}{l}\text { Reunião Diária, } \\
\text { Calendário } \\
\text { niko-niko, } \\
\text { Taskboard }\end{array}$ & $\begin{array}{l}\text { Reunião Diária, } \\
\text { Retrospectivas }\end{array}$ & $\begin{array}{l}\text { Reunião Diária, } \\
\text { Calendário } \\
\text { niko-niko, } \\
\text { Retrospectivas }\end{array}$ & $\begin{array}{l}\text { Reunião Diária, } \\
\text { Calendário } \\
\text { niko-niko, } \\
\text { Taskboard }\end{array}$ \\
\hline 44 & $\begin{array}{l}\text { Reunião } \\
\text { Diária, } \\
\text { Retrospectiva } \\
\mathrm{S}\end{array}$ & $\begin{array}{l}\text { Reunião Diária, } \\
\text { Taskboard }\end{array}$ & Taskboard & $\begin{array}{l}\text { Calendário } \\
\text { niko-niko }\end{array}$ & $\begin{array}{l}\text { Reunião Diária, } \\
\text { Taskboard }\end{array}$ & \\
\hline 45 & & & & & & \\
\hline 46 & & & & & & \\
\hline 47 & $\begin{array}{l}\text { Reunião } \\
\text { Diária, } \\
\text { Taskboard }\end{array}$ & Taskboard & Taskboard & Taskboard & $\begin{array}{l}\text { Reunião Diária, } \\
\text { Taskboard }\end{array}$ & Taskboard \\
\hline 48 & $\begin{array}{l}\text { Reunião } \\
\text { Diária, } \\
\text { Retrospectiva } \\
\text { s, Taskboard }\end{array}$ & $\begin{array}{l}\text { Reunião Diária, } \\
\text { Taskboard }\end{array}$ & Taskboard & Taskboard & Taskboard & Taskboard \\
\hline 49 & $\begin{array}{l}\text { Reunião } \\
\text { Diária, } \\
\text { Retrospectiva } \\
\mathrm{S}\end{array}$ & $\begin{array}{l}\text { Calendário niko- } \\
\text { niko, Taskboard }\end{array}$ & $\begin{array}{l}\text { Calendário } \\
\text { niko-niko, } \\
\text { Sessões de } \\
\text { design rápido }\end{array}$ & $\begin{array}{l}\text { Reunião Diária, } \\
\text { Calendário } \\
\text { niko-niko }\end{array}$ & $\begin{array}{l}\text { Reunião Diária, } \\
\text { Sessões de } \\
\text { design rápido }\end{array}$ & $\begin{array}{l}\text { Reunião Diária, } \\
\text { Retrospectivas, } \\
\text { Taskboard }\end{array}$ \\
\hline 50 & $\begin{array}{l}\text { Reunião } \\
\text { Diária }\end{array}$ & Reunião Diária & & Reunião Diária & $\begin{array}{l}\text { Reunião Diária, } \\
\text { Taskboard }\end{array}$ & Reunião Diária \\
\hline 51 & $\begin{array}{l}\text { Reunião } \\
\text { Diária, } \\
\text { Sessões de } \\
\text { design rápido }\end{array}$ & $\begin{array}{l}\text { Reunião Diária, } \\
\text { Retrospectivas }\end{array}$ & $\begin{array}{l}\text { Reunião Diária, } \\
\text { Retrospectivas }\end{array}$ & Reunião Diária & $\begin{array}{l}\text { Reunião Diária, } \\
\text { Retrospectivas, } \\
\text { Sessões de } \\
\text { design rápido }\end{array}$ & Reunião Diária \\
\hline 52 & $\begin{array}{l}\text { Reunião } \\
\text { Diária, } \\
\text { Retrospectiva } \\
\text { s, Sessões de } \\
\text { design } \\
\text { rápido, } \\
\text { Taskboard }\end{array}$ & $\begin{array}{l}\text { Sessões de } \\
\text { design rápido, } \\
\text { Taskboard }\end{array}$ & Reunião Diária & $\begin{array}{l}\text { Reunião Diária, } \\
\text { Taskboard }\end{array}$ & $\begin{array}{l}\text { Reunião Diária, } \\
\text { Retrospectivas, } \\
\text { Taskboard }\end{array}$ & Taskboard \\
\hline 53 & $\begin{array}{l}\text { Reunião } \\
\text { Diária }\end{array}$ & $\begin{array}{l}\text { Reunião Diária, } \\
\text { Taskboard }\end{array}$ & $\begin{array}{l}\text { Reunião Diária, } \\
\text { Taskboard }\end{array}$ & $\begin{array}{l}\text { Reunião Diária, } \\
\text { Taskboard }\end{array}$ & Taskboard & Reunião Diária \\
\hline 54 & $\begin{array}{l}\text { Reunião } \\
\text { Diária, } \\
\text { Retrospectiva } \\
\mathrm{S}\end{array}$ & $\begin{array}{l}\text { Reunião Diária, } \\
\text { Taskboard }\end{array}$ & $\begin{array}{l}\text { Reunião Diária, } \\
\text { Retrospectivas, } \\
\text { Taskboard }\end{array}$ & $\begin{array}{l}\text { Reunião Diária, } \\
\text { Taskboard }\end{array}$ & $\begin{array}{l}\text { Reunião Diária, } \\
\text { Retrospectivas, } \\
\text { Taskboard }\end{array}$ & $\begin{array}{l}\text { Reunião Diária, } \\
\text { Retrospectivas, } \\
\text { Taskboard }\end{array}$ \\
\hline 55 & $\begin{array}{l}\text { Reunião } \\
\text { Diária, } \\
\text { Taskboard }\end{array}$ & $\begin{array}{l}\text { Reunião Diária, } \\
\text { Taskboard }\end{array}$ & $\begin{array}{l}\text { Reunião Diária, } \\
\text { Taskboard }\end{array}$ & $\begin{array}{l}\text { Retrospectivas, } \\
\text { Taskboard }\end{array}$ & $\begin{array}{l}\text { Reunião Diária, } \\
\text { Taskboard }\end{array}$ & Taskboard \\
\hline 56 & $\begin{array}{l}\text { Reunião } \\
\text { Diária, } \\
\text { Taskboard }\end{array}$ & $\begin{array}{l}\text { Reunião Diária, } \\
\text { Taskboard }\end{array}$ & Taskboard & $\begin{array}{l}\text { Calendário } \\
\text { niko-niko, } \\
\text { Taskboard }\end{array}$ & $\begin{array}{l}\text { Reunião Diária, } \\
\text { Taskboard }\end{array}$ & Taskboard \\
\hline 57 & $\begin{array}{l}\text { Retrospectiva } \\
\mathrm{S}\end{array}$ & Retrospectivas & Retrospectivas & Retrospectivas & Retrospectivas & Retrospectivas \\
\hline
\end{tabular}




\begin{tabular}{|c|c|c|c|c|c|c|}
\hline 58 & $\begin{array}{l}\text { Reunião } \\
\text { Diária, } \\
\text { Retrospectiva } \\
\text { s, Sessões de } \\
\text { design rápido }\end{array}$ & $\begin{array}{l}\text { Reunião Diária, } \\
\text { Retrospectivas, } \\
\text { Taskboard }\end{array}$ & $\begin{array}{l}\text { Reunião Diária, } \\
\text { Retrospectivas, } \\
\text { Taskboard }\end{array}$ & Taskboard & Taskboard & Taskboard \\
\hline \multicolumn{7}{|l|}{59} \\
\hline 60 & $\begin{array}{l}\text { Reunião } \\
\text { Diária, } \\
\text { Taskboard }\end{array}$ & Reunião Diária & $\begin{array}{l}\text { Reunião Diária, } \\
\text { Taskboard }\end{array}$ & $\begin{array}{l}\text { Reunião Diária, } \\
\text { Calendário } \\
\text { niko-niko, } \\
\text { Taskboard }\end{array}$ & $\begin{array}{l}\text { Reunião Diária, } \\
\text { Taskboard }\end{array}$ & $\begin{array}{l}\text { Reunião Diária, } \\
\text { Retrospectivas, } \\
\text { Taskboard }\end{array}$ \\
\hline 61 & $\begin{array}{l}\text { Reunião } \\
\text { Diária, } \\
\text { Taskboard }\end{array}$ & Taskboard & $\begin{array}{l}\text { Sessões de } \\
\text { design rápido }\end{array}$ & $\begin{array}{l}\text { Reunião Diária, } \\
\text { Calendário } \\
\text { niko-niko, } \\
\text { Retrospectivas, } \\
\text { Sessões de } \\
\text { design rápido }\end{array}$ & Taskboard & $\begin{array}{l}\text { Reunião Diária, } \\
\text { Retrospectivas, } \\
\text { Taskboard }\end{array}$ \\
\hline 62 & $\begin{array}{l}\text { Reunião } \\
\text { Diária, } \\
\text { Taskboard }\end{array}$ & $\begin{array}{l}\text { Reunião Diária, } \\
\text { Taskboard }\end{array}$ & Reunião Diária & $\begin{array}{l}\text { Reunião Diária, } \\
\text { Taskboard }\end{array}$ & $\begin{array}{l}\text { Reunião Diária, } \\
\text { Taskboard }\end{array}$ & $\begin{array}{l}\text { Reunião Diária, } \\
\text { Taskboard }\end{array}$ \\
\hline 63 & $\begin{array}{l}\text { Reunião } \\
\text { Diária, } \\
\text { Taskboard }\end{array}$ & $\begin{array}{l}\text { Reunião Diária, } \\
\text { Taskboard }\end{array}$ & Taskboard & $\begin{array}{l}\text { Calendário } \\
\text { niko-niko, } \\
\text { Taskboard }\end{array}$ & Taskboard & Taskboard \\
\hline 64 & $\begin{array}{l}\text { Reunião } \\
\text { Diária, } \\
\text { Sessões de } \\
\text { design } \\
\text { rápido, } \\
\text { Taskboard }\end{array}$ & Taskboard & Taskboard & Taskboard & Taskboard & Taskboard \\
\hline 65 & $\begin{array}{l}\text { Reunião } \\
\text { Diária, } \\
\text { Retrospectiva } \\
\text { s, Taskboard }\end{array}$ & $\begin{array}{l}\text { Reunião Diária, } \\
\text { Sessões de } \\
\text { design rápido, } \\
\text { Taskboard }\end{array}$ & $\begin{array}{l}\text { Reunião Diária, } \\
\text { Calendário } \\
\text { niko-niko }\end{array}$ & $\begin{array}{l}\text { Reunião Diária, } \\
\text { Calendário } \\
\text { niko-niko }\end{array}$ & $\begin{array}{l}\text { Reunião Diária, } \\
\text { Taskboard }\end{array}$ & $\begin{array}{l}\text { Sessões de } \\
\text { design rápido, } \\
\text { Taskboard }\end{array}$ \\
\hline 66 & $\begin{array}{l}\text { Retrospectiva } \\
\text { s, Taskboard }\end{array}$ & $\begin{array}{l}\text { Reunião Diária, } \\
\text { Taskboard }\end{array}$ & $\begin{array}{l}\text { Reunião Diária, } \\
\text { Retrospectivas, } \\
\text { Taskboard }\end{array}$ & $\begin{array}{l}\text { Reunião Diária, } \\
\text { Retrospectivas, } \\
\text { Taskboard }\end{array}$ & $\begin{array}{l}\text { Reunião Diária, } \\
\text { Retrospectivas, } \\
\text { Taskboard }\end{array}$ & $\begin{array}{l}\text { Reunião Diária, } \\
\text { Taskboard }\end{array}$ \\
\hline 67 & $\begin{array}{l}\text { Reunião } \\
\text { Diária, } \\
\text { Taskboard }\end{array}$ & $\begin{array}{l}\text { Reunião Diária, } \\
\text { Retrospectivas, } \\
\text { Taskboard }\end{array}$ & Taskboard & $\begin{array}{l}\text { Reunião Diária, } \\
\text { Calendário } \\
\text { niko-niko }\end{array}$ & $\begin{array}{l}\text { Reunião Diária, } \\
\text { Retrospectivas, } \\
\text { Taskboard }\end{array}$ & $\begin{array}{l}\text { Retrospectivas, } \\
\text { Taskboard }\end{array}$ \\
\hline 68 & Retrospectiva & Retrosnectivac & Retrosnectivas & Retrosnectivas & Retrosnectivas & Retrospectivas \\
\hline \multicolumn{7}{|l|}{69} \\
\hline 70 & $\begin{array}{l}\text { Reunião } \\
\text { Diária }\end{array}$ & $\begin{array}{l}\text { Sessões de } \\
\text { design rápido }\end{array}$ & Reunião Diária & & Reunião Diária & $\begin{array}{l}\text { Cronograma } \\
\text { visivel } \\
\text { atualizado uma } \\
\text { vez por } \\
\text { semana }\end{array}$ \\
\hline 71 & $\begin{array}{l}\text { Sessões de } \\
\text { design rápido }\end{array}$ & $\begin{array}{l}\text { Sessões de } \\
\text { design rápido, } \\
\text { Taskboard }\end{array}$ & $\begin{array}{l}\text { Sessões de } \\
\text { design rápido }\end{array}$ & Reunião Diária & Taskboard & Taskboard \\
\hline 72 & $\begin{array}{l}\text { Retrospectiva } \\
\text { s, Sessões de } \\
\text { design rápido }\end{array}$ & $\begin{array}{l}\text { Retrospectivas, } \\
\text { Sessões de } \\
\text { design rápido }\end{array}$ & $\begin{array}{l}\text { Retrospectivas, } \\
\text { Sessões de } \\
\text { design rápido, } \\
\text { Taskboard }\end{array}$ & $\begin{array}{l}\text { Sessões de } \\
\text { design rápido, } \\
\text { Taskboard }\end{array}$ & $\begin{array}{l}\text { Sessões de desig } \\
\text { Taskboard }\end{array}$ & n rápido, \\
\hline 73 & nenhuma & Nenhuma & Nenhuma & Nenhuma & Nenhuma & Nenhuma \\
\hline 74 & & Taskboard & & & & \\
\hline
\end{tabular}




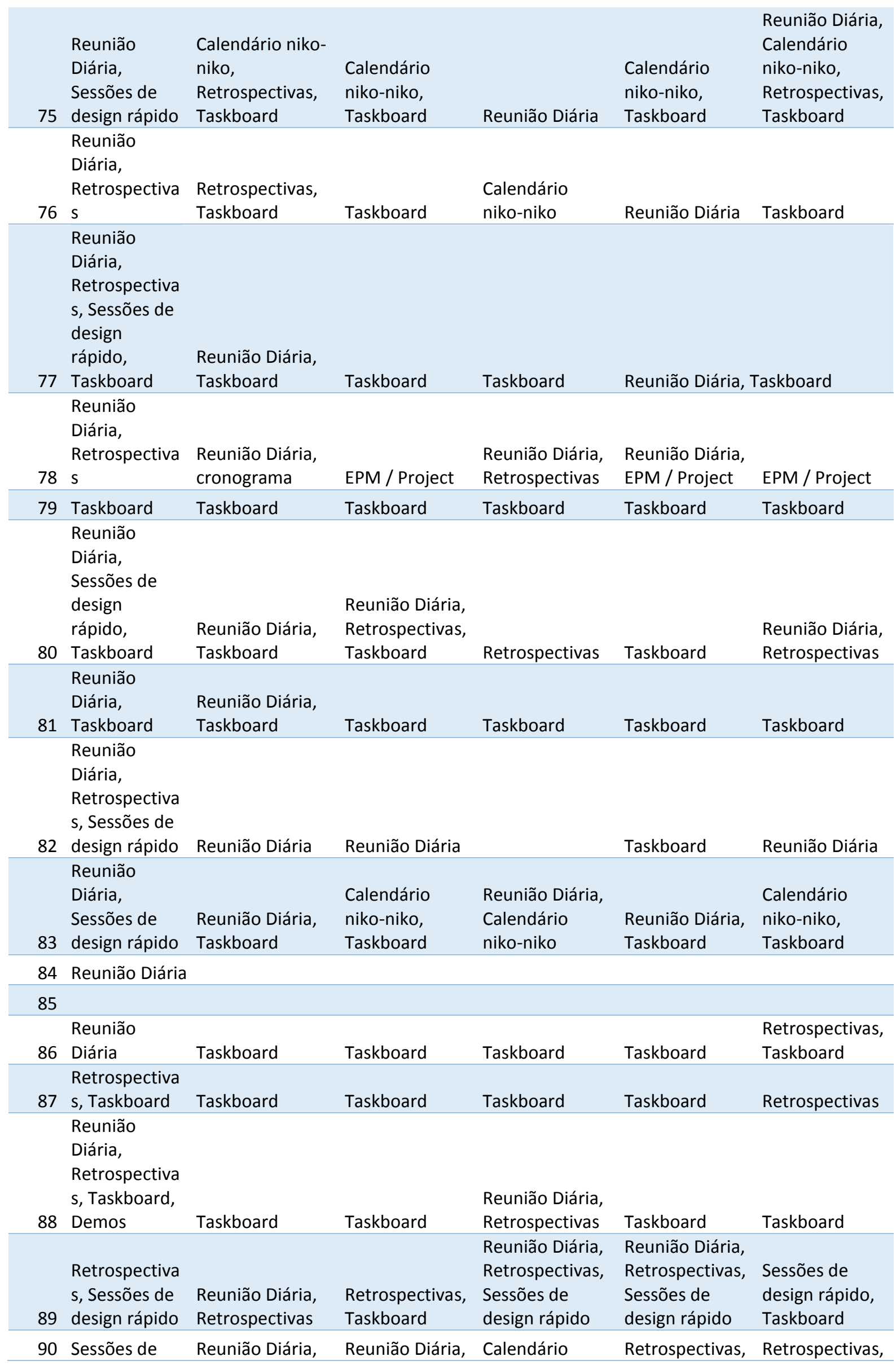




\begin{tabular}{|c|c|c|c|c|c|c|}
\hline & $\begin{array}{l}\text { design } \\
\text { rápido, } \\
\text { Taskboard }\end{array}$ & $\begin{array}{l}\text { Retrospectivas, } \\
\text { Taskboard }\end{array}$ & Retrospectivas & $\begin{array}{l}\text { niko-niko, } \\
\text { Retrospectivas }\end{array}$ & $\begin{array}{l}\text { Sessões de } \\
\text { design rápido, } \\
\text { Taskboard }\end{array}$ & Taskboard \\
\hline 91 & $\begin{array}{l}\text { Reunião } \\
\text { Diária }\end{array}$ & $\begin{array}{l}\text { Reunião Diária, } \\
\text { Taskboard }\end{array}$ & Taskboard & $\begin{array}{l}\text { Calendário } \\
\text { niko-niko }\end{array}$ & Taskboard & $\begin{array}{l}\text { Reunião Diária, } \\
\text { Taskboard }\end{array}$ \\
\hline 92 & $\begin{array}{l}\text { Reunião } \\
\text { Diária }\end{array}$ & \multicolumn{3}{|c|}{ Reunião Diária, Taskboard } & $\begin{array}{l}\text { Reunião Diária, } \\
\text { Taskboard }\end{array}$ & Taskboard \\
\hline 93 & $\begin{array}{l}\text { Reunião } \\
\text { Diária, } \\
\text { Sessões de } \\
\text { design } \\
\text { rápido, } \\
\text { Taskboard }\end{array}$ & $\begin{array}{l}\text { Reunião Diária, } \\
\text { Taskboard }\end{array}$ & Reunião Diária & Reunião Diária & Reunião Diária & $\begin{array}{l}\text { Reunião Diária, } \\
\text { Taskboard }\end{array}$ \\
\hline 94 & $\begin{array}{l}\text { Reunião } \\
\text { Diária, } \\
\text { Sessões de } \\
\text { design } \\
\text { rápido, } \\
\text { Taskboard }\end{array}$ & $\begin{array}{l}\text { Reunião Diária, } \\
\text { Sessões de } \\
\text { design rápido, } \\
\text { Taskboard }\end{array}$ & $\begin{array}{l}\text { Reunião Diária, } \\
\text { Sessões de } \\
\text { design rápido, } \\
\text { Taskboard }\end{array}$ & $\begin{array}{l}\text { Retrospectivas, } \\
\text { Sessões de } \\
\text { design rápido, } \\
\text { Taskboard }\end{array}$ & $\begin{array}{l}\text { Reunião Diária, } \\
\text { Sessões de } \\
\text { design rápido, } \\
\text { Taskboard }\end{array}$ & $\begin{array}{l}\text { Reunião Diária, } \\
\text { Sessões de } \\
\text { design rápido, } \\
\text { Taskboard }\end{array}$ \\
\hline \multicolumn{7}{|l|}{95} \\
\hline 96 & Taskboard & Taskboard & $\begin{array}{l}\text { Conversa } \\
\text { rápida }\end{array}$ & $\begin{array}{l}\text { Conversa } \\
\text { rápida }\end{array}$ & Taskboard & Taskboard \\
\hline 97 & $\begin{array}{l}\text { Retrospectivas, } \\
\text { design rápido }\end{array}$ & Sessões de & $\begin{array}{l}\text { Retrospectivas, } \\
\text { Sessões de } \\
\text { design rápido }\end{array}$ & $\begin{array}{l}\text { Retrospectivas, } \\
\text { Sessões de } \\
\text { design rápido }\end{array}$ & $\begin{array}{l}\text { Retrospectivas, } \\
\text { Sessões de } \\
\text { design rápido }\end{array}$ & $\begin{array}{l}\text { Retrospectivas, } \\
\text { Sessões de } \\
\text { design rápido }\end{array}$ \\
\hline 98 & $\begin{array}{l}\text { Reunião } \\
\text { Diária, } \\
\text { Retrospectiva } \\
\text { s, Sessões de } \\
\text { design rápido }\end{array}$ & $\begin{array}{l}\text { Reunião Diária, } \\
\text { Taskboard }\end{array}$ & $\begin{array}{l}\text { Reunião Diária, } \\
\text { Taskboard }\end{array}$ & $\begin{array}{l}\text { Reunião Diária, } \\
\text { Calendário } \\
\text { niko-niko }\end{array}$ & $\begin{array}{l}\text { Retrospectivas, } \\
\text { Taskboard }\end{array}$ & $\begin{array}{l}\text { Reunião Diária, } \\
\text { Retrospectivas, } \\
\text { Sessões de } \\
\text { design rápido, } \\
\text { Taskboard }\end{array}$ \\
\hline \multicolumn{7}{|l|}{99} \\
\hline 100 & $\begin{array}{l}\text { Reunião } \\
\text { Diária, } \\
\text { Retrospectiva } \\
\text { s }\end{array}$ & $\begin{array}{l}\text { Reunião Diária, } \\
\text { Taskboard }\end{array}$ & Taskboard & $\begin{array}{l}\text { Reunião Diária, } \\
\text { Calendário } \\
\text { niko-niko }\end{array}$ & $\begin{array}{l}\text { Reunião Diária, } \\
\text { Taskboard }\end{array}$ & $\begin{array}{l}\text { Sessões de } \\
\text { design rápido, } \\
\text { Taskboard }\end{array}$ \\
\hline 101 & $\begin{array}{l}\text { Retrospectiva } \\
\mathrm{S}\end{array}$ & Retrospectivas & Retrospectivas & Retrospectivas & Retrospectivas & Retrospectivas \\
\hline 102 & $\begin{array}{l}\text { Reunião } \\
\text { Diária }\end{array}$ & Reunião Diária & & & & \\
\hline 103 & $\begin{array}{l}\text { Reunião } \\
\text { Diária }\end{array}$ & $\begin{array}{l}\text { Retrospectivas, } \\
\text { Taskboard }\end{array}$ & Taskboard & Taskboard & $\begin{array}{l}\text { Retrospectivas, } \\
\text { Taskboard }\end{array}$ & Taskboard \\
\hline 104 & $\begin{array}{l}\text { Reunião } \\
\text { Diária }\end{array}$ & Taskboard & Taskboard & $\begin{array}{l}\text { Calendário } \\
\text { niko-niko }\end{array}$ & Taskboard & \\
\hline 105 & $\begin{array}{l}\text { Reunião } \\
\text { Diária, } \\
\text { Calendário } \\
\text { niko-niko, } \\
\text { Sessões de } \\
\text { design rápido }\end{array}$ & $\begin{array}{l}\text { Reunião Diária, } \\
\text { Retrospectivas, } \\
\text { Taskboard }\end{array}$ & Reunião Diária & $\begin{array}{l}\text { Reunião Diária, } \\
\text { Calendário } \\
\text { niko-niko, } \\
\text { Retrospectivas, } \\
\text { Sessões de } \\
\text { design rápido, } \\
\text { Taskboard }\end{array}$ & $\begin{array}{l}\text { Calendário } \\
\text { niko-niko }\end{array}$ & Taskboard \\
\hline 106 & $\begin{array}{l}\text { Reunião } \\
\text { Diária, } \\
\text { Sessões de } \\
\text { design } \\
\text { rápido, } \\
\text { Taskboard }\end{array}$ & $\begin{array}{l}\text { Reunião Diária, } \\
\text { Taskboard }\end{array}$ & Taskboard & $\begin{array}{l}\text { Reunião Diária, } \\
\text { Taskboard }\end{array}$ & Taskboard & $\begin{array}{l}\text { Reunião Diária, } \\
\text { Taskboard }\end{array}$ \\
\hline
\end{tabular}




\begin{tabular}{|c|c|c|c|c|c|c|}
\hline 107 & $\begin{array}{l}\text { Reunião } \\
\text { Diária, } \\
\text { Retrospectiva } \\
\text { s, Reuniões } \\
\text { de } \\
\text { Apresentação } \\
\text { da Sprint e do } \\
\text { produto. }\end{array}$ & $\begin{array}{l}\text { Reunião Diária, } \\
\text { Retrospectivas, } \\
\text { Taskboard }\end{array}$ & $\begin{array}{l}\text { Reunião Diária, } \\
\text { Retrospectivas, } \\
\text { Taskboard }\end{array}$ & $\begin{array}{l}\text { Reunião Diária, } \\
\text { Retrospectivas, } \\
\text { Taskboard }\end{array}$ & $\begin{array}{l}\text { Reunião Diária, } \\
\text { Retrospectivas, } \\
\text { Taskboard }\end{array}$ & $\begin{array}{l}\text { Reunião Diária, } \\
\text { Retrospectivas, } \\
\text { Taskboard }\end{array}$ \\
\hline 108 & $\begin{array}{l}\text { Reunião } \\
\text { Diária }\end{array}$ & Reunião Diária & Reunião Diária & Reunião Diária & Reunião Diária & Reunião Diária \\
\hline \multicolumn{7}{|l|}{109} \\
\hline 110 & $\begin{array}{l}\text { Reunião } \\
\text { Diária, } \\
\text { Taskboard }\end{array}$ & Taskboard & Reunião Diária, T & Taskboard & $\begin{array}{l}\text { Reunião Diária, } \\
\text { Retrospectivas, } \\
\text { Taskboard }\end{array}$ & $\begin{array}{l}\text { Reunião Diária, } \\
\text { Taskboard }\end{array}$ \\
\hline 111 & $\begin{array}{l}\text { Reunião } \\
\text { Diária, } \\
\text { Calendário } \\
\text { niko-niko, } \\
\text { Retrospectiva } \\
\text { s, Sessões de } \\
\text { design } \\
\text { rápido, } \\
\text { Taskboard }\end{array}$ & $\begin{array}{l}\text { Reunião Diária, } \\
\text { Retrospectivas }\end{array}$ & Taskboard & $\begin{array}{l}\text { Calendário } \\
\text { niko-niko }\end{array}$ & $\begin{array}{l}\text { Reunião Diária, } \\
\text { Taskboard }\end{array}$ & $\begin{array}{l}\text { Reunião Diária, } \\
\text { Taskboard }\end{array}$ \\
\hline 112 & $\begin{array}{l}\text { Reunião } \\
\text { Diária, } \\
\text { Taskboard }\end{array}$ & Reunião Diária & Reunião Diária & $\begin{array}{l}\text { Reunião Diária, } \\
\text { Taskboard }\end{array}$ & Taskboard & Taskboard \\
\hline \multicolumn{7}{|l|}{113} \\
\hline 114 & & Taskboard & & & & \\
\hline 115 & $\begin{array}{l}\text { Reunião } \\
\text { Diária, } \\
\text { Retrospectiva } \\
\text { s, Sessões de } \\
\text { design } \\
\text { rápido, } \\
\text { Taskboard, } \\
\text { Pair } \\
\text { programming }\end{array}$ & $\begin{array}{l}\text { Reunião Diária, } \\
\text { Calendário niko- } \\
\text { niko, } \\
\text { Retrospectivas, } \\
\text { Sessões de } \\
\text { design rápido, } \\
\text { Taskboard, Pair } \\
\text { programming }\end{array}$ & $\begin{array}{l}\text { Reunião Diária, } \\
\text { Retrospectivas, } \\
\text { Sessões de } \\
\text { design rápido, } \\
\text { Taskboard, Pair } \\
\text { programming }\end{array}$ & $\begin{array}{l}\text { Reunião Diária, } \\
\text { Retrospectivas, } \\
\text { Sessões de } \\
\text { design rápido, } \\
\text { Taskboard, Pair } \\
\text { programming }\end{array}$ & $\begin{array}{l}\text { Reunião Diária, } \\
\text { Retrospectivas, } \\
\text { Sessões de } \\
\text { design rápido, } \\
\text { Taskboard, Pair } \\
\text { programming }\end{array}$ & $\begin{array}{l}\text { Reunião Diária, } \\
\text { Retrospectivas, } \\
\text { Sessões de } \\
\text { design rápido, } \\
\text { Taskboard, Pair } \\
\text { programming }\end{array}$ \\
\hline 116 & $\begin{array}{l}\text { Reunião } \\
\text { Diária }\end{array}$ & Reunião Diária & & Reunião Diária & Reunião Diária & Reunião Diária \\
\hline 117 & $\begin{array}{l}\text { Reunião } \\
\text { Diária, } \\
\text { Sessões de } \\
\text { design } \\
\text { rápido, } \\
\text { Taskboard }\end{array}$ & $\begin{array}{l}\text { Reunião Diária, } \\
\text { Sessões de } \\
\text { design rápido, } \\
\text { Taskboard }\end{array}$ & $\begin{array}{l}\text { Reunião Diária, } \\
\text { Sessões de } \\
\text { design rápido, } \\
\text { Taskboard }\end{array}$ & $\begin{array}{l}\text { Reunião Diária, } \\
\text { Sessões de } \\
\text { design rápido, } \\
\text { Taskboard }\end{array}$ & $\begin{array}{l}\text { Reunião Diária, } \\
\text { Sessões de } \\
\text { design rápido, } \\
\text { Taskboard }\end{array}$ & $\begin{array}{l}\text { Reunião Diária, } \\
\text { Sessões de } \\
\text { design rápido, } \\
\text { Taskboard }\end{array}$ \\
\hline 118 & $\begin{array}{l}\text { Reunião } \\
\text { Diária, } \\
\text { Taskboard }\end{array}$ & $\begin{array}{l}\text { Reunião Diária, } \\
\text { Sessões de } \\
\text { design rápido, } \\
\text { Taskboard }\end{array}$ & Taskboard & Reunião Diária & Taskboard & Taskboard \\
\hline 119 & $\begin{array}{l}\text { Reunião } \\
\text { Diária }\end{array}$ & Reunião Diária & Reunião Diária & Reunião Diária & Reunião Diária & $\begin{array}{l}\text { Calendário } \\
\text { niko-niko }\end{array}$ \\
\hline 120 & $\begin{array}{l}\text { Retrospectiva } \\
\mathrm{S}\end{array}$ & Retrospectivas & Reunião Diária & Reunião Diária & Retrospectivas & Retrospectivas \\
\hline 121 & $\begin{array}{l}\text { Reunião } \\
\text { Diária, }\end{array}$ & $\begin{array}{l}\text { Reunião Diária, } \\
\text { Taskboard }\end{array}$ & Reunião Diária & Retrospectivas & $\begin{array}{l}\text { Reunião Diária, } \\
\text { Taskboard }\end{array}$ & $\begin{array}{l}\text { Reunião Diária, } \\
\text { Retrospectivas }\end{array}$ \\
\hline
\end{tabular}




\begin{tabular}{|c|c|c|c|c|c|c|}
\hline & $\begin{array}{l}\text { Sessões de } \\
\text { design } \\
\text { rápido, } \\
\text { Taskboard }\end{array}$ & & & & & \\
\hline 122 & & & & & Taskboard & Taskboard \\
\hline 123 & $\begin{array}{l}\text { Reunião } \\
\text { Diária }\end{array}$ & $\begin{array}{l}\text { Reunião Diária, } \\
\text { Taskboard }\end{array}$ & $\begin{array}{l}\text { Retrospectivas, } \\
\text { Taskboard }\end{array}$ & $\begin{array}{l}\text { Reunião Diária, } \\
\text { Calendário } \\
\text { niko-niko, } \\
\text { Taskboard }\end{array}$ & $\begin{array}{l}\text { Reunião Diária, } \\
\text { Retrospectivas, } \\
\text { Taskboard }\end{array}$ & Taskboard \\
\hline 124 & $\begin{array}{l}\text { Sessões de } \\
\text { design rápido }\end{array}$ & Taskboard & Taskboard & Taskboard & Retrospectivas & Taskboard \\
\hline 125 & $\begin{array}{l}\text { Reunião } \\
\text { Diária, } \\
\text { Retrospectiva } \\
\text { s }\end{array}$ & Taskboard & Taskboard & $\begin{array}{l}\text { Retrospectivas, } \\
\text { Taskboard }\end{array}$ & Taskboard & $\begin{array}{l}\text { Reunião Diária, } \\
\text { Retrospectivas, } \\
\text { Taskboard }\end{array}$ \\
\hline 126 & $\begin{array}{l}\text { Calendário } \\
\text { niko-niko, } \\
\text { Retrospectiva } \\
\text { s }\end{array}$ & Taskboard & $\begin{array}{l}\text { Reunião Diária, } \\
\text { Calendário } \\
\text { niko-niko, } \\
\text { Taskboard }\end{array}$ & $\begin{array}{l}\text { Reunião Diária, } \\
\text { Calendário } \\
\text { niko-niko, } \\
\text { Taskboard }\end{array}$ & Taskboard & Taskboard \\
\hline 127 & Reunião Diária & & $\begin{array}{l}\text { Sessões de } \\
\text { design rápido }\end{array}$ & Retrospectivas & Reunião Diária & Taskboard \\
\hline \multicolumn{7}{|l|}{128} \\
\hline 129 & $\begin{array}{l}\text { Reunião } \\
\text { Diária, } \\
\text { Retrospectiva } \\
\text { s, Sessões de } \\
\text { design rápido }\end{array}$ & $\begin{array}{l}\text { Reunião Diária, } \\
\text { Taskboard }\end{array}$ & $\begin{array}{l}\text { Reunião Diária, } \\
\text { Taskboard }\end{array}$ & $\begin{array}{l}\text { Retrospectivas, } \\
\text { Taskboard }\end{array}$ & $\begin{array}{l}\text { Retrospectivas, } \\
\text { Taskboard }\end{array}$ & $\begin{array}{l}\text { Retrospectivas, } \\
\text { Taskboard }\end{array}$ \\
\hline 130 & $\begin{array}{l}\text { Reunião } \\
\text { Diária, } \\
\text { Taskboard, } \\
\text { um bom } \\
\text { scrum master } \\
\text { e PO }\end{array}$ & Taskboard & $\begin{array}{l}\text { Reunião Diária, } \\
\text { Taskboard }\end{array}$ & $\begin{array}{l}\text { Calendário } \\
\text { niko-niko }\end{array}$ & $\begin{array}{l}\text { Reunião Diária, } \\
\text { Retrospectivas, } \\
\text { Taskboard }\end{array}$ & $\begin{array}{l}\text { Reunião Diária, } \\
\text { Retrospectivas, } \\
\text { Taskboard }\end{array}$ \\
\hline 131 & $\begin{array}{l}\text { Reunião } \\
\text { Diária, } \\
\text { Retrospectiva } \\
\text { s, Sessões de } \\
\text { design } \\
\text { rápido, } \\
\text { Taskboard }\end{array}$ & $\begin{array}{l}\text { Reunião Diária, } \\
\text { Retrospectivas, } \\
\text { Sessões de } \\
\text { design rápido, } \\
\text { Taskboard }\end{array}$ & Reunião Diária & $\begin{array}{l}\text { Reunião Diária, } \\
\text { Taskboard }\end{array}$ & $\begin{array}{l}\text { Reunião Diária, } \\
\text { Retrospectivas }\end{array}$ & Reunião Diária \\
\hline 132 & $\begin{array}{l}\text { Retrospectiva } \\
\text { s, Sessões de } \\
\text { design rápido }\end{array}$ & $\begin{array}{l}\text { Reunião Diária, } \\
\text { Sessões de } \\
\text { design rápido }\end{array}$ & Reunião Diária & Reunião Diária & $\begin{array}{l}\text { Reunião Diária, } \\
\text { Retrospectivas, } \\
\text { Sessões de } \\
\text { design rápido }\end{array}$ & $\begin{array}{l}\text { Retrospectivas, } \\
\text { Sessões de } \\
\text { design rápido }\end{array}$ \\
\hline 133 & $\begin{array}{l}\text { Retrospectiva } \\
\mathrm{S}\end{array}$ & Taskboard & Reunião Diária & Retrospectivas & $\begin{array}{l}\text { Calendário } \\
\text { niko-niko }\end{array}$ & $\begin{array}{l}\text { Calendário } \\
\text { niko-niko }\end{array}$ \\
\hline 134 & $\begin{array}{l}\text { Retrospectiva } \\
\mathrm{S}\end{array}$ & Retrospectivas & Retrospectivas & Retrospectivas & Retrospectivas & Retrospectivas \\
\hline 135 & $\begin{array}{l}\text { Reunião } \\
\text { Diária, } \\
\text { Retrospectiva } \\
\text { S }\end{array}$ & $\begin{array}{l}\text { Reunião Diária, } \\
\text { Sessões de } \\
\text { design rápido }\end{array}$ & $\begin{array}{l}\text { Reunião Diária, } \\
\text { Taskboard }\end{array}$ & $\begin{array}{l}\text { Reunião Diária, } \\
\text { Retrospectivas, } \\
\text { Taskboard }\end{array}$ & $\begin{array}{l}\text { Reunião Diária, } \\
\text { Taskboard }\end{array}$ & $\begin{array}{l}\text { Reunião Diária, } \\
\text { Retrospectivas, } \\
\text { Sessões de } \\
\text { design rápido, } \\
\text { Taskboard }\end{array}$ \\
\hline
\end{tabular}




\begin{tabular}{|c|c|c|c|}
\hline ID & $\begin{array}{l}\text { Questão } \\
24\end{array}$ & Questão 25 & Questão 26 \\
\hline 12 & Sim & $\begin{array}{l}\text { Revisão de código. } \\
\text { Tarefas pequenas. } \\
\text { Programação em par. }\end{array}$ & Foco em objetivos pequenos bem definidos. \\
\hline 13 & Sim & $\begin{array}{l}\text { Testes automatizados, programação } \\
\text { pareada, Sessões de design rápido, entrega } \\
\text { e integração contínua }\end{array}$ & $\begin{array}{l}\text { Como há uma entrega por partes, não se } \\
\text { esperando até o fim para se ter uma ideia de } \\
\text { como ficou o software, é possível trabalhar a } \\
\text { dependabilidade aos poucos e melhorando-a. } \\
\text { Não é necessário deixar para o fim para } \\
\text { verificar se esses requisitos foram atingidos, } \\
\text { pode-se fazer medições intermediárias e } \\
\text { mudar o rumo do desenvolvimento para } \\
\text { melhorar tais parâmetros. }\end{array}$ \\
\hline 14 & Sim & & \\
\hline 15 & Sim & & \\
\hline 16 & Sim & & \\
\hline 17 & Sim & Scrum, kanban e scumban. & $\begin{array}{l}\text { Por conseguir ter feedback num intervalo d } \\
\text { tempo mai curto. }\end{array}$ \\
\hline 18 & Sim & scrum, $x p$ & $\begin{array}{l}\text { Feedbacks fazem parte do desenvolvimento e } \\
\text { efitam desenvolver features pouco utilizadas } \\
\text { ou pouco úteis. }\end{array}$ \\
\hline 19 & Não & Não utilizamos metodologias ágeis. & Não utilizamos metodologias ágeis. \\
\hline 20 & Não & Não utilizamos metodologias ágeis. & Não utilizamos metodologias ágeis. \\
\hline 21 & Sim & & \\
\hline 22 & Sim & Test Driven Development & \\
\hline 23 & Sim & & \\
\hline 24 & Sim & & \\
\hline 25 & Sim & & \\
\hline 26 & Sim & & \\
\hline 27 & Sim & $\begin{array}{l}\text { Reunião diária, taskboard, reunião de } \\
\text { planejamento }\end{array}$ & Visibilidade \\
\hline 28 & Sim & $\begin{array}{l}\text { XP e Scrum, plano de testes e ferramentas } \\
\text { de testes automáticos. }\end{array}$ & $\begin{array}{l}\text { Sim, pois torna o software cada vez mais livre } \\
\text { de BUGs e os teste mais precisos e completos }\end{array}$ \\
\hline 29 & & & \\
\hline 30 & Sim & & \\
\hline 31 & Sim & $\begin{array}{l}\text { Taskboard } \\
\text { Daily meetings } \\
\text { Burndown Graphics }\end{array}$ & $\begin{array}{l}\text { Porque eles auxiliam a ver o sistema como } \\
\text { um todo e quais as peças são utilizadas para } \\
\text { sua composição. }\end{array}$ \\
\hline 32 & Sim & & \\
\hline 33 & Não & & \\
\hline 34 & Sim & & $\begin{array}{l}\text { Melhoram o desenvolvimento do sistema no } \\
\text { geral, deixando-o mais robusto e aumentanto } \\
\text { portanto a dependabilidade. }\end{array}$ \\
\hline 35 & $\operatorname{Sim}$ & & \\
\hline 36 & Sim & & \\
\hline 37 & Sim & Reuniões diárias, Taskboard, JAD. & $\begin{array}{l}\text { O fato de você estar sempre revisando o que } \\
\text { esta sendo feito. E por varias pessoas terem } \\
\text { tarefas diferentes, faz com que os erros } \\
\text { sejam minimizados. }\end{array}$ \\
\hline
\end{tabular}


Mais comunicação significa menos surpresa.

Testes automatizados

Programação em pares

38 Sim Sentar juntos
Menos surpresa significa que menos

comportamentos são considerados inesperados e, portanto, o sistema desenvolvido é mais confiável.

39 Sim

40 Sim

41 Sim

42 Sim

\begin{tabular}{|c|c|c|c|}
\hline 43 & Sim & Retrospectivas e sessões rápidas de design. & $\begin{array}{l}\text { A revisão do projeto diária, mesmo de forma } \\
\text { rápida, permite a recordação de pontos } \\
\text { específicos do sistema, permitindo possíveis } \\
\text { revisões e obtenções de pontos não tratados. } \\
\text { A dependabilidade é alcançada pela } \\
\text { minuciosidade na descrição e percepção do } \\
\text { software. }\end{array}$ \\
\hline 44 & Sim & & \\
\hline 45 & Sim & & \\
\hline 46 & Sim & & \\
\hline 47 & Não & & \\
\hline & Sim & $\begin{array}{l}\text { Sim, já trabalhei em empresa que não tinha } \\
\text { nenhuma metodologia ágil e sempre } \\
\text { precisávamos remarcar entrega de } \\
\text { projetos. }\end{array}$ & $\begin{array}{l}\text { No caso do SCRUM, a equipe é focada no } \\
\text { desenvolvimento daquele projeto, não tendo } \\
\text { interferência de terceiro, para manutenção } \\
\text { de software, acho isso muito proveitoso. }\end{array}$ \\
\hline & Sim & & \\
\hline 50 & Sim & & \\
\hline 51 & Sim & & \\
\hline 52 & Sim & & \\
\hline 53 & Sim & & \\
\hline 54 & Sim & & \\
\hline 55 & Sim & & \\
\hline & Sim & & \\
\hline 57 & Não & & \\
\hline & Sim & Reuniões e FeedBack & $\begin{array}{l}\text { Força um padrao de desenvolvimento e } \\
\text { assegura cada etapa do processo. }\end{array}$ \\
\hline & Sim & Reuniões Diárias e Pair Programming & $\begin{array}{l}\text { As práticas ágeis aumentam a } \\
\text { dependabilidade de software porque o } \\
\text { desenvolvimento de software é, geralmente, } \\
\text { dinâmico e através de tentativa e erro, de } \\
\text { forma que, as vezes, até mesmo a } \\
\text { confirmação do cliente final de que o } \\
\text { produto está atendendo suas expectativas } \\
\text { pode estar errada. As técnicas adotadas por } \\
\text { práticas ágeis tentam }\end{array}$ \\
\hline & Sim & & \\
\hline & Sim & & \\
\hline & Sim & $\begin{array}{l}\text { SCRUM } \\
\text { Canvas (não sei ao certo se encaixa como } \\
\text { prática ágil) }\end{array}$ & $\begin{array}{l}\text { Facilitam a comunicação entre equipe e } \\
\text { cliente. Quanto mais alinhados estiverem as } \\
\text { pessoas em um projeto mais fluído ele será. }\end{array}$ \\
\hline & Sim & $\begin{array}{l}\text { Sessões de design rápido } \\
\text { Reunião Diária }\end{array}$ & $\begin{array}{l}\text { Sessões de design rápido constroem um } \\
\text { design (a ser iterado) já pensando nos }\end{array}$ \\
\hline
\end{tabular}


Retrospectivas

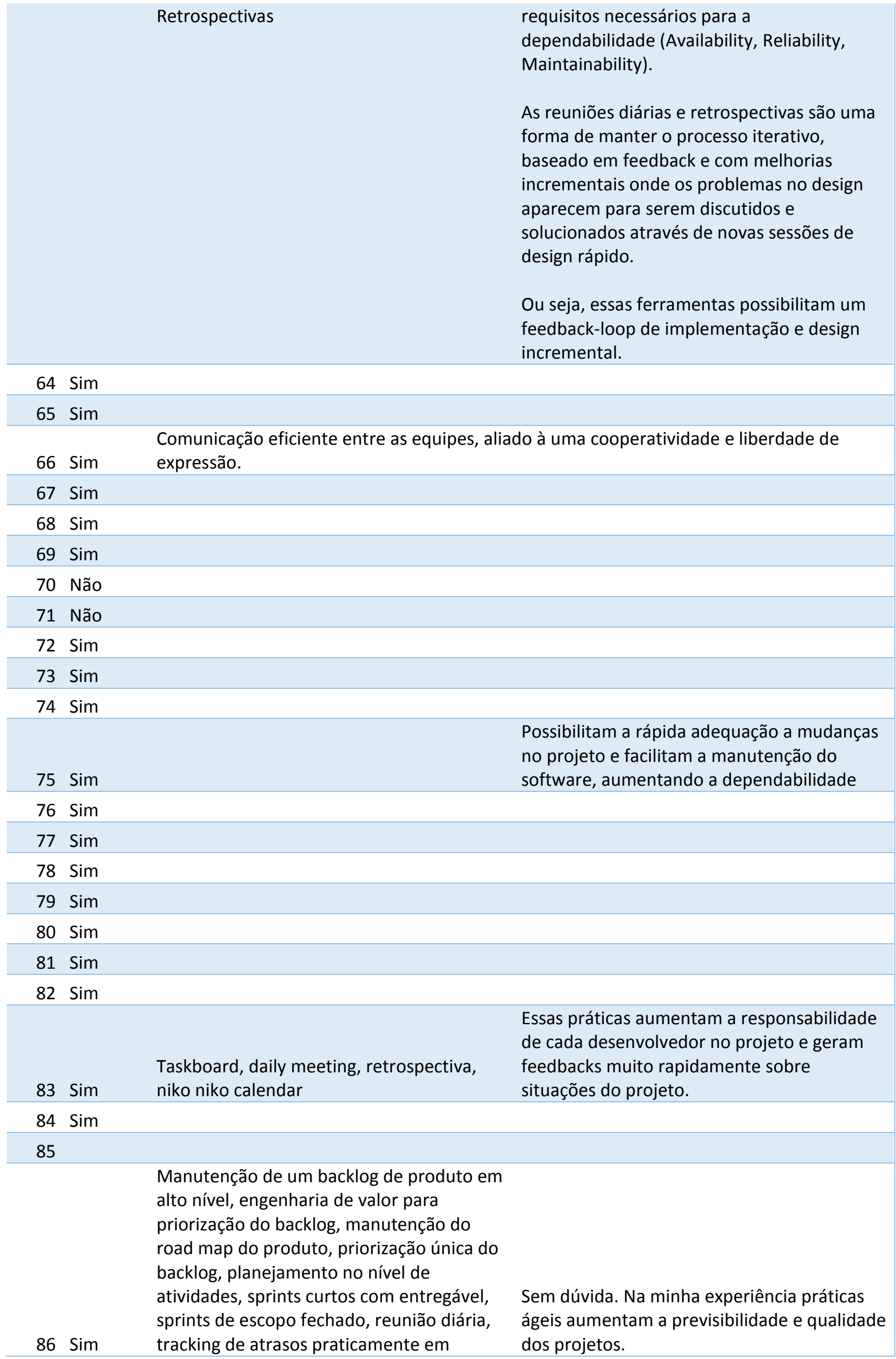


tempo-real, testes automatizados, build e deploy em ambiente de QA automatizados (integração e entrega contínua), retrospectiva, demonstração, equipe dev e qa trabalhando juntos no mesmo sprint, testes pós entrega, boas práticas de engenharia de software (IOD, TDD, DRY etc), uso de SCM, evitar ao máximo branches, comunicação através do próprio taskboard (exige o uso de uma ferramenta que ofereça isto) ao invés de e-mail, manter documentação tanto de produto (simples, objetiva e nível de negócio apenas) como interna (de arquitetura, mecanismos devops etc), idealmente usando ferramentas colaborativas (wiki, google docs), equipe de devops, reduzir ao máximo a "distância" entre a versão em produção e a versão em desenvolvimento, coletar e monitorar status da aplicação (erros, carga, tempos, hotspots), mecanismo de live testing de funcionalidade para uma fração controlada dos usuários.

$\begin{array}{lll}87 & \operatorname{Sim} & \\ 88 & \text { Não } & \\ 89 & \operatorname{Sim} & \\ 90 & \operatorname{Sim} & \text { Pair-programming, standup meetings } \\ 91 & \operatorname{Sim} & \\ 92 & \mathrm{Sim} & \\ 93 & \mathrm{Sim} & \end{array}$

$94 \mathrm{Sim}$ SCRUM

Porque você garante pequenas entregas com qualidades, cumprindo o calendário de forma

$95 \mathrm{Sim}$

No caso da empresa em que trabalho, como é pequena o SCRUM atenderia $96 \mathrm{Sim}$ perfeitamente.

Agilidade nos processos e tomadas de

$97 \mathrm{Sim}$

$98 \mathrm{Sim}$

$99 \mathrm{Sim}$

$100 \mathrm{Sim}$

$101 \mathrm{Sim}$

$102 \mathrm{Sim}$

$103 \mathrm{Sim}$

104 Sim

$105 \mathrm{Sim}$

$106 \operatorname{Sim}$

Reuniões diárias

$\begin{array}{ll} & \begin{array}{l}\text { Um bom Product Backlog } \\ \text { Boa interação entre a equipe de } \\ \text { desenvolvimento. }\end{array}\end{array}$

Concerteza é uma ferramenta que auxilia a dependabilidade do projeto. $\mathrm{O}$ mais importante no desenvolvimento de um 
Politicas motivacionais na empresa.

Ambiente de desenvolvimento favorável a novas ideias e perspectivas de desenvolvimento. projeto ágil são os requisitos não funcionais por parte do PO. Este é o principal fator que pode permitir ou não ao time de desenvolvimento cumpra suas tarefas no prazo determinado e de forma correta. A integração do time de desenvolvimento também é um fator fundamental, encontros como Coding dojo pode auxiliar e muito a coesão da equipe!

$108 \mathrm{Sim}$

Utilização adequada de qualquer das

Como você tem uma forma mais dinâmica de metodologias mencionadas nesta pesquisa, utilização concreta de taskboards, reuniões eficazes para mensuração do andamento de taregas/projetos/evolução da equipe de desenvolvimento. Creio que estes exemplos sejam extremamente importantes, mas infelizmente são métodos muito comentados mas poucos

$109 \mathrm{Sim}$ praticados.

interação ente os stakeholders e a equipe e também entre os próprios membros dessa, os processos são mais claros e fluidos; com a maior clareza de expectativas tem-se menos surpresas e frustrações nas entregas e há um maior ganho de enriquecimento na base de conhecimento dos envolvidos devido a todos estarem comprometidos e informados do andamento dos projetos.

$110 \mathrm{Sim}$

Na minha opinião as melhores praticas são as que atendem a necessidade do time e do

$111 \mathrm{Sim}$ projeto, devem ser sentidas e negociadas entre o time.

$112 \operatorname{sim}$ ok

ok

$113 \mathrm{Sim}$

114 Sim

115 Não

Nenhuma

Não aumentam

116 Não

117 Sim

$118 \mathrm{Sim}$

119 Sim

120 Não

$121 \mathrm{Sim}$

$122 \operatorname{Sim}$

$123 \operatorname{Sim}$

124 Sim Uma boa análise antes do início da produção e distribuição das atividades para a equipe Taskboards, conceituação de requisito Porque criam equipe mais autônomas e "pronto".

Revisão de Código

Pareamento

Couaching

TDD

$126 \operatorname{Sim}$

Integração Contínua automotivadas.

Porque transmitem maior confiança de que o código estará em conformidade com aquilo que foi requisitado. Também traz uma maior qualidade ao desenvolvimento; seus integrantes atuem de forma mais coesa e se tornem mais satisfeitos com seu trabalho.

127

$128 \mathrm{Sim}$

Acredito que isso varie muito de acordo com a necessidade. Se o projeto estiver na etapa de conceituação práticas como Business Canvas ajudam muito.

O principal fator é o feedback rápido. 0 cliente consegue precisa ver algo tangível o mais cedo possível para detectar possíveis

129 Sim Já com uma ideia melhor formada gosto erros de comunicação e especificação. 
bastante do clássico: US, Backlog, poker planning.

Em desenvolvimento é preciso praticar testes, clean code e construção de wireframes.

A capacidade de absorção de requisitos e priorização auxiliam no processo de dar foco em requisitos tanto funcionais quanto não funcionais, como é o caso da dependabilidade. Havendo concordância entre equipe, $\mathrm{PO}$, Stakeholders sobre as reais necessidades do projeto, pode-se focar no

Reuniões Diárias, Planning Meetings, que aquele momento pode oferecer um risco

$\begin{array}{ll}130 & \text { Sim } \\ 131 & \text { Sim }\end{array}$
Repriorização, Kanban à dependabilidade do projeto. 